\title{
Analysis of different class sizes on decision making processes and teaching behaviors of highly experienced teachers (HETs) and less experienced teachers (LETs)
}

Ha Young Kim

West Virginia University

Follow this and additional works at: https://researchrepository.wvu.edu/etd

\section{Recommended Citation}

Kim, Ha Young, "Analysis of different class sizes on decision making processes and teaching behaviors of highly experienced teachers (HETs) and less experienced teachers (LETs)" (2006). Graduate Theses, Dissertations, and Problem Reports. 3443.

https://researchrepository.wvu.edu/etd/3443

This Dissertation is protected by copyright and/or related rights. It has been brought to you by the The Research Repository @ WVU with permission from the rights-holder(s). You are free to use this Dissertation in any way that is permitted by the copyright and related rights legislation that applies to your use. For other uses you must obtain permission from the rights-holder(s) directly, unless additional rights are indicated by a Creative Commons license in the record and/ or on the work itself. This Dissertation has been accepted for inclusion in WVU Graduate Theses, Dissertations, and Problem Reports collection by an authorized administrator of The Research Repository @ WVU.

For more information, please contact researchrepository@mail.wvu.edu. 


\title{
Analysis of Different Class Sizes on Decision Making Processes and Teaching Behaviors of Highly Experienced Teachers (HETs) and Less Experienced Teachers (LETs)
}

\author{
Ha Young Kim \\ Dissertation submitted to \\ the School of Physical Education \\ at West Virginia University \\ in partial fulfillment of the requirements for the degree of
}

Doctor of Education

in

Physical Education

\author{
Lynn Housner, Ph.D., Chair \\ Andrew Hawkins, Ph.D. \\ Robert Wiegand, Ph.D. \\ Ardeth Deay, Ph.D. \\ Jaci Webb-Dempsey, Ed.D.
}

Physical Education Teacher Education

Morgantown, West Virginia

2006

Keywords: class size, decision making, health-related physical activity, teacher behavior, student behavior 


\title{
ABSTRACT \\ Analysis of Different Class Sizes on Decision Making Processes and Teaching Behaviors of Highly Experienced Teachers (HETs) and Less Experienced Teachers (LETs)
}

\author{
Ha Young Kim
}

Objectives: This study examined the decision making process employed by two highly experienced teachers (HETs) and two less experienced teachers (LETs) as they planned for and taught lessons with two different class sizes; $n=15-16$ and $n=30-31$. A secondary purpose of this study was to investigate the influence of class size on teaching behaviors and student learning. Finally, this study used in-depth interviews to describe concerns associated with teaching and preparing lessons for classes of different size.

Design and Setting: This was a mixed-methods study that utilized both behavioral analysis and qualitative methods of investigation. Qualitative methods included think-aloud, stimulated-recall techniques and semi-structured, open-ended interviews which were used to describe participants teaching concerns when dealing with class size. Quantitative methods included the use of the West Virginia University Teaching Evaluation System (WVUTES; Hawkins \& Wiegand, 1989), and Field System Analysis (FSA; Sharpe \& Hawkins, 1992) which were used to examine the influence of class size on teaching and student learning behaviors.

Subjects: Two highly experienced physical education teachers (HET1 and HET2) and two less experienced physical education teachers (LET1 and LET2, student teachers) were involved in this study. Pseudonyms were used for all participants in this study including: Erick Sam (HET1), Erin Hong (HET2), Nancy Young (LET1) and Nathan Smith (LET2). A total of 184 student participants were recruited from the two different elementary schools along with their cooperating physical education teachers.

Results: WVUTES data showed that HETs used similar instructional behaviors in terms of the amount, duration and frequency of feedback given during both classes. FSA revealed that all teachers provided individual feedback more often in smaller classes. Experienced teachers provided more individual feedback in larger classes, whereas their less experienced counter parts provided individual feedback more frequently only in smaller classes.

Conclusions: Smaller classes are more beneficial especially for less experienced teachers, due to the increase in frequency of individual feedback. Class size was an important consideration for planning, specifically selecting content and the organizational structure. Experienced teachers used multiple formations to deal with variations in class size. Less experienced teachers tend to use the one teaching format (either station or cohort) they were most comfortable with for both classes regardless of size. In this study, station teaching: 1 ) allowed students to concentrate better on instructional tasks; 2) reduced managerial tasks; 3) aided in the prevention off-task behaviors. Another critical component was the frequency of individual feedback, which kept students more active and engaged in class activities. Smaller class sizes appear more beneficial especially for less experienced teachers, due to the increase in the delivery of individual feedback. 


\section{ACKNOWLEDGEMENTS}

I would especially like to thank the teachers who were willing to serve as participants for this study. I would also like to acknowledge the great efforts of my Chairperson: Dr. Lynn Housner, and committee members: Dr. Andrew Hawkins, Dr. Robert Wiegand, Dr. Ardeth Deay, and Dr. Jaci Webb-Dempsey, whose mentorship played a major role in my continued education and professional development. I would like to thank to Dr. Templin who encouraged and supported my work. I would also like to express my great appreciation to my friends and colleagues, Dr. Scott Dietrich, Dr. Rachel Gurvitch, and Dr. Tony Pritchard who have shared ideas and offered ideas on how to take care of business at West Virginia University, since 2001. I especially would like to share my sincerest gratitude for the love and support of my parents and family who have prayed for me the entire time. 


\section{TABLE OF CONTENTS}

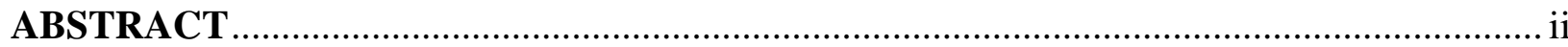

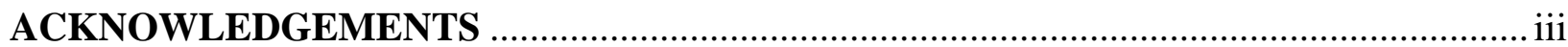

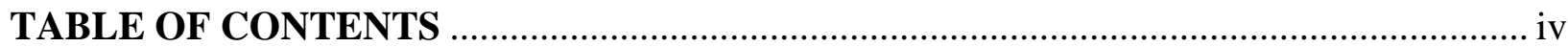

CHAPTER 1: INTRODUCTION AND STATEMENT OF THE PROBLEM.............................. 1

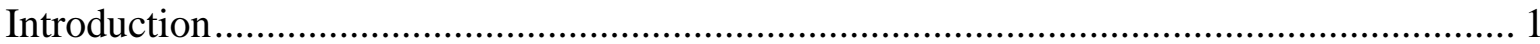

Importance of physical activity in physical education.................................................... 2

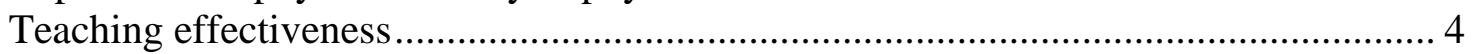

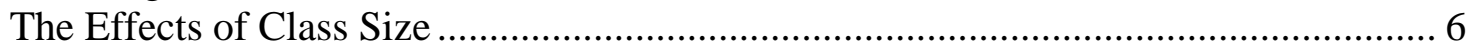

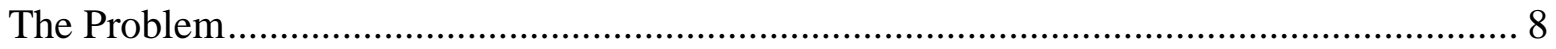

Statement of the Problem..................................................................................... 8

Research Questions ............................................................................................. 9

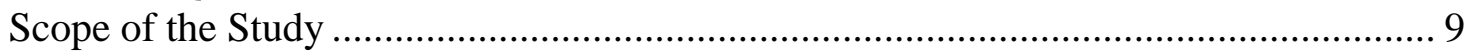

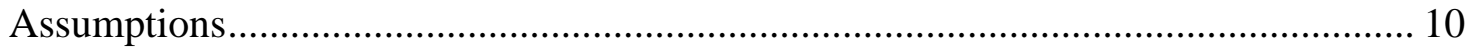

Limitations of the Study...................................................................................... 11

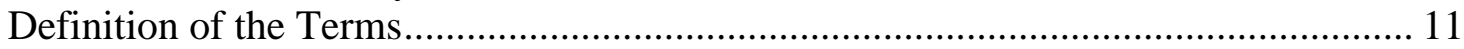

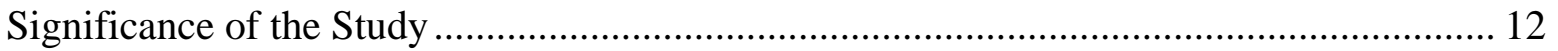

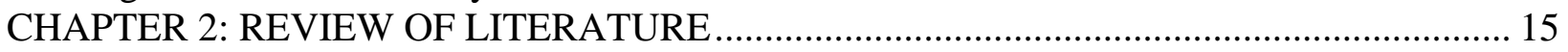

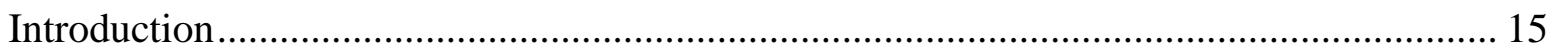

The importance of physical education .................................................................... 17

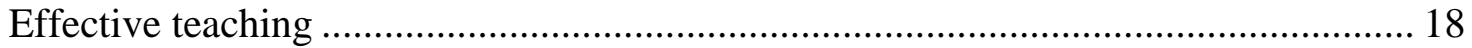

Experienced teachers and novice teachers ................................................................ 21

Impediments of effective teaching........................................................................... 25

The effects of class size ......................................................................................... 27

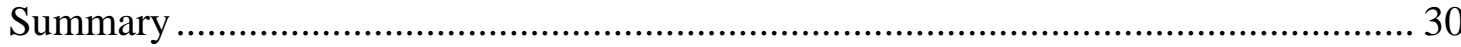

CHAPTER 3: RESEARCH DESIGN AND METHODOLOGY ………………........................ 33

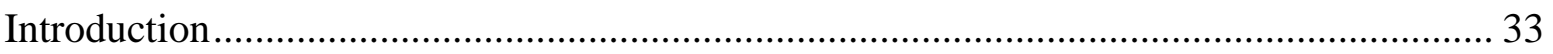

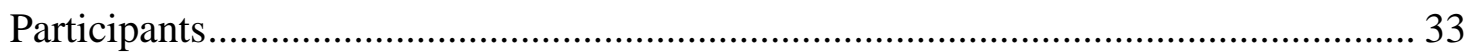

Research Design........................................................................................................... 35

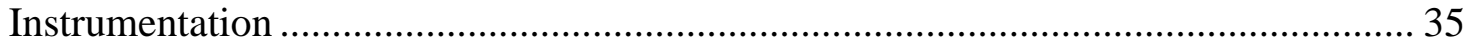

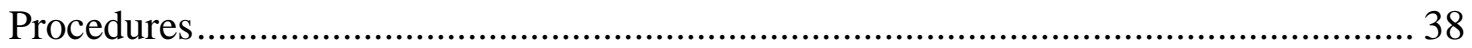

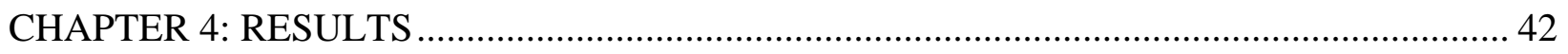

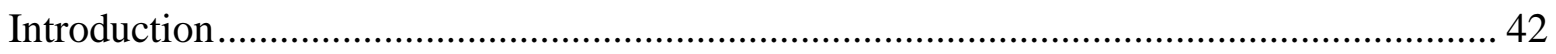

Planning the Lesson: Think-Aloud Technique ............................................................. 44

Stimulated-Recall: Interactive Decision-Making ………............................................. 45

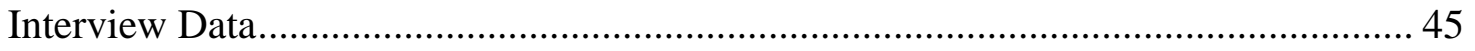

Nancy Young (LET 1) - Lesson \#1: Large Class Size $(n=31)$................................................ 46

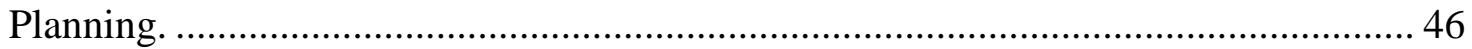

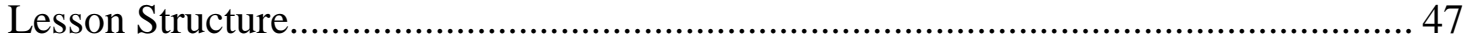

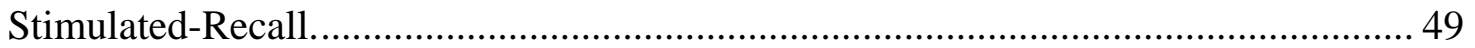

Nancy Young (LET 1) - Lesson \#2: Small Class Size $(\mathrm{n}=15)$................................................ 50

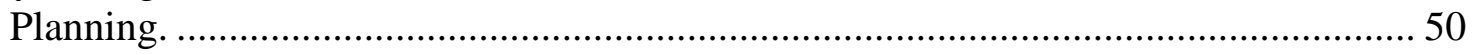

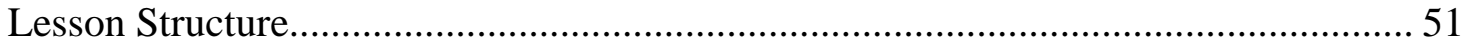

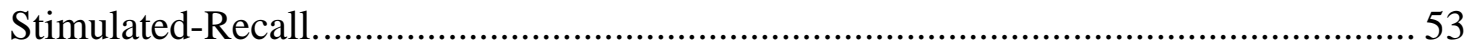

Interview Data: Class Size Comparison .................................................................. 54

Nathan Smith (LET 2) - Lesson \#1: Large Class Size $(\mathrm{n}=31)$............................................. 56 


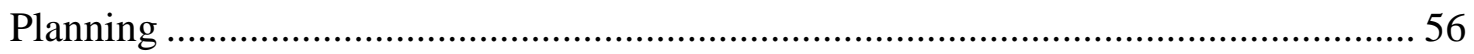

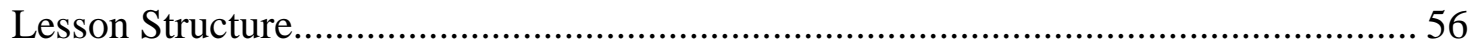

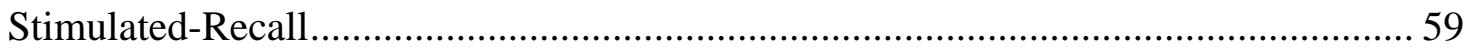

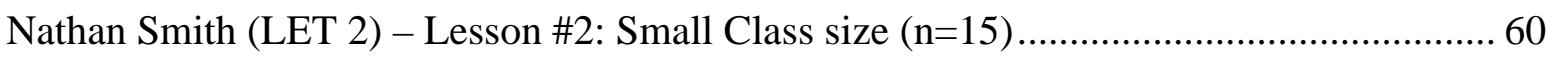

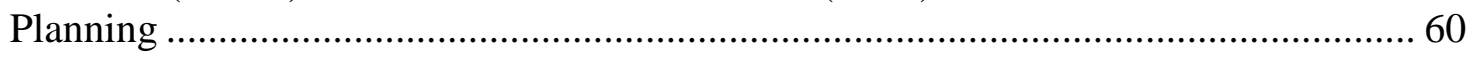

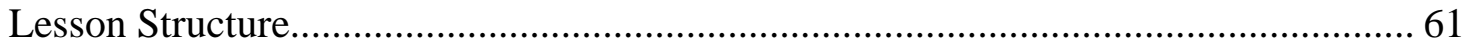

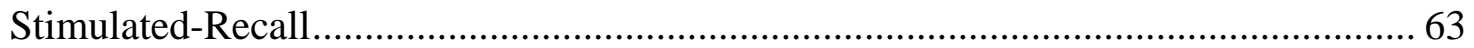

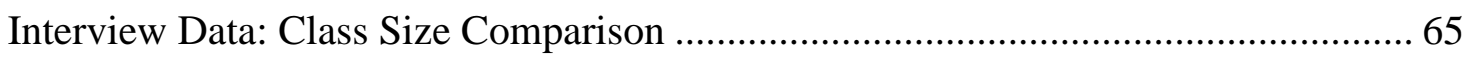

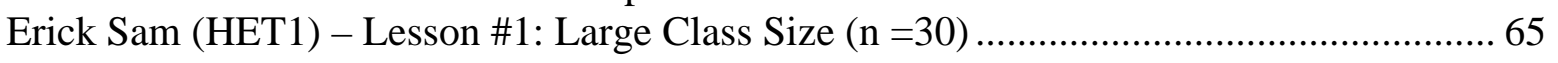

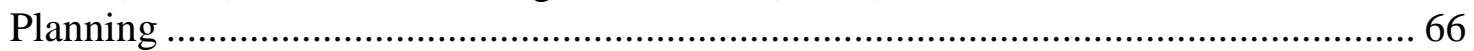

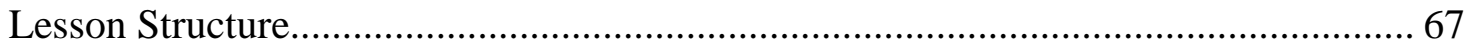

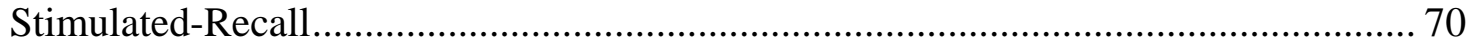

Erick Sam (HET1) - Lesson \#2: Small Class Size (n=16) ..................................................... 72

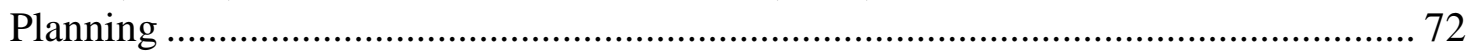

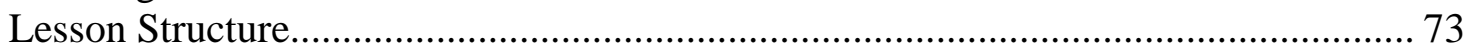

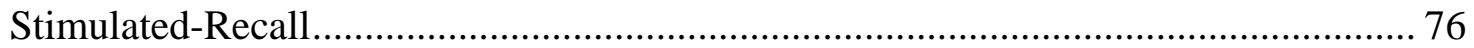

Interview Data: Class Size Comparison. .................................................................. 77

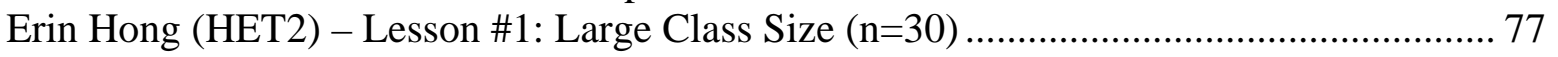

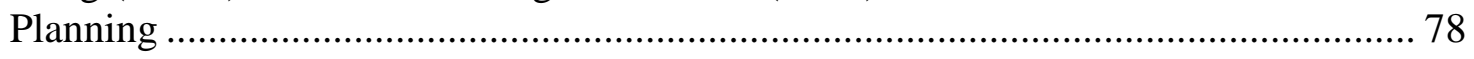

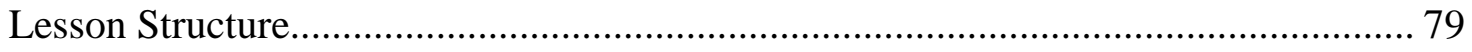

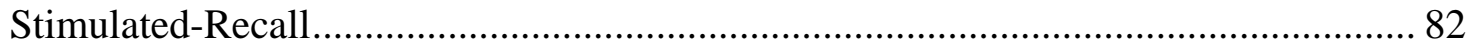

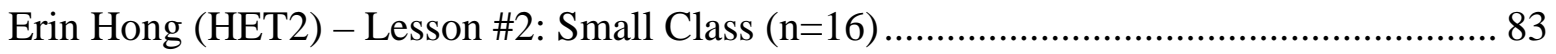

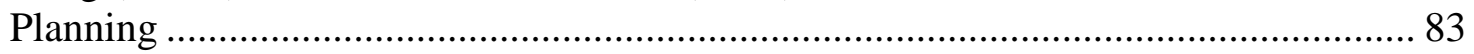

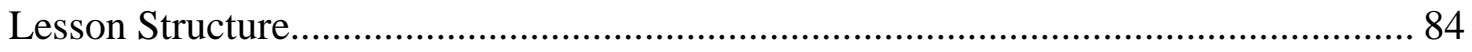

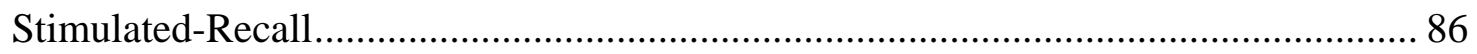

Interview Data: Class Size Comparison ................................................................... 87

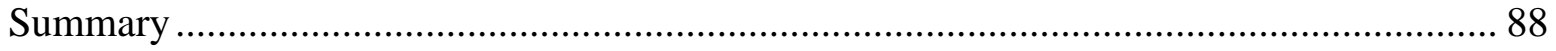

West Virginia University Teaching Evaluation System (WVUTES)............................................ 93

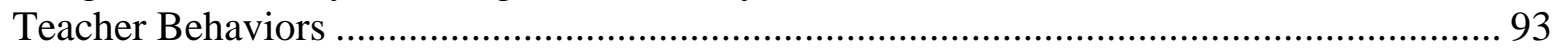

General Observation (GO) …………………………................................................ 93

Specific Observation (SO) ……………………….............................................. 93

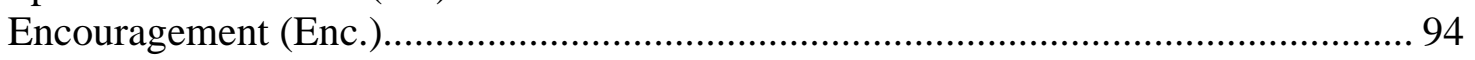

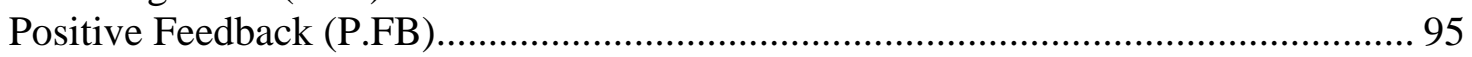

Corrective Feedback (C.FB) .................................................................................. 96

Management (Mgmt) ............................................................................................. 96

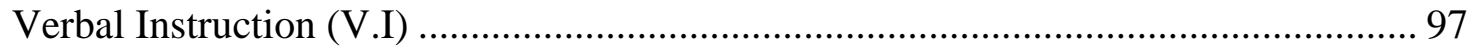

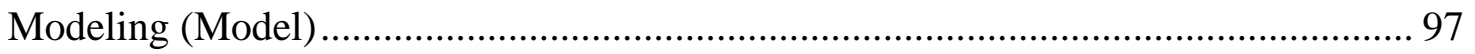

Physical Guidance (Phy.Gui.)..................................................................................... 98

Non-Task Verbal (N. Tak.V) ................................................................................... 98

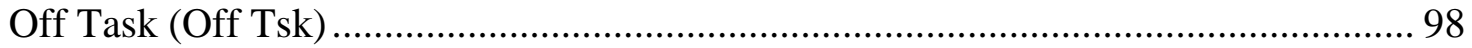

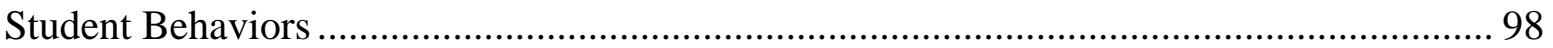

Motor Appropriate (Mo. Appr.)................................................................................ 98

Motor Inappropriate (Mo.Inapr.) .................................................................................. 99

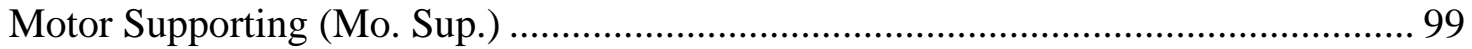

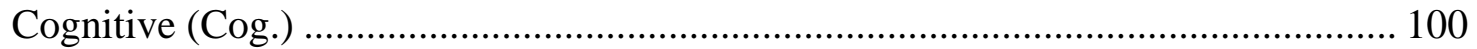

On Task Management (O.Tsk Mgmt.)......................................................................... 100

Off Task (Off.Tsk) ................................................................................................... 101 


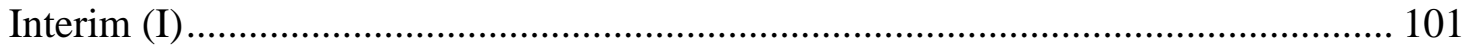

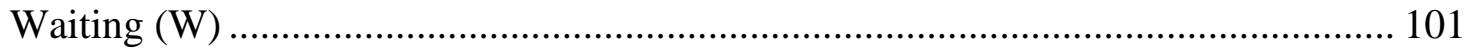

Comparison of Teaching Behaviors in Large/Small Classes............................................ 102

Teacher Behaviors ....................................................................................... 102

Student Behaviors. .................................................................................................. 104

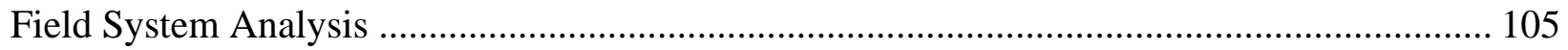

Lesson Descriptions ..................................................................................................... 106

Erick Sam: Highly Experienced Teacher 1 (HET1) ............................................... 106

Nancy Young: Less Experienced Teacher 1 (LET1) .................................................... 107

Teacher Comparisons HET/LET 1: Within Lessons (Large vs. Small) .............................. 109

Teaching Behaviors (HET 1) ................................................................................. 109

Student Behaviors (HET1) ................................................................................ 110

Nancy Young (LET1) within lessons (Large vs. Small).................................................... 111

Teaching Behaviors (LET 1) ................................................................................... 111

Student Behaviors (LET1) ................................................................................ 112

Teacher Behaviors Between Lessons (HET1 and LET1) .................................................. 112

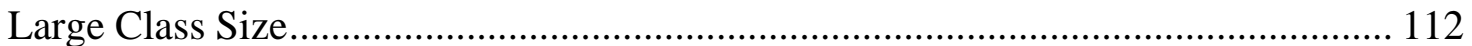

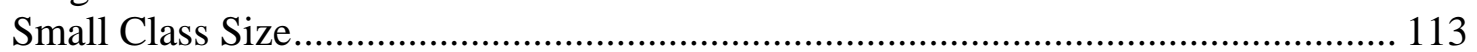

Student Behaviors Between Lessons (HET1 and LET1)................................................. 113

Large Class Size.......................................................................................... 113

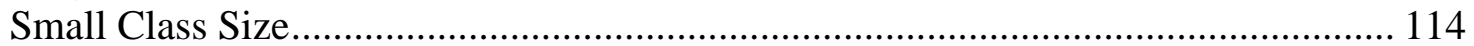

Interrelationships between Class Size and Teacher Behavior ........................................ 114

CHAPTER 5: DISCUSSION AND CONCLUSIONS ......................................................... 117

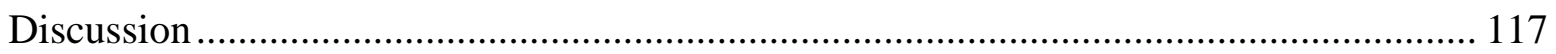

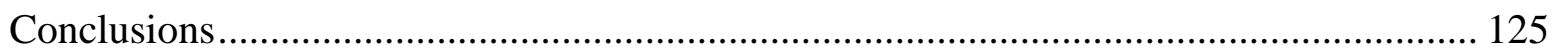

Tables and Figures..................................................................................................... 130

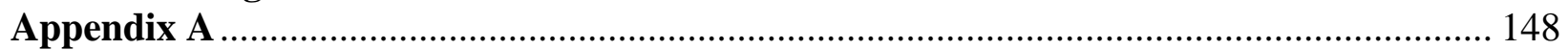

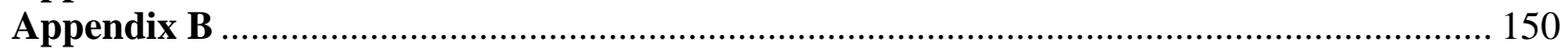

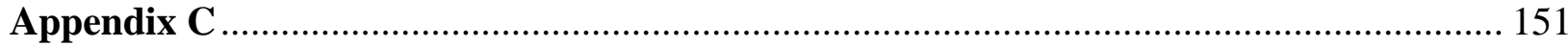

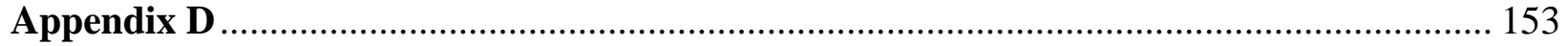

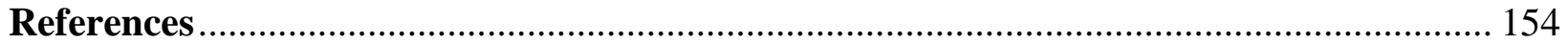




\section{CHAPTER 1:}

\section{INTRODUCTION AND STATEMENT OF THE PROBLEM}

\section{Introduction}

According to Healthy People 2010, the number of overweight children, adolescents, and adults has risen over the last four decades to the point that 11 percent of children and adolescents ages 6-19 are overweight or obese (USDHHS, 2000). It is likely that overweight children and adolescents will remain obese into adulthood (USDHHS, 2000). Inactivity during childhood is a major risk factor for lots of potentially serious health problems that can lead to increased risk of premature death.

Burgeson, Wechsler, Brener, Young, and Spain (2003) discovered while doing research on school-based physical education and activity that:

- only $8.0 \%$ of elementary schools provide daily physical education for the entire school year,

- $\quad$ about $78.8 \%$ of elementary schools allow students to be exempt from required physical education due to high physical competency test scores and participation in other school activities, community sports, or service activities, and

- among elementary schools that require physical education, the average student-teacher ratio is $27: 1$.

Despite the importance of physical activity, this research indicated that school based physical education did little to help young children become more active. Most people in the United States would likely seek a specialist like a physician or health club trainer, who has no formal training in physical education if they wanted information about weight control, nutrition, or exercise (Feingold, 1995). The lack of detailed and important knowledge regarding physical 
activity can be one factor in the increase in obesity and physical inactivity in our society. Engaging in physical activity is beneficial for maintaining a healthy body throughout a lifetime (USDHHS, 2000). Thus, physical education teachers must understand the importance of physical activities that can last over a lifetime. They should work on encouraging students to participate in a variety of different activities in order to promote and improve physical activity levels. Importance of physical activity in physical education

Health-related physical activity should be a primary focus in physical education classes. One reason for students' participation in physical education is to provide opportunities for selfexpression, social interaction, and to face new challenges, resulting in the pursuit of lifelong physical activities (NASPE, 1995). Elementary school children in particular, should gain enjoyment and pleasure from movement and physical activity as they develop competency in motor skills (NASPE, 1995). Systematic interventions that promote physical activity in schools are a valuable and effective (USDHHS, 1996) because they encourage children to remain physically active throughout their formative years and maintain lifestyle choices that may reduce the risk of heart disease later in their lives (Sallis \& McKenzie, 1991).

Health-related physical activity, movement skills, and a positive attitude toward physical education can be taught to school children in order to encouraging them to become lifelong movers (Lambdin \& McKenzie, 2003). According to Rink (2002), one goal of physical education is to enhance health by developing physically active lifestyles, most physical educators support the idea that the primary goal of a physical education is to get students to move and lead a physically active lifestyle. Physical education programs should play an integral role in reducing students’ health problems including obesity through regular physical activity. In addition, school-aged physical education, programs should provide numerous opportunities for students to 
engage in appropriate physical activity levels and motivate children to remain active during physical education classes. Consequently, increasing physical activity through quality physical education classes by decreasing student-teacher ratios might play a very important role in preventing inactivity among school-aged populations.

Students should be involved in activities that properly progress them through movements and activities that allow them to develop skills necessary for maintaining activity beyond their participation in physical education. In fact, well-created physical education programs are beneficial not only in terms of allowing students to be physically active, but also in terms of fostering social behaviors such as socialization, cooperation, and interaction with others. The physical education program transfers beneficial behaviors from sedentary habits and high-risk behaviors that might contribute to the epidemic of chronic diseases including heart disease (Sallis \& McKenzie, 1991). Students can improve their health and physical fitness levels if teachers begin to establish and implement meaningful plans for instruction based on the students' interests and needs.

School administrators believe that quality physical education is essential to the overall education of students (Kerby, 1994). According to Sallis and McKenzie (1991), physical education has been focusing not only on physical enhancement but also social and moral development. Physical education instructors must teach rules and regulations, which increase encourages appropriate social behaviors through establishing limits, rules and consequences while playing games and sport related activities with others.

Students can develop respect for peers and teachers by following the rules and regulations of games and sports. The study by Sallis and McKenzie (1991) also indicated that regular physical activity in physical education is important in promoting lifetime habits of 
physical activity with children. Thus, the physical education teachers should strive to develop health-related physical education programs that establish patterns of regular physical activity for children (Sallis \& McKenzie, 1991).

\section{Teaching effectiveness}

Effective teaching should incorporate optimal student outcomes as well as positive teaching behaviors. A students' overall performance is strongly related to their level of academic engagement (Finn, Pannozo, \& Achilles, 2003). The quality of physical education is determined based on the students' learning behaviors, activity level and achievement. Positive teaching behaviors also enhance the student's development of appropriate skills and the time engaged in motor appropriate activity during instruction. Each aspect is valuable teaching behaviors necessary for enhancing student engagement, performance, and motor skill within the physical education setting. It is important to know what makes teaching effective or ineffective for the purpose of sustaining quality physical education programs.

Students should be encouraged to achieve and maintain appropriate physical fitness levels by staying motivated in school physical education programs. High motivation is a primary element that influences learning achievement for students in an educational environment (Chen \& Darst, 2001). However, most students are not motivated in physical education lessons and consistently complain about being bored with physical education class (Mowling, Brock, Eiler, \& Rudisill, 2004). Physical education teachers need to monitor the affective demands of students as a motivator in their teaching. They also need to create proper planning in order to motivate and encourage students to be active in physical education.

Effective physical education teachers should develop specific and measurable goals that motivate and encourage students to stay on task and hold them accountable for performance- 
based experiences. However, children and youth may fail to be motivated to engage in physical activity because of the instructional variables such as class size and constraints on space, equipment, and time.

Graham and Heimerer (1981) indicate that less structured teachers tend to be ineffective, resulting in students who are uncertain about what they have to do and how they should execute a task in a class. However, Housner and Griffey in 1985 found that experienced teachers possessed more rich knowledge structures for managing students and they altered lessons based on the students' needs.

Higher rates of teacher feedback correlated significantly with higher rates of students' time for very active and moderate to vigorous physical activity (MVPA) (Van Der Mars, Vogler, Darst, \& Cusimano, 1998). Part of the reason that students have not correctly learned a skill may be due to inadequate amounts of feedback during class (Graham, 1987). Providing feedback is an essential element in facilitating student engagement, fostering positive perceptions of ability, and improving performance in physical education (Placek, \& Locke, 1986; Fredenburg, Lee, \& Solmon, 2001; Tjeerdsma, 1997).

In addition, Graham (1987) found that most physical education teachers provide general feedback for students (e.g., "good”) rather than specific feedback (e.g., “yes, that time you stepped with the opposite foot”) (p.46). He emphasized feedback, especially specific feedback, for the students' performances in physical education classes. Specific and positive feedback can better help students modify and improve their form in specific performances.

Teachers' specific observation and immediate feedback toward the students can positively affect the students' MVPA level. Schuldheisz and Van der Mars (2001) found that active supervision may enhance the students' MVPA level while passive supervision decreases 
the MVPA level. The ability of a teacher to keep students on task is obviously the most important management dimension (Graham \& Heimerer, 1981). Students are able to spend more time on task, which leads to a high level of physical activity through organization and time management in a lesson. Teachers' demonstrations also correlated positively with students' active behavior (Van Der Mars et al., 1998).

\section{The Effects of Class Size}

Large class size, shrinking budgets, and lack of school facilities are some of the barriers that may prevent physical education teachers from truly being effective. There are a number of variables become constraints for effective teaching in physical education, such as class size, facilities, or teaching experiences. Kerby (1994) asserted that "the size of physical education classes should mirror the class size of other courses in a school's curriculum.”

The factor of class size is a controllable variable directly related to successful achievement of educational goals in an educational program (Verducci, 1969). This factor affects the students' capacity for learning physically activity and limits a teacher’s decisionmaking processes within the physical education context. Thus, the class size deserves careful consideration as an important aspect for scholarly research. Reducing physical education class size has the potential to help keep students motivated during class and encourage continued achievement of appropriately structured course outcomes.

Hastie, Sanders, and Rowland (1999) found that physical education teachers had difficulties in classes due to administrative constraints. School administrators who made arbitrary decisions on class size without the input of physical educators negatively affected physical education and were identified as barriers for student motivation in physical education (Mowling et al, 2004). By providing support, benefits, and encouragement, school administrators could 
alleviate many of the challenging barriers that physical educators face on a daily basis and help them to excel in their effort to motivate, encourage and instruct student skill development.

Henry (2000) reported that pupils in a class of 16 spent nearly twice as much time in activity than did pupils in a class of 30 . This supports the belief that students can be more physically active in a class of smaller size. In addition, Hastie and Sanders (1991) indicated that students are at a disadvantage in larger classes because of reduced time of activity and equipment allocation. Students have fewer opportunities to actively engage in activity when equipment is limited within larger classes.

Physical educators have long examined the merits of smaller class size and believe that class size influences curriculum decisions and overall content planning, facilities and equipment, discipline, management, safety considerations, teaching strategies, length of the class period, and teacher morale (Carlson, 1994). The curriculum of a physical education course should be developed in order for students to accomplish appropriate goals; however, large class sizes inhibit teachers' abilities to plan and implement adequate curricula. Large class size is a factor in students failing to be motivated to be physically active in physical education and in teachers failing to provide effective teaching behaviors. Additionally, class size does influence the teacher's decision-making process in recognizing teachable moments, and deciding on proper instructional techniques for all students.

McKenzie, Marshall, Sallis, and Conway (2000) found that the large classes interferes with student levels of physical activity and limits the accomplishment of important physical education objectives such as health, fitness, and skill acquisition. In addition, according to a descriptive study by Sander (1996), one response was that some teachers gave up on focusing on skill instruction because of overcrowding. That behavior is not expected in a quality physical 
education program and in order to prevent further instances, the problems with large class sizes should be resolved in order to provide quality school physical education programs.

Problems created by large class size create an environment filled with impediments preventing teachers from being effective and incorporating valuable teaching behaviors necessary for ensuring student learning behaviors take place. The quantity of students in a class could be an important variable in terms of a student's performance and engagement, and a teacher’s decision making and teaching behaviors. To provide effective and appropriate instruction in terms of student learning performance and promoting students' engagement, what must the teacher take into consideration? Unfortunately large class size is a typical impediment in physical education, which limits a teacher's effectiveness by reducing opportunities for effective teaching (Metzler, 2005). This study examined relationships between teaching experience, planning techniques, and interactive decision making, incorporated in actual teaching behaviors within classes of different sizes.

\section{The Problem}

\section{Statement of the Problem}

This study is designed to examine the decision-making processes employed by two highly experienced teachers and two less experienced (student) teachers as they plan, teach, and evaluate two classes of different sizes, $n=15$ and $n=35$, utilizing stimulated-recall procedures. Another purpose of this study is to investigate teacher and student behaviors in the two different class sizes using the West Virginia University Teaching Evaluation System (WVUTES) and Field System Analysis (FSA). Finally, this study documented emergent teaching concerns while dealing with the challenge of class size through the use of in-depth interviews. 


\section{$\underline{\text { Research Questions }}$}

1. What association exists between planning and interactive decision-making processes made by experienced and inexperienced teachers within small and large class sizes?

2. What association exists between teacher and student behaviors within small and large class sizes?

3. What teaching concerns emerge from teachers who are presented with small and large class sizes?

\section{$\underline{\text { Scope of the Study }}$}

Four physical educators were recruited from a physical education teacher education program at a rural, mid-Atlantic University in the United States. Two cooperating teachers were designated as highly experienced teachers (HET) and two university (student) teachers were designated less experienced teachers (LET). Physical education student participants were recruited from the existing classes of the cooperating teachers. This study utilized approximately 180 physical education student participants. The independent variables in this study were class sizes of 15-16 and 30-31, and the teachers' characteristics (highly experienced vs. less experienced). The dependent variables were decision-making strategies of the teachers in planning, teaching, and evaluating lessons taught to classes of 15 and 35 students. The teachers' and students’ behaviors, and teachers’ feelings and concerns of class sizes elicited through interviews were also dependent variables.

A stimulated-recall technique was used to question instructors following the teaching episode to determine why the procedure was selected, how it affected the process, and why it was implemented at that time (Parker \& Pitney, 2003). Each instructor taught two lessons; one in 
a class size of 15-16 and the other in a class size of 30-31 so that eight observations of the four teachers (two experienced and two novice teachers) were collected and analyzed in this study. WVUTES was utilized as the initial observational instrument in this study. WVUTES was developed to provide a rich, empirical source of information regarding subject matter lessons and programs in terms of teacher behavior and the behavior of students (Hawkins \& Wiegand, 1989). WVUTES allows recording the frequency and duration of teachers' instructional behaviors during lessons regardless of class size, class length, or type of lesson (Hawkins \& Wiegand, 1989).

Based on teaching and learning behaviors, the one preeminent teaching lesson from experienced teachers in each class size - small and large - were chosen for detailed analysis of teaching and learning behaviors. Therefore, the selected four lessons (two lessons, one small and one large from highly experienced teacher; two lessons, one small and one large from less experienced teacher) were analyzed using FSA (Sharpe \& Hawkins, 1992; Delprato, 1992). FSA deals with events that produce "descriptions," "multiple concurrent factors," and "operating in real time” (Delprato, 1992) and allows a complete and accurate description (Sharpe \& Hawkins, 1992). The word "system" in Field System Analysis is meant to "convey the complex, interdependent relationships of contextual and behavioral events as they flow through time” (Sharpe and Hawkins, 1992, p.10). Therefore, this method was useful in describing specific and accurate teaching and learning behaviors that occur in teaching physical education. In addition, this FSA method provided great potential to contribute to the comparative study of experienced and novice teachers (Sharpe \& Hawkins, 1992) as is the intent of this study.

\section{Assumptions}


1. Stimulated-recall procedure is valid to examine the interactive decision-making processes (Housner \& Griffey, 1985).

2. The West Virginia University Teaching Evaluation System is valid to examine both teacher and student behaviors (Hawkins \& Wiegand, 1989).

3. Field System Analysis is valid in analyzing contextual procedures of lessons in physical education (Sharpe \& Hawkins, 1992).

4. The student participants have never been exposed to the sport of floor hockey in physical education setting.

\section{Limitations of the Study}

1. The participants will represent only an elementary school population. The results of this study might not be generalized to students in other levels of education (i.e., middle or high school).

2. Most of the students in the elementary school will be Caucasians. As a result, this study might not be generalized to schools that are more culturally diverse (i.e., Black, Asian, etc.).

3. The sport of hockey will be utilized in this study so the results may not be generalized in other types of sports (i.e., volleyball, soccer, basketball, etc.).

\section{Definition of the Terms}

1. Class size is defined as the total number of student participants in a class.

2. Teacher behavior is defined as behavior that a teacher can perform while students are engaged in movement task during a lesson.

3. Student behavior is defined as behavior that students can perform while they are engaged in movement task during a lesson. 
4. Teaching experience is characterized as a character that teachers obtain as they progress from pre-training to the present (Graber, 2001).

5. Planning is defined as decisions the teacher makes prior to the act of teaching (Peterson et al., 1978).

6. Interactive decision is defined as decisions the teacher makes during the act of teaching (Peterson et al., 1978).

Significance of the Study

Work place conditions, including class size, facilities, and equipment (Graber, 2001) are essential variables to increase student performance in physical education. However, the issue of class size has been marginalized in research on teaching in physical education compared to the issues of equipment or facilities (Graber, 2001) despite the fact that physical education teachers have expressed that they are not pleased with their class sizes (Hastie et al., 1999). Few researchers (Hastie et al, 1999; Hastie \& Saunders, 1991; McKenzie et al, 2000; Silverman, 1988; \& Verducci, 1969) have performed studies on the singular variable of class size in order to investigate the effects of class size using elementary school students or university students in the past four decades.

A small number of researchers revealed a significant difference between large class size and small class size in terms of usage of equipment (Hastie \& Sanders, 1991), developing skill performance (Verducci, 1969; Silverman, 1988), lesson context, and effective teaching behaviors (McKenzie, Marshall, Sallis, \& Conway, 2000). However, not all of the studies found the differences (Hastie et al, 1999). Hastie et al, (1999) found physical education teachers’ difficulties with curricular limitation, safety instruction, and administrative constraints; however, 
the teachers were recognized as effective in terms of four allocated behaviors including instruction, activity, management, and waiting.

Much of the research over the last century regarding class size has focused on academic classrooms (Finn et al, 2003) rather than physical education classes. In a four-year study of class size by Pate-Bain et al. (1992), the benefits of small class size revealed that:

1. Basic instruction was completed more quickly, providing increased time for covering additional material.

2. There was more use of supplemental texts and enrichment activities.

3. There was more in-depth teaching of the basic content.

4. There were more frequent opportunities for children to engage in firsthand learning activities using concrete materials.

5. There was interested use of learning centers.

6. There was increased use of practice shown to be effective in the primary grades. The benefits of small class sizes are similar in physical education settings. A student's physical activity and the teacher's effective decision-making strategies and positive and effective behaviors with a small number of students in a class are believed to be beneficial for the students' performance and motor engagement. In addition, teachers could provide more feedback and motivate the students to increase motor-appropriate activities. Most importantly, the students might be able to achieve the major goals of physical education in a smaller class size, which is a physically active lifestyle. Additionally, larger class sizes reduce students' opportunities to take part in activities and to receive individual attention and contact from the teacher. This, in turn, can lead to boring classes and a failure of the physical education's goals and objectives. 
Despite the concerns of class size in academic performance for more than a century, research on teaching in physical education with regard to class size has been limited (Hastie et al., 1999). Therefore, the issue of class size warrants thorough investigation within the context of physical education teacher education and class size effects should be verified based on the achievement of physical education goals and objectives but also its influence on teaching effectiveness and quality. 


\section{CHAPTER 2:}

\section{REVIEW OF LITERATURE}

\section{Introduction}

Research on the role class size plays in academic performance has been conducted in the United States for more than a century (Finn, Pannosso, \& Achilles, 2003). Those studies concluded that a class size of less than 20 students was optimal for improved academic success. Over the last four decades, few studies have addressed class size within activity based coursework like physical education. Research from those earlier days revealed negative effects of class size, but few studies show significant effects of larger class sizes in physical education settings.

Physical education is a program much different than typical academic subjects because of its emphasis on physical activity, sport, and enjoyment in relationship to developing a healthy lifestyle. It is widely believed that students who enjoy playing sports and games in physical education programs are more likely to stay active throughout their lifetime. One of the most important motivators of sport participation is fun or enjoyment (Theeboom, De Knop, \& Bollaert, 1995). Students may also acquire motor skills, increase their physical fitness, and obtain health benefits through sport participation in physical education programs and extracurricular activities.

However, there are many variables that might interfere with the fundamental objectives of physical education and students' regular physical activity. These include large class size, lack of equipment, limited budgets, and misunderstanding of physical education. In this study, the researcher focused on how class size and a teachers' experience influenced behaviors that are important for providing effective instruction. 
Educators believe that the number of students in a class influence student learning (Wasley, 2002). Most physical education teachers would understand that smaller class size might be a positive contextual environment in order to provide effective feedback for students to be motivated and encouraged in learning a skill. However, in some cases, physical educators have increased or doubled classroom size in physical education settings due to lack of funding (Hastie, Sanders, \& Rowland, 1999). In fact, the physical education class size should be consistent with those of other subject matter classes in middle school and high school (NASPE, 1995). It is evident that physical education is more often taught in a large class setting than any other type of instruction (Sander, 1996). Even the previously allotted time for physical education is being decreased and given to other classroom subject matters such as mathematics, science, and reading (Hastie et al, 1999) regardless of importance of regular physical activity for students.

In addition, there is a lack of understanding of the importance of physical activity to the health of children and adults (Hastie et al, 1999). The lack of understanding could be a reason for school administrators doubling the class size. The insensitivity of large class size in physical education causes a lack of health related physical activity during physical education. In addition, the lack of understanding of physical education by administrators has resulted in reducing support, resources, and even time requirements (Griffey, 1987). The administrators have to realize the importance of physical education in terms of health related activity and should provide the proper attention to the physical education program.

This chapter consists of literature related to a) the effects of class size, b) the importance of health related physical activity in physical education programs, c) teacher and student behaviors, and d) the characteristics of experienced and novice physical education teachers in terms of interactive decision making. 


\section{The importance of physical education}

Physical education is a subject matter where students can enjoy health related physical activities and establish habits that include regular physical activity. Accordingly, quality physical education programs help to prevent unhealthy behaviors by minimizing sedentary habits in school-aged populations (Sallis, \& McKenzie, 1991). It is likely that well-established habits of regular physical activity instilled by quality physical education programs should remain throughout adulthood, and thus result in healthier decisions and behaviors over a lifetime. According to Healthy People 2010, regular physical activity is considered to lower death rate and helps to prevent many diseases. The Healthy People 2010 also states that regular physical activity (USHHS, 2000):

- increases muscle and bone strength,

- increases lean muscle and helps decrease body fat,

- aids in weight control and is a key part of any weight loss effort,

- enhances psychological well-being and may even reduce the risk of developing depression, and

- appears to reduce symptoms of depression and anxiety and to improve mood (p. 27).

To increase the level of physical activity and promote regular physical activity, physical educators have to develop and provide an appropriate curriculum and program in order for students to be physically active. Achieving, maintaining, and enhancing the level of physical fitness is one of goals for physical education programs (NASPE, 1995), which is accomplished through effective lessons with games and sports in order to provide enjoyable and fun episodes. Stratton (1997) found in his study on physical activity level of school children, ages 9-15, that moderate to vigorous physical activity (MVPA) goals are obtained through instruction and 
participation of invasion games (i.e., dodge ball, hockey) rather than dance, track and field, or fitness lessons.

\section{Effective teaching}

In most cases, the teacher leads a lesson based on a curriculum and the daily lesson plan in order to guide the class in a smooth and effective way. Accordingly, the teacher would appropriately prepare for the lesson in order to be effective in terms of teaching behaviors and learning behaviors.

Graham and Heimerer (1981) indicated three climates in teaching - warmth, expectancy, and task-orientation. The teaching characteristics would provide opportunities for teachers and students to interact with each other in a humanistic way rather than in a teacher-centered way. In addition, the effective teachers provide some expectation to reach a goal and encourage students to achieve the goal with task-oriented behaviors (Graham, \& Heimerer, 1981).

Effective teachers motivate and encourage students for being physically active with the highest amount of praise and feedback in a class compared to less effective teachers (Graham, 1987; Graham \& Heimerer, 1981; Placek \& Locke, 1986). Most students are encouraged by a positive way of teaching so that praise, positive feedback, and specific feedback on students’ performance could be effective in enhancing the performance of the subject matter tasks.

Tjeerdsma (1997) has investigated teacher and student perspectives of tasks and feedback. Eight $6^{\text {th }}$ graders and their physical educator participated in this study. Stimulatedrecall interviews were conducted after a 14-lesson volleyball unit. The author found the following about feedback:

- The purpose of feedback was to improve student performance as well as to motivate and encourage the students. 
- Feedback was meant to positively reinforce correct performance.

- Feedback resulted in positive feelings for the students and increased student effort in performing the task.

According to the findings, feedback is essential to motivate and encourage students, resulting in fostering skill achievement. The positive and specific feedback encourages students to refine their forms to a proper way of conducting the performance.

Ryan and Yerg (2001) have also investigated the effects of feedback on off-task behavior. Two physical education teachers and their students were recruited in $6^{\text {th }}$ and $7^{\text {th }}$ grades. They measured time of off-task behavior repeatedly and found that the occurrence of feedback was related to decreasing the off-task behavior of students. They also suggested that feedback at a distance could be effective to reduce student off-task behaviors. It supports that paying attention to the students can help to increase the students' on-task behaviors. The ability to keep the students in on-task performance is one of the essential behaviors of an effective teacher in terms of management dimensions (Graham \& Heimerer, 1981). Teachers would dedicate more time for student activity and instruction rather than waiting time or inappropriate motor-activity in a small class size.

Graham (1987) conducted a study about feedback for students in order to gain motor skills in physical education. He mentioned that one of the reasons why students were not able to acquire skills, which was a priority for physical education, was a lack of adequate amounts of feedback to let students know how to implement a skill correctly. He also emphasized that teachers should provide specific feedback rather than general feedback.

However, most teachers spend a substantial amount of time for verbal instruction and students engage in cognitive learning (Graham, 1987). It is apparent that students should be able 
to spend more time for activity that includes teachers' encouraging behaviors and feedback to achieve the goals of physical education rather than other behaviors such as getting out equipment and waiting. Teaching behaviors play a significant role in order for students to be motivated and encouraged to achieve the goals of physical education.

In a descriptive study by Sander (1996), the author indicated that close and proper supervision was important to motivate and encourage students in physical education classes; however, it is difficult to accomplish with large classes. He also suggested that working with parent volunteers, aides, or student assistants is a helpful organizational strategy for teaching large classes in order to organize and supervise. Students become motivated and encouraged through a teacher's close attention and feedback, but the large class size inhibits the situation when students get involved in an appropriate motor activity. By closely working with students, teachers have more chance to provide effective teaching behaviors in order to foster appropriate student behaviors as well as to avoid inappropriate behaviors.

A comparison study between active and passive supervision with eight students and their physical education teacher by Schuldheisz and Van der Mars (2001) has been conducted. Active supervision meant that the teacher was closely interacting with students in order to provide a high rate of prompting, encouragement, feedback, and movement. They found that the verbal promotion of physical activity was highly recorded during the active supervision sessions while instructional interaction occurred very low during passive supervision sessions. Active supervision on the student behaviors was correlated with a high rate of MVPA level (68\%) compared to passive supervision (49.7\%).

Van der Mars, Vogler, Darst, and Cusimano (1998) have examined students’ physical activity and teachers' active supervision during fitness instruction. Eighteen physical educators 
$(f=8, m=10)$ and 54 students ( 3 per 1 teacher) participated in this study. Teachers' and students' behaviors were videotaped to collect the data of the teacher's movement and location patterns. The student activity level and teacher behaviors were coded using the system for observation fitness instruction time (SOFIT, McKenzie et al., 1991). They found that teachers' active supervision patterns were correlated with the students' moderate vigorous physical activity (MVPA) levels. As the study indicated, the active supervision components including teacher positioning, movement, feedback, and demonstration correlated to the students' physical activity level (p.71). The feedbacks (e.g., skill, corrective behavior, and specific) that the teachers provided resulted in higher rates of students' time spent walking and MVPA. Those effective behaviors develop the students' interest to be involved in an activity, resulting in increasing appropriate behaviors. Accordingly, the teachers' appropriate and timely attention would influence students in being physically active.

Experienced teachers and novice teachers

Teachers' thought processes, planning decisions, and interactive decision-making processes affect teacher behavior (Peterson, Marx, \& Clark, 1978; Clark \& Peterson, 1986). According to Peterson et al, (1978), "planning decisions are defined as decisions that teacher makes prior to the act of teaching and interactive decisions are defined as decisions the teacher makes during the act of teaching.” (p. 418). An interactive process is a cyclical process, which is a reciprocal interdependence between teachers and students, and planning process is to gather the information about the nature and context of environmental conditions (Housner, 1991).

In general, a planning process is a system that a teacher develops a plan prior to the instruction as a process of selecting educational objectives, diagnosing learner characteristics, and choosing instructional strategy for student achievement (Peterson et al., 1978). The teacher 
also monitors the students' behaviors during the instruction and modifies the planning depending on the students' behaviors and the outcomes of occurrences during the instruction (Housner \& Griffey, 1985).

Once the teacher executes a lesson, the lesson is a "water flowing system," which is rapid, simultaneous, and unpredictable. This process is mediated by the teacher's personality and characteristics such as values, beliefs, knowledge, and expectation (Housner, 1991), which are acquired from a teachers' formative experience, education, and capabilities.

There are various teaching conditions and students' backgrounds in teaching environment, which make teaching complicated. In order to overcome those conditions and difficulties, teachers should build capabilities of decision making on undesirable situations or unexpected students' behaviors through teaching experiences.

Housner and Griffey (1985) studied teacher cognition between experienced and inexperienced teachers. Eight teachers were involved in this study with four elementary school children. They found that more information, when planning, was requested by experienced teachers (53 times) compared to inexperienced teachers (37 times). Experienced teachers had more instructional strategies stored in memory (Jones, Housner, \& Kornspan, 1995) in order to substitute the possible unexpected situations when teaching. They also found that experienced teachers were focusing on managing activities to facilitate motor skill acquisition and there were fewer instances of students' off-task and waiting behaviors during the instruction than with inexperienced teachers. However, one limitation of this study was that it was conducted in a laboratory setting with four students, which is a small number of students to generalize the results. 
Jones, Housner, and Kornspan sought (1995) to compare the knowledge and cognitive processing strategies employed by 10 expert and 10 novice basketball coaches. The total cues that they requested were 82 and 38 for experts and novices, respectively. The experts focused more on players (53 times out of 82, 65\%) and objectives $(13,16 \%)$ than novices on players (12 times out of $38,32 \%)$ and objectives ( $8,21 \%)$. It was coincided that these two categories were the most requested by experts and novices when planning. Additionally, in planning decision making, experts concentrated on instructional process (28\%), evaluation (19\%), and objectives (13\%), and novices focused on instructional process (27\%), activity (17\%), and evaluation (16\%). In addition, the novice teachers focused more on managerial tasks resulting in providing small amounts of feedback while experienced coaches relied more on abilities and characteristics of the players for planning compared to novice coaches. The experienced coaches also focus on the objectives, implementation to accomplish the objectives, and evaluating the accomplished objectives when they develop a plan for coaching.

Ahlgren, Housner, and Jones (1998) studied teaching effectiveness using qualitative methods. They recruited 10 experienced and 10 inexperienced basketball coaches as participants in this study. The findings revealed that experienced coaches were evaluated more in positive statements (64\%) than inexperienced coaches (28.8\%). In addition, they found that positive exemplars of effective teaching for both experienced and inexperienced coaches included clear demonstration and explanations, stating the purpose and objectives, well-organized instructional tasks, skill related orientation, and a positive learning climate.

There are a few characteristics of experienced physical education teachers and novice teachers in terms of planning and decision making in teaching. Teaching is complex and difficult due to unexpected incidents during teaching. Decision making is defined as how a 
teacher makes a decision in an unexpected situation in teaching (Housner, 1991). Teachers should be able to enhance the capabilities of decision making through experiences, reflection, and studying. According to Housner (1991), both experienced teachers and novice teachers requested students' age, ability level, the number of students, availability of equipment, and time for planning. However, experienced teachers required more information regarding students’ backgrounds and facilities. Experienced teachers have considerably more knowledge with workplace ecology in teaching than novice teachers.

In their mathematics classroom study, Livingston and Borko (1989) found that experienced teachers had no written plans but they more often described extensive lesson materials in a lesson than the novice teachers. The experienced teachers rely more on their previous experiences and knowledge in planning. They also found that the experienced teachers accepted students' questions and comments as a springboard for discussion.

Graham, Hopple, Manross, and Sitzman (1993) conducted a comparison study using interviews, field notes, and observation (videotaping) between three novice and three experienced teachers on the insight into their situational decision making. The lessons were focused on basketball dribbling with $3^{\text {rd }}$ to $5^{\text {th }}$ graders. The investigators found that the experienced teachers focused more on child-centered instruction compared to the subjectcentered instruction of novice teachers. They also found that novice teachers more frequently stopped a lesson to present an extension, refinement, and application than experienced teachers (22.4 times vs. 15.3 times).

Hawkins and Sharpe (1992) conducted a comparison study of experienced and novice physical educators using Field System Analysis (FSA). The study has been expounded and analyzed visually using matrices, graphics, and charts of teaching behaviors. They found that 
experienced teachers were encouraging students through positive feedback. For the experienced teachers, the proportion of positive feedback was higher than negative compared to novice teachers. In the description of sequential behaviors, encouragement and positive verbal feedback were followed after specific observations of the expert. Both teachers demonstrated individual modeling followed by verbal skill statement, but the expert provided unique verbal skill instructions with content-specific encouragement, skill statements, positive feedback, and positive nonverbal communication.

In addition, the expert was more likely to be positioned in the center of the gymnasium. The novice teacher, however, remained for a longer period of time in a peripheral position, determining what to do next. And the expert's general observation time was shorter in duration than novice's. The expert performed quick, general observations and transformed to specific observation to provide a variety of positive and encouraging behaviors. The researchers indicated that the expert focused more on instruction task rather than managerial concerns upon which the novice concentrated. Impediments of effective teaching

Carlson (1994), in her descriptive study, mentioned that physical educators have long thought about the merits of smaller class size. Physical educators believed that the class size influenced curriculum decisions and overall content planning, facilities and equipment, discipline, management, safety considerations, teaching strategies, length of the class period, and teacher morale.

Biddle and Berliner (2002) mentioned that the teacher was able to provide a more supportive circumstance for the students' learning performance with higher morale in small classes. It is true that a teacher's morale is significant; however, teachers may not be motivated 
and encouraged to be effective due to the large number of students. The teachers may be able to provide appropriate feedback with memorization of the students' names as well as inspire the students physically, emotionally, and mentally in a small class size. Teachers would have opportunities to get to know each student's performance and learning preferences in small class size. The teacher is also expected to provide proper feedback to motivate and encourage each student in the situation.

Safety is another concern in a large class. There are often too many students to safely teach skills in a limited space. In Hastie, Sanders, and Rowland's study (1999), one physical education teacher mentioned in an interview that the teacher should help the students to stay in their own space and move around in general space in order not to bump into each other at the beginning of the year. They also found in the study that large classes had more potential for discipline problems than small classes. Another descriptive study by Kerst-Davis in 1994, indicated that large classes are unsafe for teaching active sports in physical education.

Legislators do not often provide the funds necessary to allow principals to schedule single classes in physical education (Hastie et al., 1999). McKenzie, Marshall, Sallis, \& Conway (2000) found that students in physical education specialists' classes engaged in more activity than those in classroom teachers' classes. According to Sallis and McKenzie (1991), assessing quality physical education is difficult, but one way to assess the quality could be the availability of physical education specialists in schools. The specialists provide more time for being active with skill drills and fitness activities than the other teachers who provide more free time.

Of course, physical education specialists are the best individuals to teach physical education classes in terms of learning proper skills and knowledge in sports. However, there may not be enough in the budget to hire physical education specialists in all schools. Therefore, 
school administration would rather require a large number of students to meet the daily physical activity requirement at the same time (Hastie et al., 1999), which would not be appropriate for students to achieve moderate to vigorous physical activity. To provide quality physical education for students, physical education teachers should be recruited.

Schools need to have enough equipment to provide increased activity time and reduce waiting time for students. Students in classes with an unlimited amount of equipment spent more lesson time involved in motor appropriate activity than the students with limited equipment (Hastie \& Saunders, 1991). That supports that students are disadvantaged in larger classes due to less time allocated to curriculum activity and less opportunity to actively interact with the equipment.

Students' outcomes are coming from the teachers' effective teaching. However, if the class sizes were large, it becomes very difficult to accomplish optimal student learning outcomes as well as effective teaching in that class. On the contrary, extra achievements from small classes are greater when the class has fewer than 20 students, especially in the early grades (Biddle \& Berliner, 2002). In addition, Achilles et al. (2002) indicated that those who had been in small classes obtained higher levels of achievement than those who had been in regular classes or in larger classes with aides.

The effects of class size

In a descriptive study of classroom size by Posnick-Goodin (CTA, 2003), one teacher mentioned that many students are getting lower grades (i.e., Cs or Ds) because the class is so big. The students might have earned better grades but they could not grasp the contents as quickly had the class size been as small as 20 or lower. One teacher indicated that there is a big difference between class sizes of 20 and 30 in terms of managing students' misbehaviors in a 
classroom. In addition, CTA indicated that there were advantages of class size reduction in California based on a researcher's analysis. The advantages are following:

- Students' test scores are significantly better than when in a large class size.

- Poor and minority students are making great gains compared to other students (AERA, 2003).

- Parents' involvements are greater and expanded.

- Students are less disruptive.

- The rate of teacher attrition is reduced.

According to a four-year study of class size in a classroom setting by Pate-Bain, Achilles, Boyd-Zaharias, and McKenna (1992), the effective teachers who scored in the 15\% of scaledscore average gains in reading and math frequently provided positive attitudes toward children, emphasized positive behavior, and tried to promote learning and motivate students. The teachers were also able to provide immediate feedback on the students' behaviors. In addition, they indicated that class size contributes to the success of the most effective teachers.

Hastie, Sanders, and Rowland (1999) studied the effects of class size with three female elementary physical education teachers using observations and interviews. The teachers had a minimum of 38 students and a maximum of 75 students in a class but they had one or two aides due to the large class sizes. However, the teaching aides had never received any teacher education. The lessons were recorded with four student behavior categories, including activity, instruction, management, and waiting. The recorded behavior categories were analyzed to calculate the percentage that student spent in each category. They found through the three teachers' lessons that approximately $47.3 \%$ of time was devoted to activity, $25.7 \%$ to instruction, $18.6 \%$ to management, and $8.4 \%$ to waiting. These results were considered to represent a high- 
quality instruction for students. On the other hand, through the interviews, the teachers expressed difficult working conditions and felt marginalized by the administrators. There were discrepancies found between observations and interviews because the teachers were considered as good teachers according to the allocation time of student behavior categories. However, the teachers described difficult working conditions, including large class size, an unsafe setting, administrative constraints on effectiveness, and usefulness of aides through the interview processes.

Hastie and Saunders (1991) have investigated a study about class size and equipment availability on student involvement. Three physical education teachers - two female and one male - participated in the study and the lessons focused on soccer with a total of 160 students from $5^{\text {th }}$ and $6^{\text {th }}$ grades. The class sizes ranged from 12 to 44 . They found that there was significantly less transition as the class size decreased. In smaller classes, the students devoted more time to motor engagement than organizational procedures. In larger classes, more lesson time was spent in transitions because there was difficulty organizing the large number of students, resulting in reduced opportunities for feedback. In addition, the researchers indicated that more off-task behaviors occurred in the double class sizes $(n=44)$.

Verducci (1969) studied focusing on college level students on three different class sizes ( $n=15, n=37$, and $n=60$ ). The study focused on the effects of class size in the learning of a motor task in a college tennis class. The course was scheduled for nine weeks and met twice per week. There were three categories of class size to compare and contrast, including small vs. large, small vs. medium, and medium vs. large. There was a significant difference found between small and large class sizes but a miniscule difference between the other two groups (small vs. medium and medium vs. large). 
The relationships of student achievement of volleyball serve and forearm pass tests on class size and selected teacher presage variables were examined by Silverman (1988). The study consisted of seven physical education teachers from a middle school and a high school ( $m=4$, and $f=3$ ) and about 250 students. The range of class sizes was 15 to 39 with a mean of 25.

Silverman found that increased class size negatively correlated with student achievement, particularly concerning serve skill.

According to McKenzie, Marshall, Sallis, and Conway (2000) in their study that consisted of 430 lessons taught by 126 teachers in 24 schools, there was no statistically significant difference for the effects of class size on lesson context and teacher behaviors. The authors, however, indicated that large classes interfere with being physically active and limit the accomplishment of important physical education objectives such as health, fitness, and skill acquisition as well as attitude toward physical education.

\section{Summary}

The number of students in class is a direct influence on teaching effectiveness (Pate-Bain et al., 1992). Teachers should be able to transfer positive teaching behaviors into behaviors that students need for learning. Teachers should also be able to motivate students to be physically active. Throughout most of the studies examined in this chapter, large class size is revealed as a negative factor in the teaching and learning environment in order to provide effective teaching and appropriate skills instruction. Decreased participation is a difficult and unnecessary side effect of large class size which may also result in a decreased level of physical activity, which is contrary to one of the goals in physical education (Rink 2002). In addition, providing physical education with smaller class sizes would play a role not only to reduce students' health problems 
and obesity but also to enhance physical condition and maintain their healthy lifestyle through regular physical activity.

Students should be able to spend a lot of time engaged in motor appropriate activities during physical education. Many researchers have discovered negative effects of class size (Verducci, 1969; Silverman, 1988; Hastie \& Sanders, 1991; Hastie, Sanders, \& Rowland, 1999; McKenzie, Marshall, Sallis, \& Conway, 2000); however, class size presents some negative effects especially if utilizing equipment is important for developing and acquiring psychomotor skills, lesson context, and effective teaching behaviors. Students can have more opportunities to engage in motor appropriate activity with enough equipment and plenty of encouragement from a teacher instructing a smaller class size.

In addition, as the students are encouraged by a teacher’s close attention and supervision, those who are in smaller class sizes have more chances to get the active supervision and positive and specific feedback (Graham, 1987; Ryan \& Yerg, 2001). Despite the positive effects of small class size, many school administrations continue to double the class size in physical education programs.

As a result, the class size is a considerable variable for a researcher to examine the differences of teaching behaviors in small and large class sizes. Hastie et al. (1999) indicated that there was limited research on class size conducted in the physical education teaching environment. That fact encourages the investigator to conduct this research to examine the impact of class size on decision-making process, teaching and learning behaviors, and feeling and concerns in teaching with experienced and inexperienced teachers. According to this research, it is both beneficial and useful for both experienced and novice teachers to obtain and 
understand the knowledge of experts and for future teachers to overcome the difficulties of teaching environment in order to enhance teaching effectiveness. 


\title{
CHAPTER 3:
}

\section{RESEARCH DESIGN AND METHODOLOGY}

\author{
Introduction
}

For students to achieve the objectives and goals of lesson teachers need to be effective at motivating students. Teachers encourage students to stay on task and hold them accountable for performance-based experiences. However, physical education failed to provide what students believe are meaningful experiences (Griffey, 1987). Rarely are students provided with sufficient encouragement and motivation in physical activity due to variables like: class size, inappropriate curriculum, space, equipment, or time. Large class sizes might be one controllable factor that teachers and administrators should consider when striving to provide effective physical education.

This study was designed to examine the decision-making process employed by two experienced teachers and two student teachers as they planned for and taught classes of two different sizes: ( $n=15-16$ and $n=30-31)$. Another purpose of this study was to investigate behaviors used by teachers and students in different sized learning environments using field system analysis. Finally, the intent of this study was to describe teachers' concerns in terms of class size through the use of interviews.

This chapter is divided into the following sections: a) participants, b) research design, c) pilot study, d) instrumentation e) procedures and f) data analysis.

\section{$\underline{\text { Participants }}$}

Two highly experienced physical education teachers (HET1 and HET2) and two less experienced physical education teachers (LET1 and LET2, student teachers) were involved in 
this study. Pseudonyms for the participated teachers have been used in this study including Erick Sam (HET1 ), Erin Hong ( HET2), Nancy Young ( LET1) and Nathan Smith (LET2).

Erick Sam (HET1) was a male physical education teacher at the elementary school level and he was also the cooperating teacher for Nancy Young (LET1) at the elementary school. Erick Sam earned a master’s degree in a PETE program and had been working as a physical education teacher and basketball coach for approximately 34 years.

Erin Hong ( HET2) was a female elementary physical education teacher at an elementary school. She was cooperating teacher of Nathan Smith (LET2) She had received a bachelor's degree in a PETE program and had approximately 26 years of experience as a physical education teacher.

Nancy Young (LET1) was a female senior student in a physical education teacher education program at a mid-Atlantic university. She was enrolled as a student teacher at an elementary school when she volunteered for this study.

Nathan Smith (LET2) was a male senior student in a physical education teacher education program at a mid-Atlantic university. He was enrolled as a student teacher at the elementary school level at the time he volunteered for this study.

A total of 184 student participants were recruited from the two different elementary schools along with their physical education teachers. All participants voluntarily participated in this study. The study was made up of two groups, one small group of students ( $\mathrm{n}=15-16)$ and one large group of students $(\mathrm{n}=30-31)$ from two elementary schools located in close proximity to the university. Since videotaping classes and conducting interviews with the teachers was a necessary part of this investigation, parental consent was obtained via signature on an informed consent form. Teachers encouraged students to take the form home and return consent forms to 
their physical education teachers two weeks prior to the beginning of this study. Teacher and student participants were not compensated for their participation in this study.

Institutional Review Board (IRB) for the Protection of Human Subjects’ approval was obtained prior to collecting data. Participation was entirely voluntary and did not affect the participants’ academic status. Confidentiality was maintained throughout this study by not using linking participant names to the data. Video-taped lessons and data from think-aloud, stimulatedrecall, and interviews were audio-taped, transcribed and labeled anonymously. Videotaped lessons, audio cassette tapes and interview transcripts were kept locked in a cabinet located in the office of the primary investigator at all times.

$\underline{\text { Research Design }}$

This was a mixed-methods study that utilized both behavioral analysis and qualitative methods of investigation. A field system analysis with judgmental aids (visual graphics and charts) were used to compare and contrast teaching and student learning behaviors between highly experienced (HETs) and less experienced teachers (LETs) in two different size classes. Think aloud, stimulated-recall, and semi-structured, open-ended interview techniques were used to describe participants teaching concerns dealing with class size in this study. Instrumentation

This study used three different methods to measure and analyze data - Stimulated-recall (SR; Housner \& Griffey, 1985), West Virginia University Teaching Evaluation System (WVUTES; Hawkins \& Wiegand, 1989), and Field System Analysis (FSA; Sharpe \& Hawkins, 1992).

Stimulated-recall (SR) Stimulated-recall is a technique that was used to investigate cognitive processes like decision making, by asking subjects to recall their cognitive activity 
(Lyle, 2003). The SR method has been used in physical education (Allison, 1987; Allison, 1990;

Byra \& Sherman, 1993; Ennis, 1994; Housner \& Griffey, 1985; Lee, Landin, \& Carter, 1992;

Martinek \& Griffith, 1994; Parker \& Pitney, 2003; Schempp, 1995; Tan, 1996; Tjeerdsma, 1997;

\& Walkwitz \& Lee, 1992) and classroom settings (Supaporn, Dodds, \& Griffin, 2003) in order to investigate cognitive processes. Lyle (2003) indicated that stimulated-recall continues to be popular and Housner and Griffey (1985) described that "the study of interactive decision making has been conducted almost exclusively through the use of stimulated-recall during videotape replay” (1985, p.45), which was an introspection procedure in which individuals were stimulated to recall videotaped behaviors that are replayed and shown (Lyle, 2003).

Stimulated-recall interviews were conducted at the completion of the first and second lessons of each participant to examine the decision-making processes employed by two experienced teachers and two student teachers as they plan and teach two classes of different sizes; $n=15-16$ and $n=30-31$.

The West Virginia University Teaching Evaluation System (WVUTES). The West Virginia University Teaching Evaluation System (WVUTES) was utilized as one of the observational instruments in this study. The WVUTES was developed to provide empirical information regarding subject matter lessons and programs in terms of teacher behavior and the behavior of students in the teacher's class (Hawkins \& Wiegand, 1989). It is useful to observe both teacher and student behaviors regardless of class size, class length, or type of lesson (Hawkins \& Wiegand, 1989). One best lesson in each class size from two different types of teachers - HETs and LETs - was selected using WVUTES. Therefore, four lessons (one small class size and one large class size lesson from HETs and LETs and one small class size and one large class size lesson from novice teachers) were analyzed and described using field system 
analysis based on the effective instructional behaviors and students' appropriate learning motor behaviors.

Field System Analysis (FSA). Field system analysis (FSA) provided a tool for better understanding the instructional performance that takes place within complex interactions among teachers and students in a given environmental context (Sharpe, Lounsbery, Hawkins, and Eldar, 1995). Procedures included: verbal field description, category system construction, data presentation, and data interpretation (Sharpe and Hawkins, 1992) FSA produced descriptions of multiple concurrent factors. Operating in real time (Delprato, 1992), these procedures possess the unique capability of capturing teaching behaviors as they occur in a practical setting (Sharpe and Hawkins, 1992). The data is then graphically displayed using matrixes and charts (Sharpe \& Hawkins, 1992) so it can be expressed and interpreted visually using FSA.

Interviews. This study used the qualitative methods of formal interviews following the completion of the second stimulated-recall for each participant. This method was used to enhance the value of behavioral findings by providing rich descriptions of thoughts, goals, and decisions in addition to valuable information collected on the type and frequency of teacher and student behaviors (Ahlgren et al, 1998). Interviews were useful in understanding what teachers actually believed and were concerned about in dealing with the challenge of different class sizes. Recorded interviews which lasted approximately 3-7 minutes were conducted immediately following instruction. Interview questions were designed using an open-ended format and responses were transcribed at the completion of each lesson then used for further analysis. Teachers had opportunities to discuss limitations of their behaviors in terms of class size, student behavior, and pre-planning for the lesson for both groups. Data collected using interviews was later used to represent the teacher's feelings as they instructed classes of two different sizes. 


\section{$\underline{\text { Procedures }}$}

Approval from the Institutional Review Board (IRB) for the Protection of Human Subjects was sought and obtained prior to collecting data. Two less experienced teachers (LETs) agreed to participate as novice physical educators. Two experienced physical education teachers (HETs) and their students also agreed to participate in this study. All participants contributed their time and effort on a voluntary basis, which did not influence school or grades status. Student participants were informed that they were allowed to drop out of the study at anytime, without any penalty.

Consent forms were sent home with potential student participants for parents to read, sign, and return to the physical education teacher. When informed consent forms were returned, the teachers then assigned students into one of the two groups ( $n=15-16$ and $n=30-31)$. For this study, one or two students in each group was randomly selected for specific observation in order to analyze typical student behaviors that occurred during the lesson.

Observer reliability. Three observers were involved in the coding of data for this study, in an effort to achieve a high level of inter-observer agreement. Inter-observer Agreement (IOA) was conducted to confirm the reliability of the primary observer's coding of teacher and student behaviors. One videotaped lesson from each group was randomly chosen for IOA analysis. Agreement was established when codes from all three observers' reached 80 percent or above for that lesson, thereby confirming that data collected was reliably coded.

Independent variables procedures. Certain teaching information was given to teachers, such as the duration of lesson (30 minutes), the number of students in each class ( $\mathrm{n}=15-16$ and $\mathrm{n}=30-31$ ), what equipment, facility, and which teaching content (floor hockey) was to be used. Floor hockey is an indoor sport that includes plenty of tasks for the development of a lesson plan 
as an introductory lesson. The opportunities to decide the teaching content was provided to the all teachers. Each teacher taught two consecutive episodes back to back, where lessons were taught one at a time. The procedures for collecting data are described as followed:

1. Each teacher was audio-taped verbalizing their thoughts while preparing a lesson plan for their first (Large) class. - Think-aloud technique.

2. Teachers conducted the first lesson using the lesson plan they devised with the thinkaloud technique (Figure 3.1).

3. Following instruction, the videotaped lesson was presented to the teacher while they answered questions about their teaching behaviors, using the stimulated-recall questionnaire -Stimulated-recall Technique.

4. Each teacher was audio-taped verbalizing their thoughts while preparing a lesson plan for their Second (Small) class (Figure 3.2). - Think-aloud technique.

5. Following instruction, the videotaped lesson was presented to the teacher while they answered questions about their teaching behaviors, using the stimulated-recall questionnaire -Stimulated-recall Technique.

6. The formal interview was conducted with all four participants at the completion of the second stimulated-recall process.

7. All eight lessons were analyzed using WVUTES. Based on that data, two "best teach" lessons were selected for each teacher, one for each class size (small \& large). Selected lessons were then analyzed using FSA.

Dependent variable procedures. Decision-making processes employed by two experienced teachers and two student teachers as they planned for and taught two classes of different sizes, $n=15-16$ and $n=30-31$, were evaluated using the stimulated-recall process 
described above. The stimulated-recall process was conducted at the completion of the first and second lessons. Eight lessons were analyzed using WVUTES, two lessons taught by both experienced teachers (4 totals) and two lessons taught by both novice teachers (4 totals). Based on WVUTES data a total of four "best teach" lessons (one from each category) were selected for behavioral analysis using FSA. The "best teach" completed by a less experienced teacher in both small and large classes (2 total) and the "best teach" completed by a highly experienced teacher in both small and large classes (2 total). A total of four lessons were selected for behavioral analysis using FSA so that visual and graphical charts could be constructed showing the teaching and learning behaviors that occurred during the lessons.

Formal interviews, which lasted approximately 3-7 minutes, were conducted after the second stimulated-recall to describe teacher concerns and feelings in further detail. Interview data was then categorized and coded based on similarities and differences found within teacher responses.

Data Analyses. This study utilized five different methods to analyze the data collected. First, the think-aloud technique was used to collect data on how teachers prepare for their lessons. Second, stimulated-recall was conducted immediately following the first and second lessons so that the decision-making process employed by the teachers could be further examined. Third, the researcher used a WVUTES analysis to select the best teaching episodes that occurred within each category: HET small, HET large, LET small and LET large. Fourth, the four best teaching episodes selected from each category were analyzed using field system analysis (FSA). This method was used to investigate relationships between teacher and student behaviors (dependent variables) and two different class sizes (independent variables). Visual graphs and 
charts with frequency, duration, percentage of instructional time, and rate were provided using FSA.

Finally, formal interviews were conducted at the end of the second stimulated-recall session. These interviews were then transcribed and analyzed for a rich description of teachers' thoughts and concerns in dealing with different class sizes. 


\section{CHAPTER 4:}

\section{RESULTS}

\section{Introduction}

This study was designed to examine the thought process, and teaching behaviors employed by two highly experienced physical education teachers (HETs) serving as cooperating teachers, and two less experienced physical education "student” teachers (LETs) as they planned for, taught, and evaluated floor hockey lessons while teaching classes of two different sizes; small ( $n=15-16)$ and large ( $n=30-31)$. The following techniques were used to examine HET's and LET's thoughts, concerns, and decisions: think-aloud protocols collected during lesson planning, stimulated-recall data collected after each lesson, and teacher interviews at the conclusion of the study.

Another purpose of this study was to investigate teacher and student behaviors that occurred during classes taught by HETs and LETs as they presented lessons to both large and small classes. Behavioral analysis was performed utilizing the West Virginia University Teaching Evaluation System (WVUTES), a systematic observation instrument designed to collect real-time, teacher and student behavior data related to research-based definitions of effective teaching in physical education. Finally, a thorough analysis was completed on lessons selected for their effectiveness using a field system analysis, which is a tool used to understand instructional performance that takes place during complex interactions among teachers and students (Sharpe, Lounsbery, Hawkins, \& Eldar, 1995).

All teachers in this study cited the number of students in class as an important planning factor. Based on their knowledge and teaching experience, teachers were expected to develop lesson plans for both class sizes (15-16 and 30-31). Class size information was given to them 
during the think-aloud planning process prior to planning each lesson. All of the teachers in this study believed they had more time to complete lesson content with the smaller classes. This resulted in planning extra content, mostly game type activities for smaller classes. However, Nancy (LET1) did not finish the game she planned even with the smaller class, whereas Erick (HET1) did finish the game with his class. For, Nathan (LET2) the smaller class led to more practice and game time compared to his larger class as you will see later in his lesson structure (pp. 62-63 and pp. 66-67). HETs drew upon their knowledge of lesson content and the appropriate use of materials in addition to successfully motivating students through the use of music.

Safety of their students was one major concern that teachers consistently mentioned. However, only female teachers, Nancy Young (LET1) and Erin Hong (HET2), were concerned with safety during the think-aloud component of the study.

Teaching formation was another concern raised by teachers in terms of how to best organize students in different size classes. For example, Nancy (LET1) utilized a station teaching setting for both large and small classes whereas Nathan (LET2) utilized cohort teaching for both large and small classes. Meanwhile, Erick (HET1) used two different teaching formations, a station-based approach for the large class and a cohort-based approach for the small class. Erin (HET2) used cohort teaching for both classes and Erick (HET1) found that station teaching effective to better focus on instructional tasks while reducing management behaviors. Station teaching was found to be useful for preventing off-task student behavior during the lesson.

Teaching and learning behaviors identified by WVUTES and FAS showed that less experienced teachers (LETs) took full advantage of smaller classes by spending more time (duration) displaying effective instructional teaching behaviors like: specific observation, 
encouragement, positive feedback, corrective feedback, verbal instruction, modeling, and physical guidance and more often (frequency). Smaller classes had a higher percentage of student learning behaviors like: motor appropriate and cognitive activity. Thus, smaller class sizes appear more beneficial for LETs. In contrast, highly experienced teachers (HETs) demonstrated similar amounts of duration and frequency of instructional behaviors across both class sizes. Highly experienced teachers spent more time in specific observation of large class sizes, and provide more verbal instruction to smaller sized classes.

\section{Planning the Lesson: Think-Aloud Technique}

Information regarding class size, facility, and equipment was provided to teachers before they began the planning process. The number of students in the large class size ranged from 30 to 31 and the small class size ranged from 15 to 16 . HETs and LETs taught one lesson each to a large and a small class. Each lesson was taught to a class of different students and all student participants were in the 5th grade.

Lessons were taught at two different elementary schools (East and West Elementary). Both gymnasiums measured 82 feet long and 67 feet wide and had typical floor markings such as lines demarcating a basketball court and four badminton courts. Both locations had their own floor hockey equipment with a sufficient number of sticks and pucks. One elementary school substituted wiffle balls because they did not have pucks. Each student had a stick, along with a puck or ball except during team play, when equipment was used like in a normal game situation. Students had no prior exposure to floor hockey content and teachers were free to plan tasks and objectives as they saw fit. Student participants were involved in just one class that was either large or small in size. All teachers in this study were asked to teach a large class first, because they could gain an advantage from teaching the content to the smaller class followed by a larger 
one. For this reason, they were each asked to teach the large class followed by the smaller class in order to give the same experience to all teachers in this study. This measure was taken in an attempt to eliminate carryover effects from teaching the lesson to the smaller group and then to the larger class.

Think-aloud techniques were employed by asking teachers to "verbalize all questions, thoughts, and planning decisions” as they planned their lessons. Planning sessions had no time restrictions. For HETs planning was completed in the office of the cooperating teachers at their elementary schools and all verbalizations were audio taped.

\section{Stimulated-Recall: Interactive Decision-Making}

Stimulated-recall was completed for the cooperating teachers following each lesson by showing videotapes of the lessons to teachers. For both of Mr. Erick Sam’s (HET1) classes and Mrs. Erin Hong's (HET2) small class, stimulated-recall data was collected immediately after each lesson. However, remaining lessons (Mrs. Hong’s large class and two less experienced teachers), stimulate-recall data was collected after school due to conflicts with teaching schedules. For stimulated-recall data, only the conversation time between the investigator and the teacher was recorded. The procedure took place in the library at West Elementary School for HET1 and in one of classrooms in East Elementary School for HET2. For LETs, the think-aloud and stimulated-recall were conducted in the investigator's office, located at a nearby university. Interview Data

All teachers were interviewed immediately after the completion of the second stimulatedrecall process. 


\section{Nancy Young (LET 1) - Lesson \#1: Large Class Size (n=31)}

Nancy is a 22-year-old, senior physical education major at a large Mid-Atlantic University. Her overall GPA was 3.57 and she is student teaching at West elementary school when she volunteered to participate in this study. Nancy is completing the final five weeks of her 15-week student teaching experience. Prior to her participation in the study, Nancy successfully completed her middle and secondary student teaching experiences.

Planning. In Nancy’s first lesson, she taught a class of 31 fifth grade students (21 males and 10 females). Nancy took 11 minutes, 15 seconds to plan for this 33 minute lesson. In the planning process, Nancy's primary concern was to ensure that her class had all of the necessary equipment, such as hockey sticks and wiffle balls. Another major concern for her was safety of the students since hockey sticks and wiffle balls were being used. Several times in the planning process, Nancy mentioned "the safety aspects” of the students properly using the equipment.

Nancy asked many questions regarding instructional strategies and management, such as “Can I use a station teaching strategy?”, “Is there a person to help?”, “Are there any specific guidelines that I need to follow?”, and “Is there any research found that I need to follow?” Nancy planned to use three stations: passing, dribbling, and goal shooting. Ten to 11 students were assigned to each station because she had approximately 30 to 35 students in the class. She also emphasized working in pairs at each station to avoid having a student working alone. Nancy planned to walk around to the different stations, observe students, and provide feedback. She said, "I am not worried about the 30 plus students in the class. I am confident with the large class size.” Nancy planned the lesson around managing three specific stations without any clear objectives or goals for the students in her large class. 
Lesson Structure. The lesson lasted approximately 33 minutes, 46 seconds. The lesson began with warm-up activities the teacher had planned. Following the warm-up activities, Nancy demonstrated the grip, proper passing and receiving, dribbling, and goal shooting as well as a safety aspect. For safety she focused student attention on keeping the stick below waist level while the students were practicing the tasks.

Nancy demonstrated each of the three stations using four different students. One girl and one boy for station one: partner passing and receiving. One boy for station two: goal shooting, and one boy for station three: dribbling. The rest of the students sat against the gymnasium wall during instruction. The entire gymnasium was utilized for the lesson activities. All students had one turn in each station so that they had a chance to participate in all three stations. For dribbling practice, two students at a time weaved in and out of cones as other students waited their turn. For passing and receiving, two students worked together as a team. Five student pairs were lined up to perform this task simultaneously. For the goal shooting station, there were four sets of goal posts. Therefore, 10 students were divided into groups of 2 or 3 since there were only four goals. In groups of three, when two were working as a goalie and shooter, one was waiting for her/his turn. While the students were participating in the three stations, the teacher provided feedback for the students, such as "hit it and stop it," "keep the stick below your waist," "keep it under control,” "below your waist,” "use two hands,” "way to keep it under control,” "under control,” and "keep the stick down.” Nancy kept saying "high stick,” which was a reminder of the safety aspect of the lesson. After the students had experienced all three stations, Nancy reviewed each station with student demonstrations and teacher demonstrations. Closure was not planned but was implemented as part of the lesson. The detailed structure of the large class size lesson with allotted time is as follows: 


Duration
Warm-up


gymnasium.

- Reviewed each station with student demonstration and tea cher demonstration - CFU.

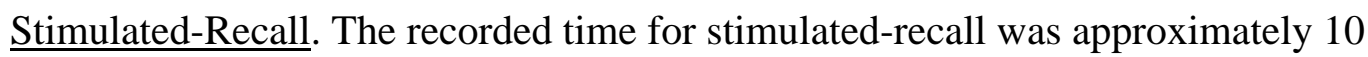
minutes, 5 seconds. Nancy mentioned that she spent too much time explaining what to do in the introduction period. But she said, "I wanted to make sure that I was getting the point across exactly what they needed to do. I also had volunteers for the student demonstrations to check for understanding." She also said, "Most of the students paid attention to me, but it was difficult to ensure that everyone paid attention in this large class size, because they were a handful.”

For her teaching, Nancy mentioned that she did a decent job on feedback, but generally provided positive feedback. "I gave some corrective feedback but spent more time on management than skill performance in this large class size, because nobody should get hurt by the sticks," she said.

Nancy could not provide individual feedback. She said, "I went through the stations but I maybe provided feedback once in a station.” She tried to evaluate what they were doing in all three stations. She said, "managing this class was more difficult because the wiffle balls were rolling around the gymnasium and it was a distraction that went on at all three stations.”. She had planned to use pucks for the lesson, but she used the wiffle balls in her lesson. She has never indicated why she selected the wiffle balls instead of pucks. Even though she had concerns about the safety of the equipment, she felt there was no problem with equipment because the hockey sticks had plastic handles and foam heads. She said, "That still means that many things are going on because all the students have a stick and wiffle ball.” But, she felt that the facility was safe. 
Nancy felt that the pupils were active and most of them were engaged in their tasks, except at the dribbling station, where there was waiting time because only two students could practice at a time due to the limited space (space? Was space the problem or how she structured the task?). "The teaching was not stressful but it was hard to manage the large class size of 30 students," she said.

Nancy had time to review all the tasks that had been taught with student demonstrations and teacher demonstrations. She did not mention the review in the think-aloud process. In addition, one task was not completed according to her plan, which was a game. She said, "I knew in the middle of the lesson that I would not have enough time to do that game, so I just focused on the station drills.” Finally, she mentioned that the lesson was more about safety management in order to make sure that nobody got hit by hockey sticks and pucks.

Nancy Young (LET 1) - Lesson \#2: Small Class Size ( $\mathrm{n}=15)$

Planning. For her second lesson Nancy taught 15 fifth grade students. There were 8 males and 7 females in the class. She took 6 minutes, 35 seconds to plan for her 29 minute, 46 second lesson.

“I like station teaching strategy,” Nancy said. She wanted to keep the three stations just as she had in the larger class. She said, "The station teaching was helpful for keeping students active, moving, and prevent them from getting bored.” She felt this lesson will go smoother than the lesson in the larger class so that she could add a game of dribbling tag, which was mentioned as a main goal for the small class size lesson. She, however, wanted to focus on skill drills, passing and receiving, dribbling, and goal shooting, because the lesson was an introductory lesson for the students. 
One objective of this lesson was to teach grip and stance. Thus, Nancy wanted to check everyone's grip and stance because if they did not know how to do those skills, they would not be able to achieve success. However, she did not mention any cues.

Nancy thought that she could observe all of the students much more efficiently than she had done in the large class size and keep an eye on high sticking, which was a safety concern. In terms of her gymnasium management, one difference between the large and small class sizes was her use of a few poly spots, near which she put sticks and pucks. She thought that that would make things easier for the next group that arrived at the station.

Lesson Structure. The lesson lasted 29 minutes, 46 seconds. The lesson began with warm-up activities which were not planned. At the beginning of her introduction, Nancy explained a safety issue, which was a primary objective of her lesson. She demonstrated gripping the stick and the three stations of the lesson—passing and receiving, dribbling, and goal shooting — thoroughly. She demonstrated all three tasks in each station with a student volunteer, one boy for partner passing and receiving, another boy for goal shooting, and one girl for dribbling. The rest of the students were sitting against the gymnasium wall during instruction. The entire gymnasium was utilized for the lesson. All students had one turn in each station so that they had a chance to practice all three stations. For dribbling practice, two students at a time weaved in and out the cones as the other students waited their turns. For passing and receiving, two students worked together as a team, lined up with one other group with three students. For the goal shooting station, there were two teams, but one had three students so that while two were working as a goalie and shooter, one was waiting her/his turn. All students had one turn (at least one turn or only one turn) at each station so that they had a chance to practice all three stations. For dribbling practice, two students at a time weaved in and out of the cones while the 
other students waited their turn. For passing and receiving, two students lined up and worked together as a team along with one other team of three students. For the goal shooting station, there were two teams but one had three students so that while two were working as a goalie and shooter, one was waiting her/his turn. While the students were participating in the three stations, the teacher provided feedback for the students, such as "nice stop," "keep it under control when dribbling, two hands on stick," "put your bottom hand on the tape, make sure you put your bottom hand stays on the tape," "keep it below your waist," "thumbs down," "which foot should be forward?”, "better to keep it under control than fast dribbling," "do not be afraid of bending over," and "make sure keep that your right hand is on the tape." After examining those three stations, the teacher checked for the students' understanding by asking a few questions without demonstration, which was not planned. The detailed structure of the large class size lesson with allotted time is as follows:

$\begin{array}{ll}\text { Duration } & \text { Content } \\ \text { Warm-up } & \end{array}$




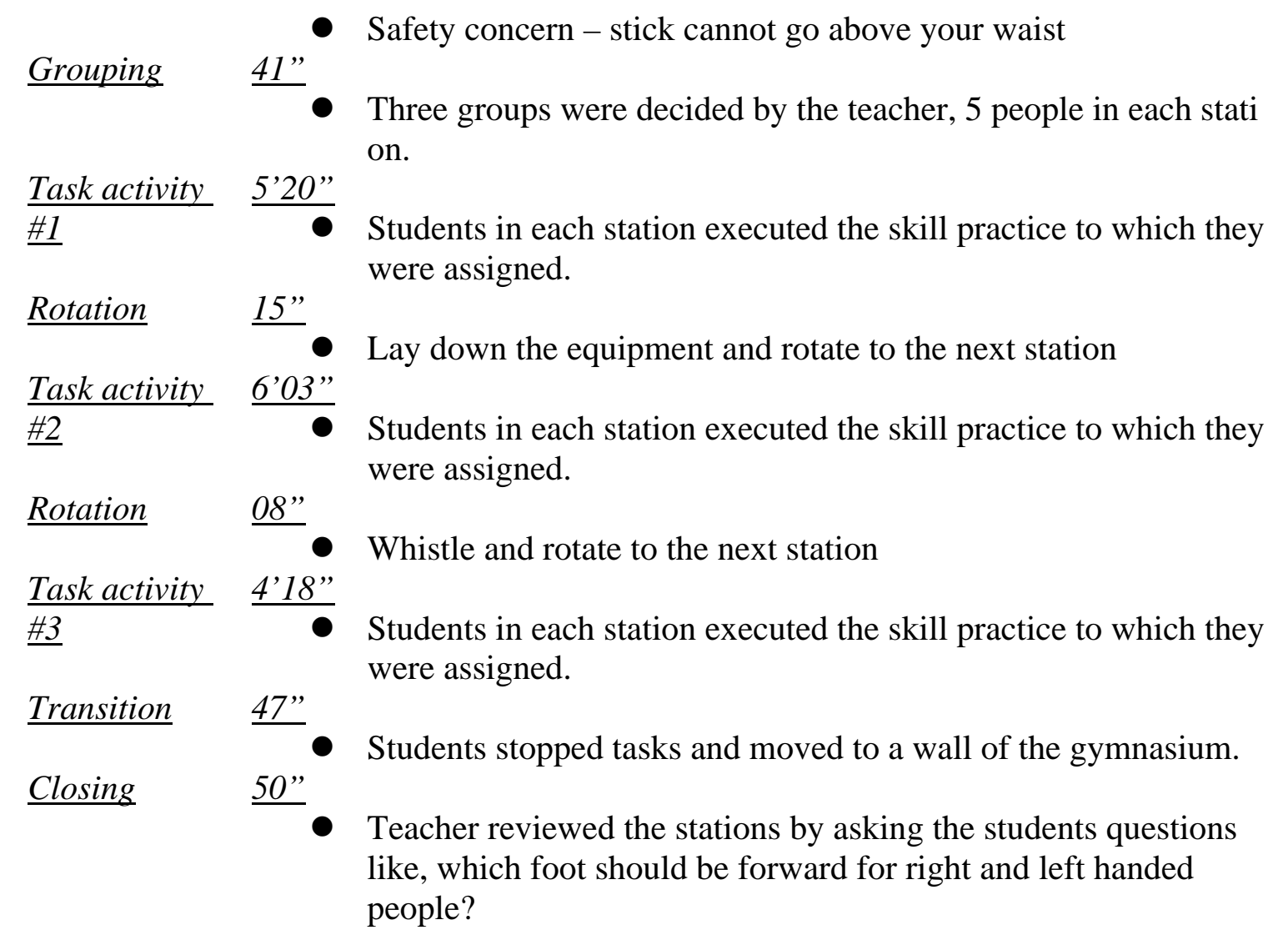

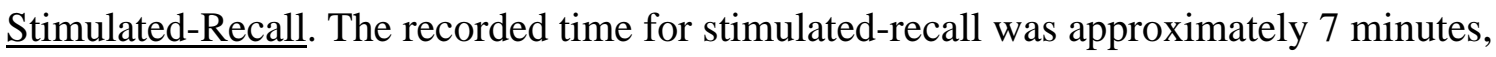
15 seconds. Nancy believed that she had much better success with demonstration and checking for students' understanding than she had in the large class. She said, "I paid attention to them and the introduction was smoother than in the large class.” She felt that she did not have difficulties with student behavior during the verbal introduction in this group. She said, "I was able to visually see those kids and the kids were looking at me. Nobody was disturbing anyone.” Nancy was able to walk around to each individual student and correct their form, but she said, "I said good job rather than bad." She thought that, for the most part, she provided appropriate feedback because she tried to move around to all three stations in every rotation. She felt that most students were on task and well behaved. However, she felt that the dribbling station had a long waiting time because she could set up only two dribbling sessions. 
Nancy had no problem with the facility or equipment. "The lesson was safe because of foam sticks and wiffle balls,” she said. She thought that the students were active so that physical activity was high. The lesson was not stressful and she felt that the students did what they were told.

Even though Nancy did not plan for a review, Nancy had time to review in the small class, too. However, she asked them questions without any demonstration. That was a different approach than in the larger class. In fact, she said, "I wanted to spend more time on actual tasks and drills rather than checking for understanding through demonstrations for five minutes.”

According to her plan, Nancy missed the dribble tag game, which was her main goal. In fact, she thought that she might have enough time for a game when she planned. However, she said, "In the middle of the lesson, I realized that I might not have enough time to do the game, so I elected to have more practice time.”

Interview Data: Class Size Comparison. The recorded time for the interview, which was used to compare and contrast both class sizes, was approximately 5 minutes, 30 seconds. Nancy felt that the station teaching for a large class size was great because, as she said, "I could spread them out instead of having them straight in a line. I could reduce waiting time.” However, she insisted that the "large class size was stressful. I had to focus on managing and safety in order to make sure the kids were staying at the stations rather than being able to focus on their skill performance because kids moved around.” She thought that there was no way to have one-onone interaction with each individual, and that there were no advantages to the large class size. "The more kids, the more things to do," she said. She also mentioned that the lesson with the large number of students had a safety problem of being hit with a hockey stick and "it was hard to have a successful lesson.” 
The small class size was "wonderful,” Nancy said. With 15 students in the class, "they tended to listen a lot more and they did what they were told.” Thus, she could tell the students what to do and what not to do more easily in the small class size. She also said, "Safety was an issue for this small class size but not as big an issue as the large class size, because the students were more on task under the teacher's better supervision.” 


\section{Nathan Smith (LET 2) - Lesson \#1: Large Class Size ( $\mathrm{n}=31$ )}

The second novice physical education teacher selected for this study was Nathan, a 26year-old male, senior student in the final phase of the physical education teacher education program at a mid-Atlantic university. He had successfully completed his middle school and secondary student teaching placements and now was beginning the final five weeks of his last 15-week student teaching experience. Mr. Smith was enrolled as a student teacher at West Elementary School and had an overall GPA of 3.25 at the time he volunteered for this study.

Planning. Nathan taught 31 fifth grade students (15 males and 16 females) for his first lesson. He took only 2 minutes and 40 seconds to plan for this lesson and failed to identify clear objectives or goals for students to achieve during this lesson, which lasted a total of 38 minutes 53 seconds.

Nathan planned to teach grips combined with forehand and backhand passing in one task. He did not mention anything specific about how he planned to teach these skills to students. His intentions were to teach the combined skills when the students were divided into pairs. Nathan said, "I would like to extend this skill by increasing the passing distance in order to raise the level of difficulty for this task, while they continue to work on passing with their partners.” Also he wanted to end the lesson with a game that required quick forehand and backhand passing.

In order for students in the large class to be fully involved his game, Nathan had to divide the class into six or seven groups of five. The game consisted of zigzag passing in order to practice speed and controlling the puck. One person cycled down the line passing the puck to the person in front them, then moved left to the next person.

Lesson Structure. This lesson lasted 38 minutes, 53 seconds and began with a short period of warm-up activities, which was mentioned during planning. Nathan gave no specific 
objectives of this lesson during his introduction; he did explain how to grip the stick and gave a few demonstrations of forehand and backhand passing along with how to receive the puck. He used approximately half of the facility for practicing forehand and backhand passing with students lined up in two straight lines down the middle of the gymnasium. However, the game used the entire space available in the gymnasium. This game was a team competition that required students to make good passes as quickly as possible because speed was a factor. There were 6 groups of 5 students with one group of 6 where each member of a group had to complete a pass to everyone else in the group, then they had to sit down and wait until other teams finished, when the instructor would announce the winning team. For each game, six separate groups were competing all at the same time and the game was played a total of six different times. Nathan did not check for understanding or allow any time for a closure or review with the students. He dismissed the class after asking them to put the equipment back in the basket. The detailed structure of the lesson with the large class went as follows:

Duration

Warming up

Introduction

Grouping
Content

1'13"

Running laps and sitting in the home base

1'47”

- Provided verbal instruction on gripping and passing and rece iving through teacher demonstration. He mentioned that lefthanded people had to hold the middle of the stick (about $10 \mathrm{t}$ o 12 inches down from the top of the stick -1 foot long) wit $\mathrm{h}$ their left hand and right handed people had to hold the mid dle of the stick with their right hand.

- Cues for Forehand pass - step forward and sweep

- Cues for Backhand pass - step forward and pull, but do not change the grip, hold the stick as the forehand grip

\footnotetext{
2’33”

- Students picked up the sticks and found a partner.

- Students stood in two lines facing each other.
} 
Checking grips and

handing out the

pucks

Task activity \#1
forehand

Transition

Task activity \#2

Backhand

Transition

Check for Understa nding

Grouping for

Game application

Verbal instruction

Handing out pucks

and

regrouping

Practice for the game
1'07”

- The teacher checked each students grip then handed out one puck

to each pair.

$\underline{\text { 4'58" }}$

- Students lined up in two lines and practiced forehand as a pair.

- After 2'22” - extended distance forehand passing attem pted

- Teacher moved around and provided feedback - "step and push," "pass a little bit lighter to your partner," “pass straight to your partner," and "remember, push it.”

$37^{\prime \prime}$

To practice the backhand pass and reception, students returned to the line in which they started

$\frac{5^{\prime} 25^{\prime \prime}}{\bullet}$

- Students lined up in two lines and practiced backhand as a pair.

- After 3'24” - extended distance backhand passing attempted

- Teacher moved around and provided feedback - "don't change your grip," "step forward front foot and pull," "step and pull,” and "never changed grip.”

$\underline{42 ”}$

- Students put stick down on the floor and returned their pucks to the basket

$\underline{48 ”}$

- Teacher asked questions about forehand and backhand pass and receive

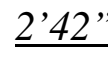

- Students separated with their particular colored stick and moved to the same colored poly spots that had already been set up for this game - 5 groups of 5 students and 1 group of 6 students.

- The 6 groups were spaced out throughout the entire gymnasium.

\section{1’28"}

- Teacher provided verbal instruction about the game with a group demonstration how to implement the game

3’09"

Teacher handed out a puck to a each group and correcte $\mathrm{d}$ their positions as well as explained how to play the game to each group

$\underline{1 ’ 49 ”}$

- Students practice for the game as a group 


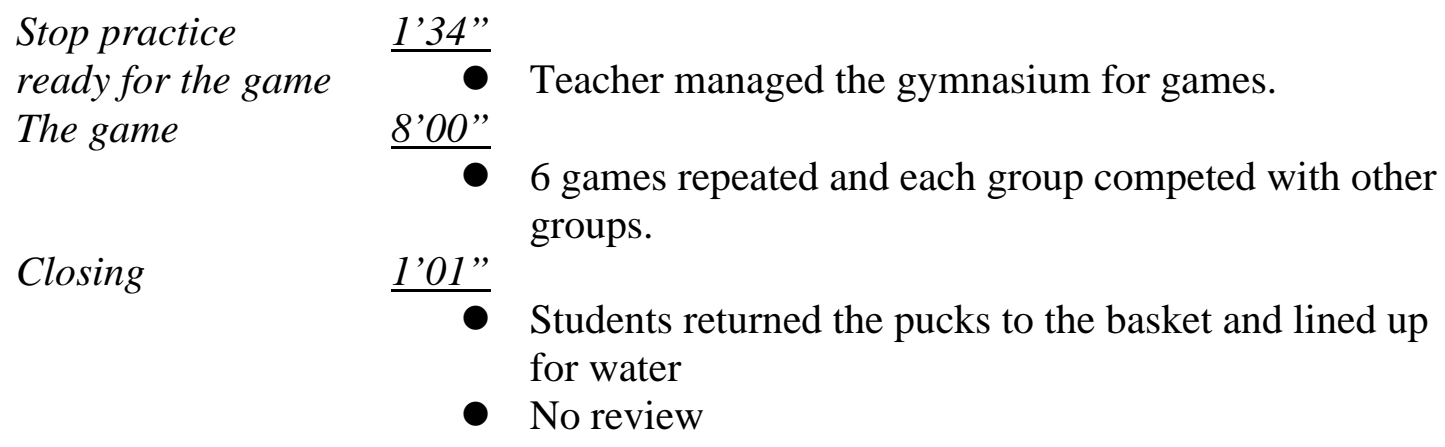

Stimulated-Recall. The time recorded for stimulated-recall was 6 minutes, 55 seconds. Nathan noticed right away, "I explained forehand and backhand grips, but I didn’t demonstrate that to the students and my introduction could've been done more smoothly considering the large class size. But, I'm still working on that and I hope it'll be better next time."

Nathan felt lining students up in pairs was the easiest way to observe all of his students. He notes that, "It seems more organized than if they were all spread around the entire gymnasium.” He felt that he gave good feedback, but most of it was corrective feedback rather than positive feedback and encouragement. He gave very little individual feedback, mostly because he spent a lot of time dealing with a student who was misbehaving. He mentioned that "I went around and tried to provide feedback if I saw that they needed it. When I saw people who needed help, I tried to correct them, but I am sure I didn’t get to each individual student, there was not enough time to do that.” For the most part he felt like students performed well, and they spent the majority of the time on-task like he expected. Nathan indicated that he was not used to managing this class and he was still trying to work on that, "I am still getting used to it. It takes me some time to get it worked out with these kids.”

Nathan felt like he used the learning space safely and appropriately. But he was concerned about safety issues with the hockey sticks. He said, “I didn’t mention that, but after this [stimulated-recall] session, I realized I need to explain the safety issue of using hockey 
sticks.” He felt that students were very physically active, and he was not stressed out about instructing the larger class size. He indicated that "they [ $5^{\text {th }}$ grade students] are old enough to listen, so there was no trouble with students doing what I said.”

Nathan had no review time with the students and he said, “I didn’t go through the review because I ended up taking more time than expected, to set up and organize students." He felt that the lesson proceeded as he planned in terms of tasks, space and student practice.

Nathan Smith (LET 2) - Lesson \#2: Small Class size ( $\mathrm{n}=15)$

Planning. Nathan taught his second lesson to 15 fifth grade students, there were 8 males and 7 females in this class. He took approximately 2 minutes, 45 seconds to plan for this lesson which lasted a total of 30 minutes and 58 seconds.

Nathan said, "The plan for the small class size was the same as the large class size, the only difference was going to be more activities with the smaller class." He was confident in his ability to work more individually with students and get through tasks quicker than he did in the larger class. He also felt that keeping an eye on all of the students would be easier for him to do in the smaller class. He described, personalized interactions such as feedback and encouragement that he planned to use to keep students engaged in using proper technique, he also mentioned, "With less people, it’ll be easier for me to observe and keep track of all of them.”

Nathan was not stressed out about this lesson and he was confident that he could cover all the tasks and activities quicker, resulting in more time for game activities, which was his primary goal for his second lesson. Once again, Nathan did not specify any specific student objectives for the lesson with the smaller class. 
Lesson Structure. Nathan's second lesson, which lasted 30 minutes, 58 seconds, began by having the students run a few laps around the gymnasium. This was not discussed during the planning process most likely because it is a standard routine for all physical education classes. At the beginning, he modeled and explained how to grip the stick and he had students demonstrate forehand/backhand passing and receiving. He demonstrated the forehand and backhand grip by himself and then asked a student to be his partner for the demonstration. Nathan and the boy showed the class how to do a forehand pass, a backhand pass and how to receive the puck. Approximately half of the facility was used for practicing forehand and backhand passing. Nathan added an extension to the forehand and backhand practice exercises by increasing the distance between partners. The entire gymnasium was utilized during the game application, as was done in the lesson with the larger class. Students were divided up into 3 groups of 5 people for the application task where they were required to make individual passes each of the other group members as quickly as possible, then they had to sit down and wait until other teams finished then the instructor announced which teams place first second and third. This game was repeated a total of eight times. Nathan added an extension to the game by asking partners to make two passes with each group member during the last three games. This was an activity he added for the lesson with the smaller class. Nathan had enough time to check for understanding by asking questions about forehand/backhand, passing/receiving concepts during the lesson closure which was not mentioned during planning. A description about how this lesson was executed is presented below.
Duration
Warming up
Content
Introduction

$$
\text { 36" }
$$$$
\frac{3,34 "}{-}
$$
Running laps and sitting in the home base
- Provided verbal instruction on how to grip the stick an d passing 


\section{Grouping \\ Checking their grips and handing out the pucks}

Task activity \#1

- forehand

Transition

Task activity \#2 and receiving: teacher and student demonstrations.

- Grip - left handed person has to hold the middle of the stick with left hand. Right handed person has to hold the middle of the stick with right hand. He said, "Put your stick half way down and the other hand is facing toward your body.” Stick has to be kept on the ground all the time, it should never come above your waist safety issue.

- Forehand - step forward and sweep and do not slap at it.

- Backhand - step forward and sweep but not to change grip, hold the stick as the forehand grip. Step toward where you want to hit and do not push it too hard. The tasks for the forehand and backhand passes required $t$ hat the students attempt 10 with a partner and then bac $\mathrm{k}$ up toward a line (extension through distance). Once completed with the forehand, return to the first positio $\mathrm{n}$ and try backhand pass with a partner, same as foreha nd.

- Provided verbal instruction on class organization

- Students practiced as a pair on two lines (10 feet apart) on the gymnasium floor. They stood on the lines faci ng each other.

- Extension - after 10 passing and receiving attempts wi th their partner, they should move back to the other lin e.

1'18"

- Students picked up the sticks and found a partner.

- Students stood in two lines facing each other.

47”

- Teacher checked the grip of each individual and handed out a puck to each pair.

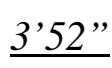

Students lined up on two lines and practiced forehand as a pair.

- After 2'13"- extended distance forehand attempted

- Teacher moved around and provided feedback - "step toward where you want to go," step with the lead foot, " "you do not have to slap at it," "do not interfere with anybody else," "just like sweeping a floor," and "make sure you are stepping."

$\underline{26 ”}$

To practice backhand pass and receiving, students returned to the line where they started 
- backhand

Transition
Grouping for a game
application

Verbal instruction

Practice for the game

Stop practice and ready for the game The game

Closing
- Students lined up on two lines and practiced backhand as a pair.

- After 3'03"- extended distance backhand attempted

- Teacher moved around and provided feedback - "step and pull," "step torward where you want to go," "remember, just pull it," and "you got to have control to make a good pass."

\section{2”}

- Students put stick down on the floor and returned their pucks to a basket

$\underline{49 "}$

- Students separated with their particular colored stick and moved to the same colored poly spots that had already been set up for this game -3 groups of 5 students.

- The 3 groups were located throughout the gymnasium. $\underline{1 ’ 03 "}$

- Teacher provided verbal instruction about the game with a group demonstration on how to implement the game.

- Handed out a puck to each group.

2'48"

- Students practice for the game as a group

\section{$\underline{51 ”}$}

7'26"

The first five games required five people as a group to participate in the drill one time through, and the last thee games required five people as a group to participate in the drill two times through. Thus, the team that was faster than all the others was named the winner of the game.

1'13' Students sat on the floor.

- Teacher reviewed cues for forehand and backhand passing and receiving through asking questions.

Stimulated-Recall. The time recorded for this stimulated-recall session was 5 minutes, 30 seconds. Nathan provided verbal instruction with a demonstration to the smaller class. He also included student demonstrations to verify that they understood what to do, and how to do it. Nathan said, "As a matter of fact, I forgot to do a demonstration in the larger class, but I 
remembered to do it with the smaller one." He responded that, "Everyone seemed to be paying attention and students asked questions about the task, so I'm pretty sure they were on-task.”

Nathan said, "I gave much more feedback to the students this time than I did in the larger class because it was so much easier with fewer students. I could actually look at every student to see what they were working on and give both positive and corrective feedback to them individually!” He felt that he had an opportunity to look at each student at least two or three times while they were working in their activities.

Nathan said, “Everyone was on task, I can’t even think of anybody who was off task.” He did not have to worry about people not understanding instructions or tasks and there was plenty of space for the activities to be performed safely. He said, "Everyone was spread out far enough so they couldn't bother each other.” Nathan also mentioned that students received much more activity time since everything went smoothly, resulting in more time for a game and a review at the end of the lesson.

Nathan did not take much time to review, but he said, "From what I observed, I felt that the students obtained the skills that were taught throughout the lesson, that's why I didn't spend too much time reviewing." Nathan planned an extra game because he felt that the students would complete all of the tasks faster than the larger class he said, "Even though we had more time, I completed the same number of tasks that I did with the larger class, so students actually went through two or three more times during the game.” He mentioned that the students had more opportunities to practice, so they came away with a higher level of skill, because of the additional practice. This was anecdotal evidence because he did not really collect any success rates or passing completion percentages with either class. 
Interview Data: Class Size Comparison. The recorded time for this interview which compared the differences between teaching both class sizes, was 4 minutes 35 seconds. Nathan felt like he did not get to see all of the students in the larger class and indicated that the learning environment he used was the same for both classes but "as far as keeping them under control, I felt like I yelled a lot more with the larger class.” He mentioned that, "the lesson with the larger class seemed in control, just a lot more chaotic.” He said, “Another problem with that class was that you saw a lot more off task student behavior because they were waiting for their turn and for further instructions.”

On the contrary, Nathan said, "The lesson with the smaller class was less stressful because I didn’t have to raise my voice. I was using a normal tone the entire time. They listened to me and they did very well." He felt like he provided a lot of feedback when teaching the smaller class because he said, "I was able to see every student and help each student individually.” He also said:

The instruction with the smaller number of students was a better situation and an easier lesson because overall I was comfortable with everything and I can tell they progressed and that they were able to get a lot more practice with the tasks than with the large number of the students . . . and I could see all the students all the time.

Nathan insisted that the small class size had more advantages than the larger one. He felt like students in the small class got more practice and game time because they were able to pick up the tasks quickly and complete the tasks quickly. He said, "We definitely had a lot more practice time with the smaller class, and I think that was practice with a higher quality of skills.” Erick Sam (HET1) - Lesson \#1: Large Class Size $(\mathrm{n}=30)$

Erick Sam was an experienced elementary, physical education teacher working at a school located in a mid-Atlantic state. He earned a master's degree in PETE and has worked as a 
physical education teacher/basketball coach for the past 34 years. He was Nancy Young's (LET 1) cooperating teacher at the time of this study.

Planning. For his first lesson Erick taught 30 fifth grade students comprised of 19 males and 11 females. He took 10 minutes and 20 seconds to plan for this 30 minute, 23 second lesson. Erick was going to have three different stations with activities. He selected, goal shooting with a goalie for his first station where, two different kinds of shots would be explained and then executed - push shot and slap shot - using both dominant and non-dominant hands. The second station consisted of dribbling, serpentine style through cones that were set-up in a row. He emphasized moving through a progression of various speeds - walking, jogging, and running. Erick said, "The important concept is controlling the stick, keeping the ball out in front of the student all the time.” The third station emphasized passing and trapping. Trapping required stopping the ball just in front of them, after the ball was passed their way. Erick felt that students were going to try and hit a ball that was moving towards them instead of working on trapping it and then passing it to someone else. Therefore, he used this station to introduce, three different ways of stopping the ball: Using their sticks, feet, or hands to put it back down on the floor, then making a good pass or shot after striking it, instead of swinging at it as it was coming towards them.

Erick planned to use a portable stereo in his lesson to play music which would replace using the whistle. He wanted to play music during the activity time, and then stop the music at the end of the session in order to signal to them to rotate to the next station.

Erick planned to move around the gymnasium and correct their form and give them feedback during activity time. He wanted to encourage students and provide lots of positive 
reinforcement to students to try and motivate them to correct their form and look for those who were struggling to perform techniques the correct way.

If time permitted after the station-based activity, Erick planned a game to provide students with an opportunity to apply skills that they had just practiced. He said:

The object of the game is to try to control the ball as they were dribbling around the gymnasium and, at the same time, the students were going to try to tap other people's balls outside of the line. If the balls got tapped out, the students were going to have to go out of the game and do five jumping jacks or push ups, and retrieve the ball and come back to the game.

Another possible game was passing and then shooting to a target. Erick said the rules of the game were:

One person has to pass to another partner. The other partner spread [his or her] legs apart, and that was the target. Two passes were used, the push pass and the slap pass. The objective of the game was to try to hit the ball between their partner's feet and/or hit their feet. If they hit the partner's feet, they were awarded one point if they put the ball between the legs, they get two points. The object of this game was to be the first person to get the seven points.

Erick hoped to accomplish both skill practice and games during this lesson. However, he had two major concerns, time and space. He mentioned that "there were a lot more students in a small area. The large class size is a challenge because it will be congested.” He also said "everyone should get a series of turns but because of the space, however, they may not get as many repetitions as they are supposed to get because of the large number of students that have to go. Hopefully, waiting time will be minimal and I'll try to get as many students involved in the activities as possible.”

Lesson Structure. The lesson for the large class lasted 30 minutes, 23 seconds. Mr. Sam took a minute and a half at the beginning before warm-up activities to explain the three stations that were going to be implemented in this lesson. He added warm-up activities that were not in his original lesson he planned. In the three stations during the main instruction period of the lesson, he included passing and receiving, dribbling, and goal shooting. This was instructed 
primarily through student demonstrations at each station. For the first station, a boy and a girl practice taking shots with a one person playing goalie. For this goal shooting station, there were four sets of goal posts. Therefore, 10 students were divided into groups of 2 or 3 . And, for the groups of three, when two were working as a goalie and shooter, one was waiting for her/his turn. The second demonstration was two other girls, which dribbled through cones and then passed it back to the other partner. For dribbling practice, students weaved in and out of the cones while the other students waited their turn. The third station used two other boys to demonstrate three different ways to stop (trapping) before passing it back to their partner. For passing and receiving, two students worked together as a team. A total of 5 teams were established by lining up and practicing passing and receiving. The rest of the students watched the demonstrations while sitting against the wall of the gymnasium. During the main lesson, Erick used courtesy words to address students like: “sir,” "ma’am,” and “thank you very much,” as well as using the names of the students. The entire gymnasium was utilized for the lesson. All the students were involved in the activities, and the teacher walked around the entire gymnasium in order to interact with and provide feedback to the students. All of the students had at least one turn in each station so that they all had a chance to practice all three stations. As the students were involved in the three stations, the feedback provided was "remember, walking first," "keep the ball in front of you," "stop before you hit it," "only hit your ball,” "push shot first and slap shot later," "put it on the spot and hit it from the spots," "do not hit a moving ball, trap it first," “you can use your foot to stop the ball,” "keep your hands wide,” and "keep your stick below your waist.” He could not implement any games that he planned. Also, Erick had enough time to review for approximately 1 minute, 42 seconds, which was not planned during the think-aloud process. The detailed structure of the lesson with the large class went as follows: 

Duration
Content
Pre Introduction
$\underline{1 ' 48 \text { " }}$
Warming up
Introduction
Brief explanation of the three stations for the lesson Grouping 56” Grouping 56”
- Verbal instruction was provided using student demonstrations in each station.
- $1^{\text {st }}$ station: Dribbling with three speeds - walk, jog, and run. The task was to weave in and out of the cones that had been set up prior to the lesson. There were three rows that three pairs could do at the same time. Once they completed dribbling while walking, they had to dribble while jogging and running.
- $2^{\text {nd }}$ station: Passing and trapping - push shot and slap shot. He said, "Thumbs go down to the stick, pretend you are sweeping the floor." He also said, "You stop your own ball, do not worry about other balls, just let it go and do not hit a moving ball."
- $3^{\text {rd }}$ station: Goal shooting - a pair, shooter and goalie. There were two poly spots. The students had to hit two shots at each spot, push shot first and slap shot later. After they had done 4 shots, they would trade places - goalie and shooter.
- Three groups were decided by the teacher, 10 people in each station.

Task activity \#1 $\quad \underline{4} 36$ "
Rotation $\quad \underline{56 "}$

Task activity \#2 $\quad$ 5'54"

All the students in each station executed the skill practice to which they were assigned.

Rotation

$\underline{1} 01$ ”

Students put the equipment down and stood by the cones

- All the students in each station executed the skill practice to which they were assigned.

- Students put the equipment down and stood by the cones.

- Teacher checked student understanding through questions (for instance, What are the three speeds on dribbling?, What are the ways to stop the ball?, and What are the two shots?)

Task activity \#3 5’14"

All the students in each station executed the skill practice to which they were assigned. 


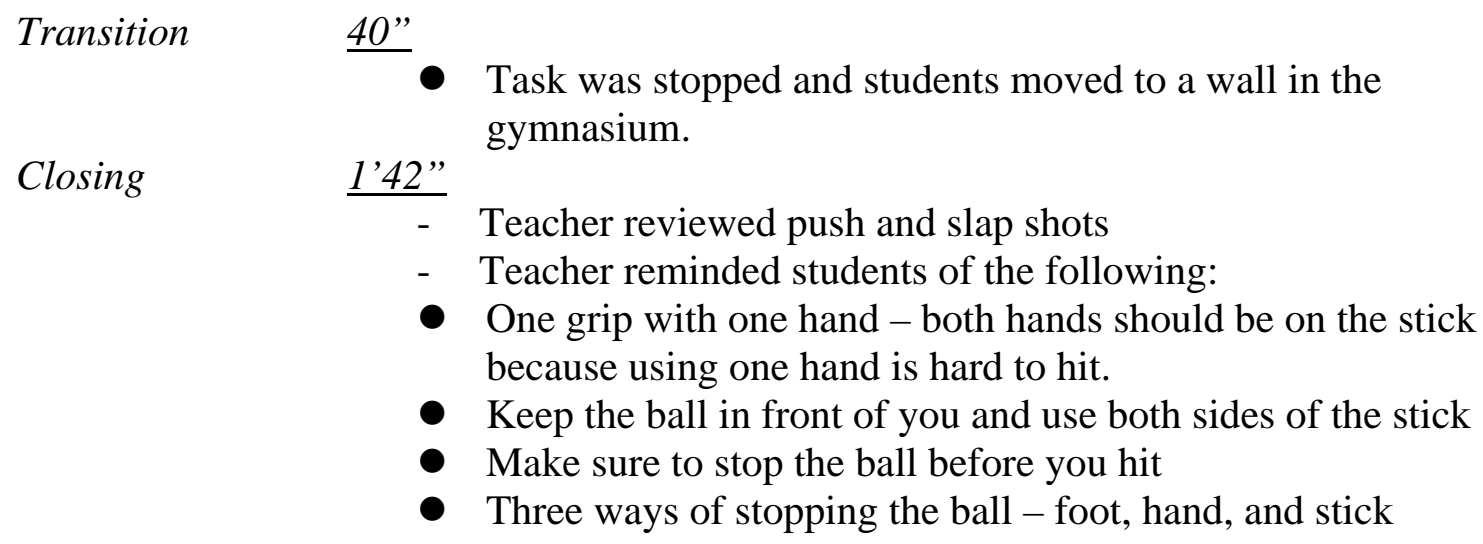

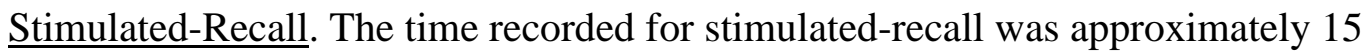
minutes, 45 seconds. Erick had a unique introduction format with the larger class, which started with a brief introduction on the topic, and then a warm-up, and lastly a detailed introduction on the topic. Regarding the format of introduction, Erick indicated that students were curious about what was going to happen when they came in and saw the equipment set-up. He mentioned the reason why he used this unique format was: "I tried to give them a quick review of what was going to happen and do a warm up and the main verbal introduction because I wanted them to be eagerness to learn and play.”

Erick realized that the introduction with the large group proceeded smoothly in terms of teacher demonstration, the students were responding to verbal introduction. He felt that he explained the tasks thoroughly and the majority of the students did pay attention and there were no interruptions during the verbal introduction. However, he admitted one problem with the large class size was that, while he felt everyone was paying attention, he could not be totally certain they understood what he was saying.

He successfully integrated music during the middle of the lesson because he forgot to use it at the beginning. In fact, a student asked Erick, “Why didn’t you turn the music on?” and he responded, “I forgot. I'll turn it on for you." Erick added later, "I use music most of time, when I 
teach and students like to hear the music while they're working on the skills.” He used music as the signal for starting and stopping stations, and to help motivate students to keep moving; depending on the beat, some students really get into it. He mentioned that "students are playing the tasks and at the same time, they are singing. It helps if they are having a good time while they are doing this stuff, and music is very useful for that and students like it.”

In general, Erick did not provide any feedback on high sticking, which could be a risky violation in floor hockey. He responded to a question regarding high sticking, saying "I did not want to say negative things, rather I tried to provide positive words, but I agree I should have notified the students about the high sticking for the safety reason.”

While Erick observed he approached a student who was sitting outside of the learning environment and brought him into the gymnasium. He responded to a question regarding this student:

That kid does not like physical education and he is intimidated by bigger kids. As a teacher, I believe we should encourage and motivate all students to try to get them in the learning place the best we can. Especially, the kid needs motivation. He is not the most skillful student but he is capable of doing everything we covered in class.

Erick felt that he tried to provide feedback, encouragement and motivation to the students while he walked from station to station. He walked around the entire gymnasium to prevent students from getting off task and misbehaving. He felt that students cooperated and listened well to his instructions. He had no problem with the using facility and equipment appropriately. Erick said, "The teaching was not as stressful as other lessons. I always enjoy what I do. If you really enjoy what you are doing, it makes it a lot more fun.”

Erick could not implement the game he had planned due to the lack of time. He responded by saying, "it would have been a nice challenge for the students to apply the skills they just learned with a game, but we really didn’t have enough time to do that.” 
Erick tried to review all three stations, ways to hit, stop, dribble, and shoot goals. He did all the tasks he had planned except for the game. He felt like students did not have as many repetitions as he would've liked, but overall all the skill development and success was pretty good as stated by the teacher.

Erick Sam (HET1) - Lesson \#2: Small Class Size (n=16)

Planning. For his second lesson, Erick Sam taught 16 fifth grade students, 5 males and 11 females. He took approximately 3 minutes, 15 seconds to plan this 33 minute and 31 second lesson.

Erick planned to do a cohort activity with the smaller class rather than using the stationbased approach that he used with the larger class. He was going to start out with dribbling around the gymnasium with three speeds: walking, jogging, and running, using the entire gymnasium. He also wanted to include a game application task, which was called: dribble-tag. This was not included in the larger class due to time constraints. In describing the rules of the game, he said, "You attempt to dribble along the lines, if you lose control of your ball, you have to retrieve the ball and then do five jumping jacks to come back into the game.”

Once dribbling was completed, Erick planned a partner passing and trapping drill. He said, "A student gets with a partner and then takes 5-7 steps apart from each other for this task." He also planned shooting practice with two different shots: the push and slap shot. He was also going to emphasize three different ways of stopping balls, including foot, hand, and stick.

In addition, Erick planned a modified game called shooting game with a partner. He described the rules of the shooting game as follows:

Hit the ball between the partners' two feet using either a push or slap shot. The way the point value works is that if you get it between the partner's legs, you get two points, from a short distance first. If you hit your partner's foot, you get one point. If you get seven points, you win the game. 
Erick also planned to have the distance gradually increase during the game by having students take two steps backward at certain times. The goal for this small class lesson was to add a couple of games for students to apply skills they just learned and practiced during the first part of the lesson. He did not explain the main objective for dribble tag during planning however, the objective of the shooting game was to practice and improve on shooting accuracy.

Lesson Structure. The lesson for the small class lasted 33 minutes, 31 seconds and it started with warm-up activities, which were also not mentioned during the planning process. During the introduction, Mr. Sam explained the importance of using the stick safely. He described three tasks for this lesson including: grip/dribbling, passing/trapping, and shooting primarily through teacher demonstrations. To allow students ample space to practice skills he used the entire gymnasium for the activities: dribbling, zigzag dribbling, and diagonal dribbling. The second task was dribble tag, which utilized the entire gymnasium as well. The students tried to knock the other's wiffle ball out of the boundary, which were the basketball court lines. Students who lost their wiffle ball out of bounds had to perform five jumping jacks as a penalty prior returning. The third task was a shooting practice, including slap shot and push shot. All students practiced shooting techniques in pairs so that there were 8 pairs of students working on shooting. Following the practice, a shooting contest ensued where one partner spread their legs and the other partner tried to score a goal between the legs. If they scored a goal between the legs, they received two points, and if they hit a foot, they earned one point. Their goal was to earn a total of seven points throughout this game. Erick used a cohort teaching style and included games in the small class lesson. As students practiced, he provided lots of feedback for students, such as: 
dribble the ball; just walk in the beginning; keep the ball in front of you; use both hands; keep your thumb on the tape; that's the way to go; keep it going; keep it out in front of you; keep moving around the whole gymnasium; and keep that ball under control

Lastly, he held a lesson closure/review where students were asked to summarize the activities that were taught and practiced. The closing was not planned during the earlier thinkaloud process. The detailed structure of the lesson with the large number of the students is as follows:

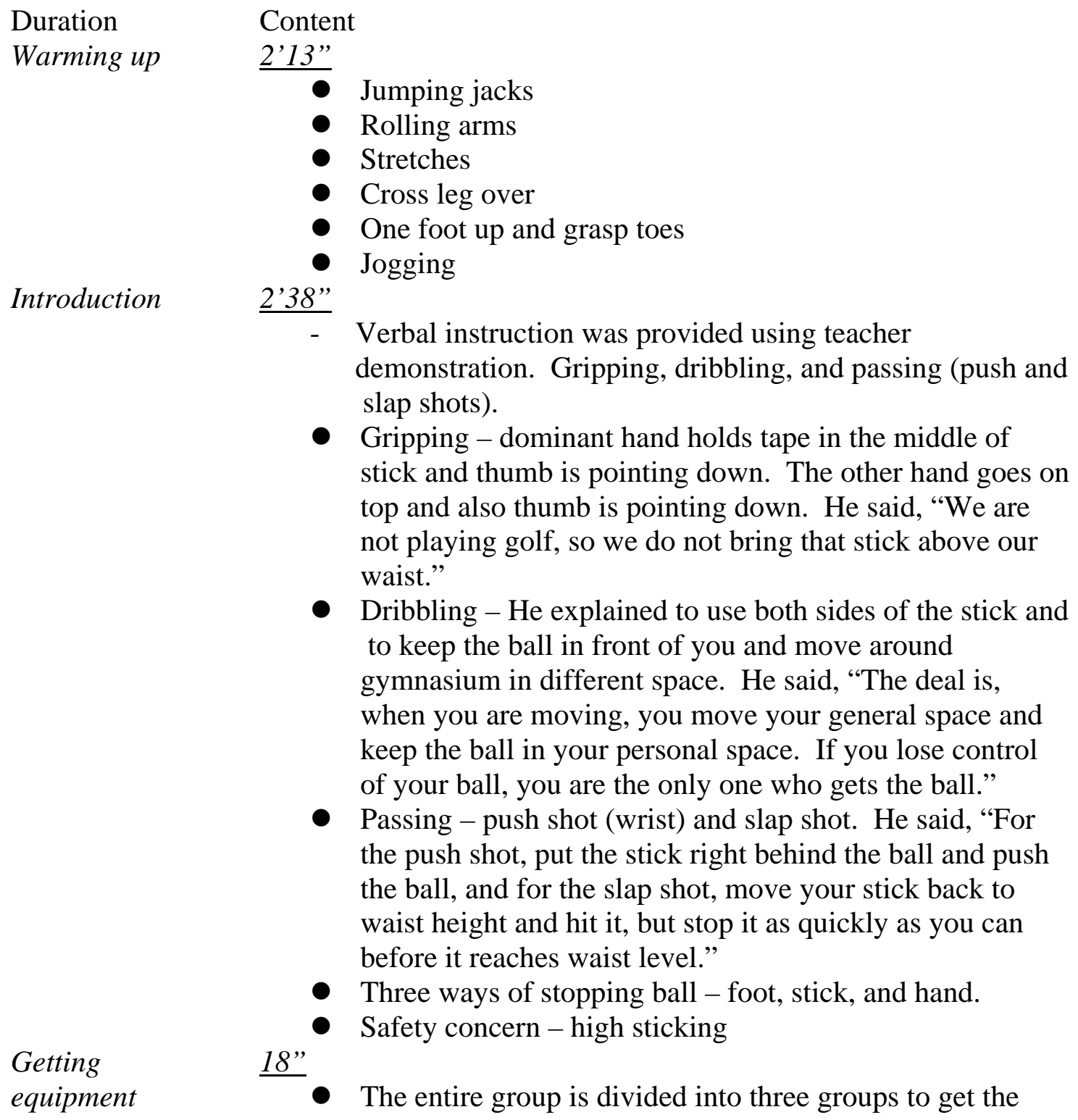

- Gripping - dominant hand holds tape in the middle of stick and thumb is pointing down. The other hand goes on top and also thumb is pointing down. He said, "We are not playing golf, so we do not bring that stick above our waist."

- Dribbling - He explained to use both sides of the stick and to keep the ball in front of you and move around gymnasium in different space. He said, "The deal is, when you are moving, you move your general space and keep the ball in your personal space. If you lose control of your ball, you are the only one who gets the ball."

- Passing - push shot (wrist) and slap shot. He said, "For the push shot, put the stick right behind the ball and push the ball, and for the slap shot, move your stick back to waist height and hit it, but stop it as quickly as you can before it reaches waist level.”

- Three ways of stopping ball - foot, stick, and hand.

Getting

equipment

18”

- Safety concern - high sticking

Task activity\#1 6’59” 


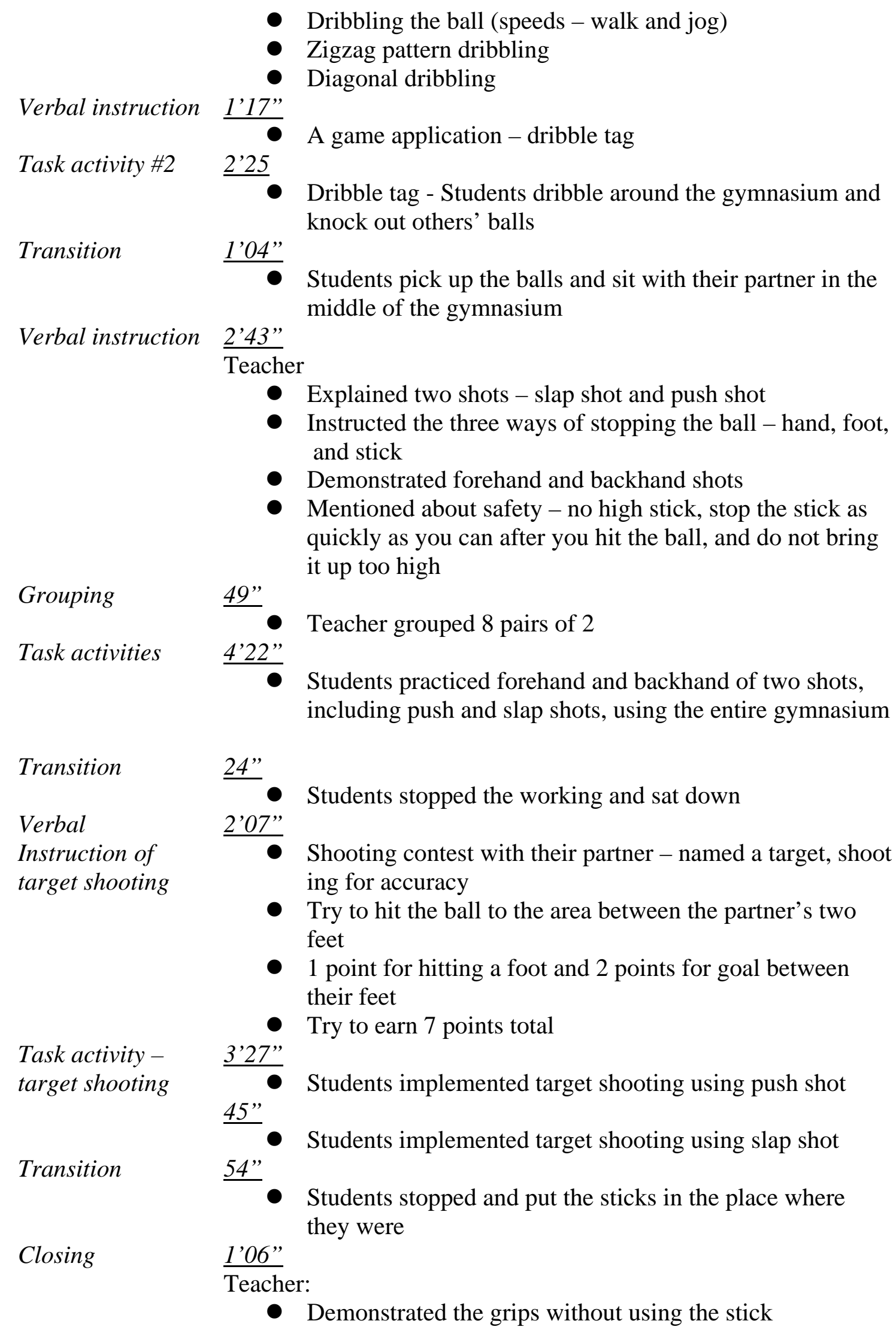


- Reviewed shooting with the push and slap shots

- Indicated the importance of accurate shooting

- Explained 3 different ways to stop the ball

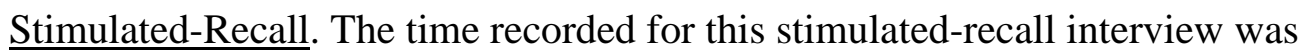
approximately 9 minutes, 10 seconds. Erick said, "In the small class it helps when you can explain things and get them into activity quickly.” He felt that everyone understood and they were getting on task quickly. He mentioned, “You’re going to have a few students who don’t pay attention while you provide instruction. But the way I tried to handle that was to call their names and immediately ask them questions about what I just said.” However, he thought that most students listened fairly well during the introduction.

Erick stated: My strongest point was providing feedback. Personally, I tried hard to provide feedback in my classes. I circulated today and walked around and corrected and encouraged them. Being negative is not the best thing to do; we should encourage them to be active, and continuing to encourage them makes the students happy about themselves.

Erick felt that he also provided a lot of individual feedback saying, "It helps when I can give everybody a little bit of attention as class goes on.” There was one instance of misbehavior during a transition time between activities he said, "Generally, the class was very good.”

Erick believed there was plenty of space because of fewer students and there was no problem with the facility. Erick stated that, "Safety was good and the teaching environment was just fine.” He also noticed an increase in physical activity and their skills seemed to be improving compared to the larger class, as a result this lesson was not very stressful.

Erick reviewed grips, passing, two shooting techniques forehand and backhand (push and slap shots), as well as the ways of stopping the ball. He also said, "I just covered it all like I planned because this was a smaller class. The smaller amount of students helped the lesson go 
more or less like planned he said, "I felt like we reached an acceptable rate of success throughout all of the activities: dribbling, passing, shooting, and the games.”

Interview Data: Class Size Comparison. This interview lasted 6 minutes, 55 seconds and was used to compare and contrast teaching both class sizes. Erick felt that the best way to teach the larger class was using a station-based teaching strategy, focusing on dribbling, passing, trapping, and goal shooting. He said, “The lesson with the large number of students created extra difficulties because there were about 10 kids at each station, and they could've been more active but the station was the only efficient way to cover those skills.” Furthermore, Erick felt students in the larger class could not get as many practice repetitions as he had hoped. He also had to leave one station in order to watch students at another station.

He felt that students in the small class were much more efficient at performing skills than the students who were in the larger class. The teaching ran at smoother and quicker pace, and more effective demonstrations were provided. He mentioned, "I walked around and everyone had many more chances to contact the ball.” In general, he was able to focus on each student skill level with greater accuracy in terms of providing feedback. In addition, he thought he could make transitions much quicker and provide verbal instructions more clearly, then move them into the activities quicker.

\section{Erin Hong (HET2) - Lesson \#1: Large Class Size $(\mathrm{n}=30)$}

Erin Hong was the second experienced teacher in this study. She received a bachelor's degree in PETE and has approximately 26 years of experience as a physical education teacher. She teaches physical education at an elementary school located in the mid-Atlantic region of the United States. She was also the cooperating teacher for Nathan Smith (LET 2). 
Planning. For her first lesson, Erin Hong taught 30 fifth grade students there were 12 males and 18 females in the class. She took approximately 8 minutes, 30 seconds to plan for this 38 minute, 40 second lesson.

Erin was confident in her teaching ability because she feels that is organized and well prepared, “I’m an organized person, and I’ve developed lesson plans for teaching, I’ve even typed a lesson plan for tomorrow. However, I wrote down a few more things, such as class management and safety concerns, for the larger class.” Safety was a priority for her teaching from the beginning since students were using hockey sticks and pucks. She said, "I'd like to incorporate safety issues more in my lesson plan, I think I'll have to keep mentioning it more during the lesson.”

Erin planned the following tasks for her first lesson: grips, dribbling, and passing. She wanted to have the flexibility to modify the lesson depending on situations as they developed during her instruction. She even indicated that "it's easy to change [in the middle of teaching]." She also said, "My plan is to cover the basics of hockey, handling the stick, dribbling, and passing. I am not going to go too in-depth. My plan comes from a Sport Play and Active Recreation for Kids (SPARK) background. I like the basic framework of that program but I am not using it totally; so it’s useful for me to develop lesson plans.” Erin has not taught field hockey for a long time because she felt that this was an unsafe sport. Because of her concerns regarding this sport, she was going to have the students stand in lines in the hopes of avoiding someone getting hit. She wanted to go over safety even before the lesson got started. Erin also planned to move in and around the learning environment so she could avert problems before they happen and provide feedback. She mentioned that "once I get them set-up, it becomes easy.” Lastly, she said, “My planning is a plan just like that, but I don’t use it totally, because I 
see things aren't working so well and often I'll change it.” She not only used some materials to plan and implement the activities, but she also relied on her teaching experience as a physical educator.

Lesson Structure. The lesson for the large class lasted approximately 38 minutes, 40 seconds. Erin Hong began with warm-up activities, which were not planned in the planning process. For the first part of her introduction, she previewed the necessary cognitive knowledge (rules and regulations) regarding the sport of hockey. She also emphasized the safety aspect of floor hockey at the beginning of the instruction. She instructed gripping as well as passing and receiving during the instruction of the lesson. Erin also used music while the students were working on the subject matter tasks. During the instruction, she used the students' names and used courtesy words such as “thank you very much.” The entire gymnasium was used in this lesson from the beginning. The lesson focused on gripping, forehand, and backhand passing and receiving. For the dribbling practice, the students were walking around the entire gymnasium. However, for the passing and receiving practice, the students were working as a pair where they lined up, using a total of four lines on the gymnasium floor. Once those activities were completed, a speed game was conducted using pairs, such as one game in which students kept track of how many times they passed and received as a group. After that students began another game that focused on shooting this time. One partner spread her or his legs and the other partner tried to shoot between the legs. This game was not designed to be a competitive activity. Erin did not mention these games during the planning process. She also completed a lesson closure at the conclusion of the class. She basically just reminded the students of the safety aspect, not the lesson activities that had been taught. The closing period was not planned during the think-aloud process prior to the lesson. The detailed structure of this large class lesson went as follows: 


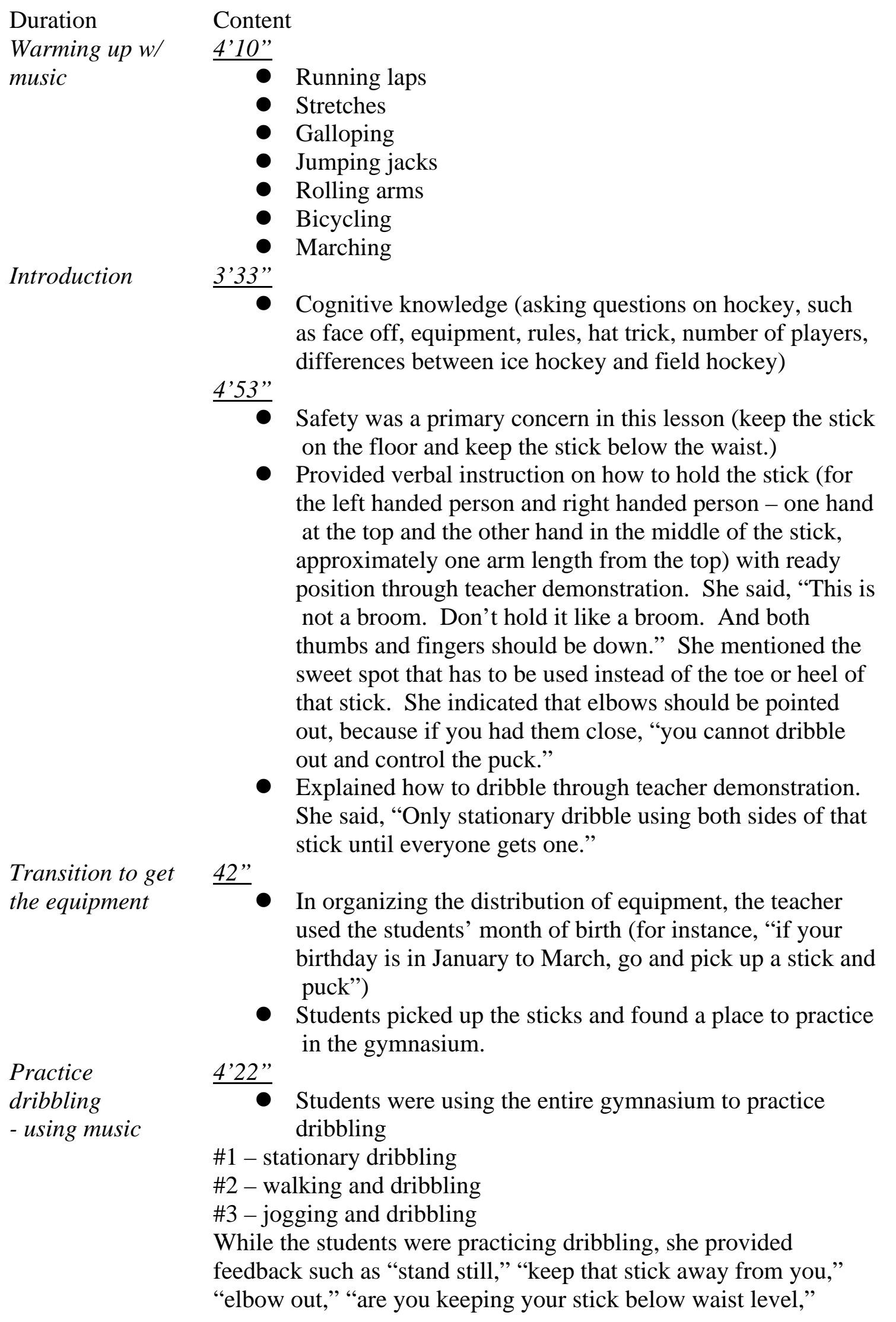




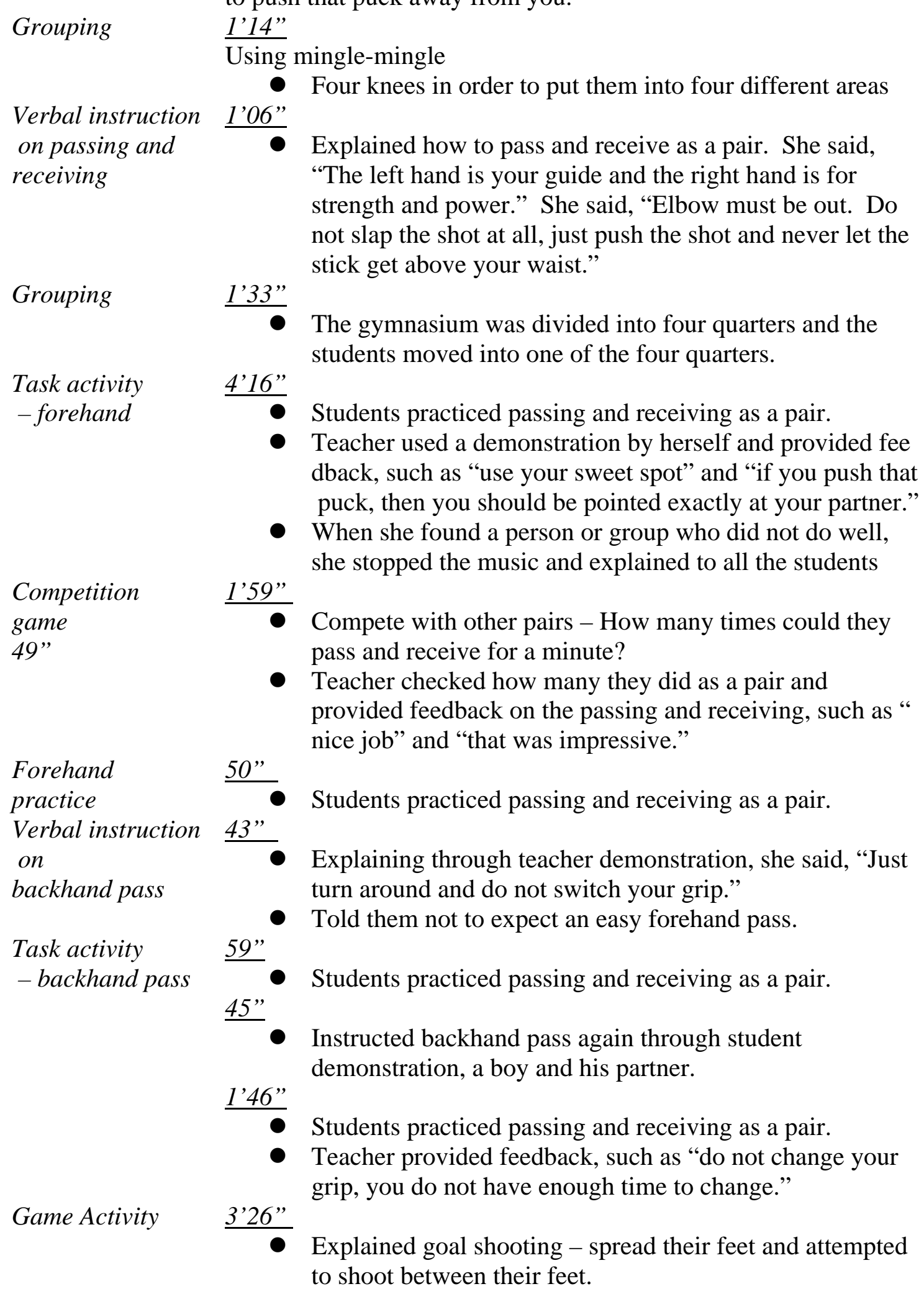

- Teacher checked how many they did as a pair and provided feedback on the passing and receiving, such as “ nice job” and "that was impressive." 
- Students implemented the game of goal shooting with their partner.

Returning the equipment

Closing

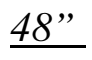

- Students returned the equipment. $\underline{1 ’ 35 \text { ”' }}$

- Teacher told them not to be surprised if their back hurt, be cause it could happen.

- Teacher reminded them of safety, which was the most important aspect.

- No review on the tasks.

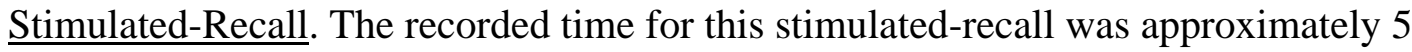
minutes, 15 seconds. The first question for her was "Why did you use music while you were teaching?” Erin responded, “I am using SPARK, which is Sport Play and Active Recreation for Kids, and they use music rather than the whistle. The first time, I was really afraid of using music because that made it harder to hear instructions because the sound actually gets worse in the gymnasium. But, I found out that kids responded very well to the music. Students know when to start and stop or freeze automatically with the music. Erin mentioned that, "Now I am using music because it really works I spent plenty of time during the introduction. Next, I provided a demonstration, but the introduction went too long I ran out of time.” As a matter of fact, she also went through some cognitive information where students previewed the rules and regulations for floor hockey. She did this to raise the students' curiosities and expectations for the hockey. She believed that student attention in the large class was appropriate, and she did not notice any difficulties with the students’ behavior during her instruction.

Erin thought she provided enough feedback, most of it being positive feedback, although she provided some corrective feedback. She said, "I am very good at correcting." She also said, "I tried to provide feedback to each individual as many times as I could, but I could not provide as much as I wanted to because of the large size.” She did not think there were any difficulties 
with the students misbehaving or being off task. In addition, Erin had no problems with managing the class and facility. She believed the facility was safe and all issues were covered and handled well. However, she thought that the equipment needed improvement because the sticks were too short for the fifth graders, but she could not afford to buy more than one set of hockey sticks. She was satisfied with the students’ physical activity level, and she believed that the size of the class was not a cause of stress during her lesson.

Erin took time to review, but that part of the session was short. In fact, she said, "I do not take as much time like some people because I believe keeping them active and moving is much more important, so I did not spend a whole lot of time on the closure.” She taught the lesson as she planned, but she said "I always change my lesson plan depending on the situation and students’ activities.” She used music while she was teaching, which was not indicated in her planning.

Erin Hong (HET2) - Lesson \#2: Small Class ( $\mathrm{n}=16)$

Planning. For the second lesson, Erin Hong taught 16 fifth grade students 11 males and 5 females were in the class. She took approximately 5 minutes, 15 seconds to plan for her 24minute, 21 second lesson.

Erin said, "No matter what size class I have, the lesson plan will be the same as the large class so I am sure to cover the fundamental skills.” The large class size could be more of a challenge in terms of observing students. But she thought will have a better opportunity to observe all of the students in the smaller class. She planned to get around the class so she could pay attention to safety, just as she had done with the large class size, and she felt that it was possible to spread students further apart in the small class. She said, "I'll spread them out a lot thinner, then I do not have to watch nearly as much as I did with the class of 30 students.” 
Erin thought more time was available compared to the large class size because it required less time to get them organized with the small number of students. She planned on adding two more drills, including dribbling by themselves and dodging people, but she was not exactly certain if she could make that happen. She also planned to use music in this lesson, just as she had in the large class size.

Lesson Structure. Due to an activity scheduled at the school the lesson for the smaller class began late and only lasted approximately 24minutes, 21 seconds.

Erin started by discussing cognitive knowledge (rules and regulations) regarding the sport of hockey, which was not planned during her planning process. She spent about half a minute on warm-ups following this discussion. She then emphasized the safety aspect of floor hockey at the beginning of verbal instruction. She instructed gripping as well as passing and receiving during the verbal instruction of the lesson. The teacher used music while the students were working on subject matter tasks she planned. The entire gymnasium was used in this lesson just as it was for the large class size lesson. The students practiced in stationary dribbling tasks and walking while dribbling. They practiced forehand and backhand passing and receiving as a pair, lining up using two lines on the gymnasium floor. At the completion of those practices, a game application was implemented as a speed game. The game was designed for the students as a pair to pass and receive as many as they could for 30 seconds. The speed game was repeated twice for 30 seconds. At the completion of that game, the students were asked to practice backhand passing and receiving as a pair. Due to the time limit of this lesson, a backhand speed game was not implemented. In fact, Erin planned more games and more drills for this small class size, but she was not able to lead those games and drills due to a limited time for the class. She had a time to 
review forehand and backhand at the end, which was not planned in her think-aloud process.

The detailed structure of the large class lesson is as follows:

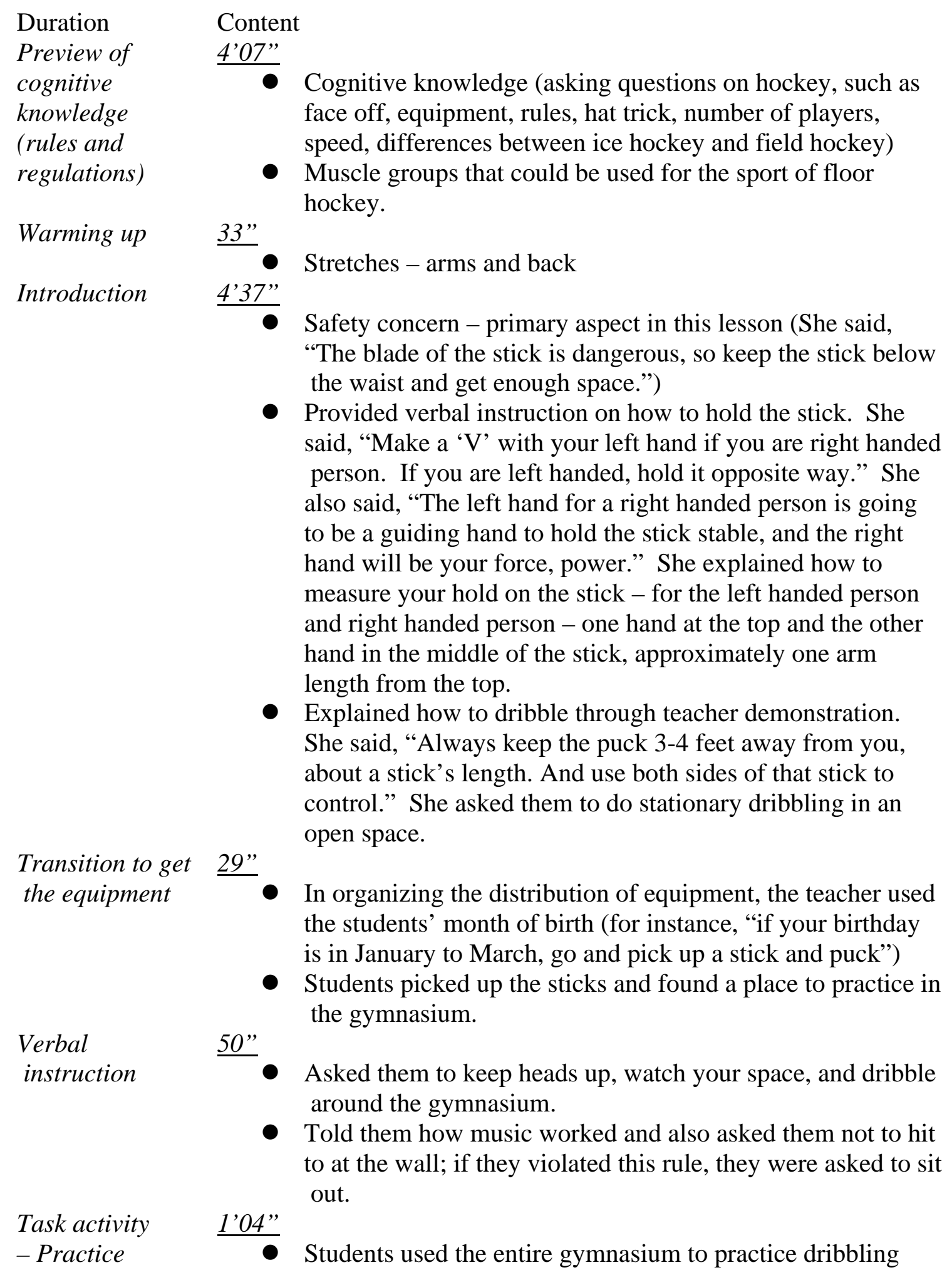




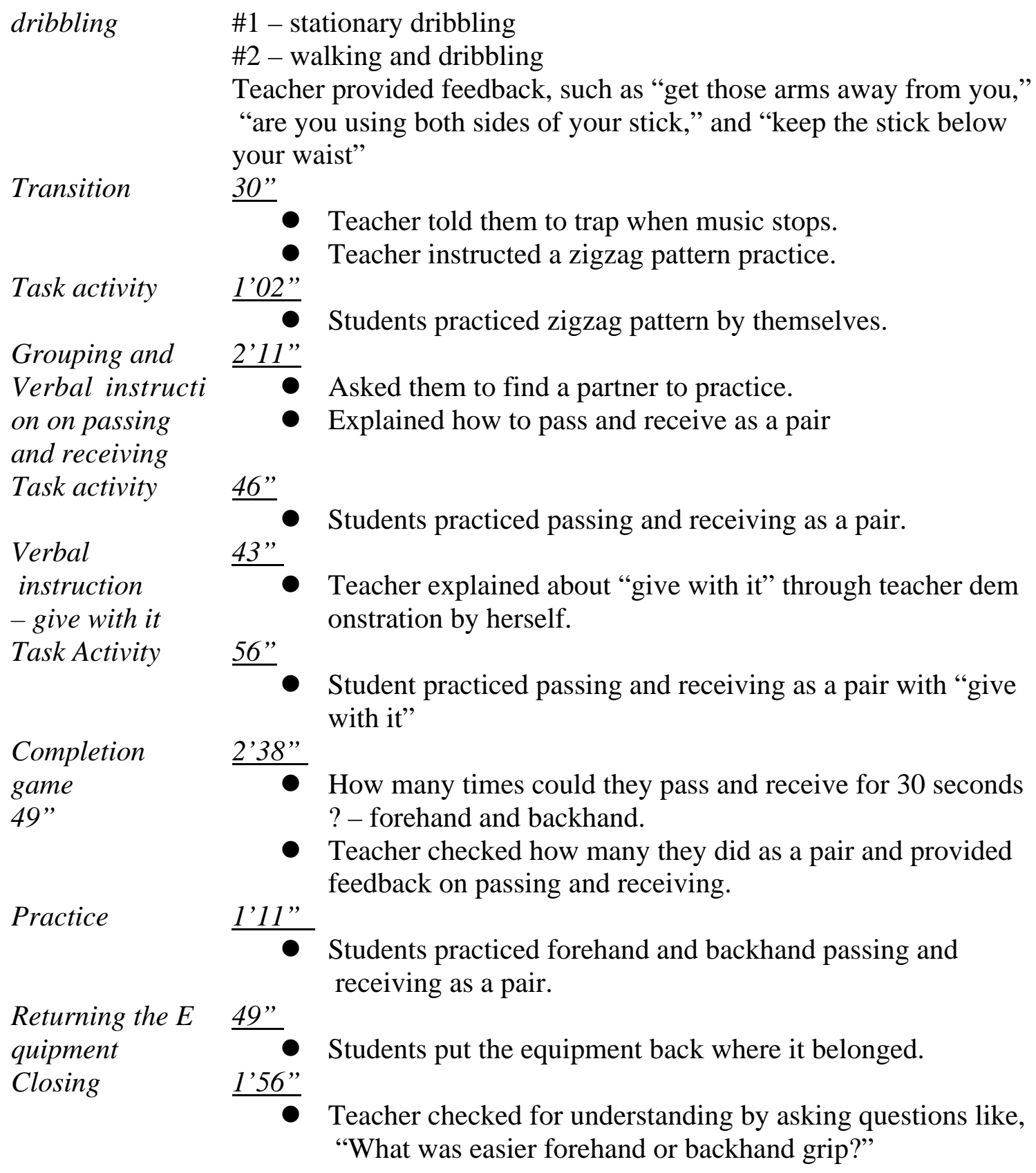
receiving as a pair.

Returning the E 49" quipment Closing

\section{$\underline{46 ”}$} 43"

- Teacher explained about "give with it" through teacher dem onstration by herself.

$\underline{56,}$

- Student practiced passing and receiving as a pair with "give with it”

How many times could they pass and receive for 30 seconds ? - forehand and backhand.

- Teacher checked how many they did as a pair and provided feedback on passing and receiving.

Students put the equipment back where it belonged.

Teacher checked for understanding by asking questions like, "What was easier forehand or backhand grip?"

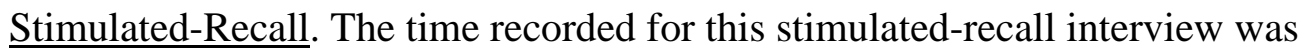
approximately 5 minutes, 35 seconds. Erin Hong said, “The verbal introduction went well, but it seemed too long again, like it did with the large class size.” She covered the same basic cognitive knowledge with a preview on the sport of floor hockey, like she had done with the large class 
size, before she got into the main activity lesson. The reason for the preview of the sport was to have the students gain interest in what they were going to do and why they were going to do it, which she called the "interest approach.” In general, she tried to teach the objectives of the lesson before they were exposed to the main activity tasks. She also mentioned that "because of the fairly long introduction, they seemed bored, so I stepped it up a little bit and pay them some attention,” which was her way of asking them to pay attention during the instruction.

Erin enjoyed offering feedback to the students in order to help them improve their skill performance. "Correcting was not a problem," she said. In terms of providing feedback to each individual, she said, "That was much better with the small number of students. I got more interaction individually with the kids than I had in the large class size. I got to talk to each one of them.”

Though there were a few high stick violations Erin was pleased with the students' behavior. She felt that they were not related to any misbehavior on the students' part. Her only major difficulty was the time was limited because, as she said, "I was rushed because I started a little late.” She mentioned that safety was always an issue for her but she said, "That was not as bad as it was in the larger class.”

In closing, Erin asked students to line up as she conducted a short review. She asked students a few questions in order to make sure they were able to recall the fundamental aspects of floor hockey, such as grip and rules. One difference between the small and the large class size was a trapping task was added in the small class lesson.

Interview Data: Class Size Comparison. The recorded interview where Erin compares and contrasts lessons from both class sizes lasted approximately 2 minutes 55 seconds. Erin Hong used the same teaching style for both class sizes. She said, "I tried to provide feedback in 
the large class size but I couldn't get to everyone. The large class was much harder because I couldn't give all of them the feedback that they needed." She also mentioned that "she was seriously concerned about safety in the large class. Your eyes have to be moving all the time, and focusing on one child and helping them is much harder. That's really the difficulty.”

Erin said in terms of smaller classes, "it was easier to manage students due to their proximity.” Teaching floor hockey safety was a major issue for her, but she was less concerned with the safety aspect with this class than she did in the large class. She felt that providing feedback was easier with the smaller class, so she was able to get to everyone and help them all in the smaller class.

Interestingly Erin said: I do not want a class much smaller than that. I do not want a class much smaller because it will be harder to teach. It becomes boring. I want to see variety and different skill levels. But large class size is a lot harder. Class size makes a difference.

\section{Summary}

Throughout the four teachers' first think-aloud exercises for large classes, all of the teachers constructed their lessons using similar tasks, instructional methods, concerns, and management strategies. Detailed components from each teacher's lessons were somewhat different, but each teacher planned to include basic floor hockey components in their first class with the large number of students, which preceded the lesson with the smaller class.

In particular, the HETs think-aloud procedure proceeded smoothly compared to that of the LETs. Experienced teachers were more confident in developing lesson plans illustrating how they planned to teach and what they planned to do during their lessons. They took less time to plan and came up with more exercises and tasks, their lesson plans were better organized. On the contrary, one of the student teachers, Nathan (LET2), had a relatively shorter and simpler planning process. Nancy (LET1) felt that the other student teacher was passive since she asked 
many questions even though information was given to her before the procedure started.

However, she had a detailed safety feature for her plan as a priority concern, much like Erin (HET2).

Highly experienced teachers drew upon their experiences, and useful guidelines for better teaching. One experienced teacher Erin, (HET2) planned to use the Sport Play and Active Recreation for Kids (SPARK) curriculum, which is designed to be a guide for physical education specialists and classroom teachers (SPARK, 2000). Both highly experienced teachers and less experienced novice teachers understood that the SPARK curriculum was instructional material for elementary physical education school programs. Erick (HET1) and both less experienced teachers never mentioned if they were going to use the SPARK curriculum in their lessons; however, HET1 used music in his lesson to stimulate the environment and for management purposes. Thus, both experienced teachers used music in their teaching.

Experienced teachers were knowledgeable compared to the novice teachers in terms of providing various tasks for the sport of hockey, such as gripping, dribbling, passing, trapping, and goal shooting. In fact, Erick, one of experienced teachers, wanted to include a goal shooting task with a pair of students, utilizing a shooter and goalie. He was also concerned about the students’ engagement in the large class size. However, he never indicated any safety aspects during his planning procedure. He hoped to have minimal waiting time and many repetitions of the tasks but doubted it would occur in the large class size.

The other experienced teacher, Erin (HET2), was greatly concerned about the safety issues in the sport of hockey stating that, "I'll limit their unsupervised time with hockey sticks by only sending a few kids to get the sticks when we need them.” The experienced teachers had a 
well-structured plan and the planning procedure ran more smoothly compared to the novice teachers.

Both experienced teachers mentioned a specific desire to correct their pupil’s technique and provide feedback while they were observing throughout the lesson. The novice teachers never mentioned how or why they were going to provide feedback on the pupil’s performances.

Generally, all teachers taught lessons as they were planned. rick (HET1) and Nancy (LET1) did not implement a game they planned toward the end of the class due to the lack of time in the large class.

Each of the four teachers realized difficulties in their teaching during the stimulatedrecall. Despite these difficulties experienced teachers, Erin (HET2) and Erick (HET1), were satisfied with their lessons in terms of providing enough feedback and interaction with the students in the large class size. Both experienced teachers were confident and complimentary of the lessons they taught. One major difference between novice and experienced teachers revealed in the stimulated-recall interviews was less experienced, novice teachers did indicate problem areas in their instruction and they were more critical of their own teaching.

Another difference between experienced and inexperienced teachers was experienced teachers elicited student curiosity before actually teaching the lesson and used music effectively during their lessons. As Erick said, "Music is effective and the students really like it.” He believed that music was helpful in keeping the students active during the lesson. In fact students were quick to remind Erick to turn the music on after he forgot, because the students noticed right away it was missing and they enjoy listening to music while they are working on activities.

Nathan (LET2) was critical of his lesson, but he acknowledged he was still developing his skills as a teacher. He admitted, "The introduction in the large class was not implemented 
smoothly. But I'm still working on that and I hope to make it better next time. I am still getting used to it. It takes me some time to work things out with the kids.” He did not, however, mention anything about safety in his planning. But he mentioned "the issue of hockey stick safety" during the stimulated-recall process.

Nancy (LET1) said, "I spent too much time explaining what to do in the introduction period." She actually performed very well during her instruction in terms of explaining all the stations and utilizing teacher and student demonstrations. She indicated problems with time management in her lesson. It seemed that Nancy focused too much on verbal instruction compared to keeping kids active by giving students simple instructions and then do the tasks.

Nancy mentioned that managing the students in the larger class was an issue for her because it was more difficult to keep students focused on the task. Safety was also an issue for Erin (HET2) in fact it was a major issue for both females, but it was barely mentioned by male teachers. Nancy tried to walk around all three stations but there was difficulty in providing all of the students with feedback. As she mentioned, she could not afford to provide individual feedback to all of the students due to the management issue in the large class size.

All four teachers were positive with the small number of students for their teaching in terms of teaching pace, management, providing feedback, and adding more tasks. They believed that the smaller class would make it much easier to manage students and deal with more tasks due to "the smoother teaching pace" and "less time to get them organized with the small number of students," as Nancy (LET1) and Erin (HET2) said, respectively. They also believed that they could provide enough feedback through "personalized interaction,” as Nathan said.

In terms of using teaching strategy, only Erick (HET1) changed the manner of instruction from station teaching to group teaching due to the small number of students. The rest of the 
teachers kept their teaching method the same as they used in the large class size (LET 1 stations, LET2 cohort, HET2, cohort).

Throughout their second lesson with the smaller number of students, generally, the experienced teachers taught as they planned. It seemed that novice teachers still had a problem with managing time because Nancy (LET1) and Nathan (LET2) could not execute games activities they planned, even though Erin (HET2) could not use the extra game she planned. Novice teachers mentioned that they elected to have the students spend more time practicing rather than implementing a game. Nathan said, “Students actually went through two or three times during the game,” and Nancy thought that “I might have enough time but I wanted to make sure their skills improved rather than just having them play a game.”

All four teachers said that lessons with the smaller number of students went smoothly and they were all positive that learning and skill development occurred within their lesson because of the amount of feedback the provided (especially individual feedback), management, students’ activity level, and safety aspects. The teachers were able to provide appropriate and ample feedback to each individual student compared to the large class size. Safety was still a concern for teachers but in the small classes, despite it not being a big problem. Erick (HET1) and Erin (HET2) said respectively, "Safety was very good and the teaching environment was just fine," and "safety was always an issue but it was not bad at all in the small class size.” In addition, they were satisfied with the students’ increase in physical activity levels compared to the large amount of practice time required in the large classes.

Formal interviews with each of the four teachers revealed that teachers described many advantages found when teaching smaller classes, including providing effective individual feedback, dealing with fewer management and safety problems, and having a quicker pace, 
resulting in more activity time for students to achieve optimal levels of skill performance. They also described many disadvantages to teaching the larger classes. Responses from all teachers’ indicate:

- High amounts of waiting time results in less student activity time and more offtask behavior.

- More stressful teaching, results in a short temper and teacher raising their voices.

- Lessons were not as successful: more kids = more confusion and less activity.

- Less space for the students to practice skills safely and fewer practice attempts. $\underline{\text { West Virginia University Teaching Evaluation System (WVUTES) }}$

The researcher observed and recorded lessons taught by all teachers and coded both student and teacher behaviors alternatively every two minutes starting with teacher behaviors utilizing the WVUTES observational instrument. Teacher and student behaviors (Tables 4.1 4.4) are described in detail as follows.

\section{$\underline{\text { Teacher Behaviors }}$}

General Observation (GO). GO was defined as the teacher watching student groups or individuals in a passive manner and with no relationship to instruction. Overall, GO ranged from $7.6 \%$ to $27.4 \%$ and the mean GO time was for $16.1 \%$ small classes and $17.4 \%$ for the larger classes. Surprisingly the greatest difference in GO occurred between Erick Sam’s (HET1) small class lesson (21.8\%) and his large class lesson (8.1\%). All other teachers spent more GO in large classes. This finding makes intuitive sense since one would expect GO as a managerial task of supervision and this strategy should be higher in larger classes.

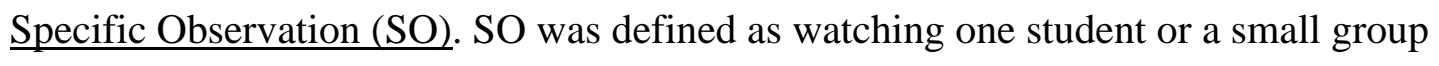
engaged in a subject matter activity. SO is typically instructional in nature and precedes many 
instructional behaviors like feedback. Therefore, one can expect SO will be higher in smaller classes rather than larger ones, since less attention was needed to manage smaller classes and teachers could devote more attention to instructional aspects of each lesson. SO ranged from $32.5 \%$ to $8.4 \%$ and had a mean of $23 \%$ for small classes and $18.1 \%$ for large classes. All but one teacher devoted more time in specific observation behaviors in the smaller class size than the large class size. Erick (HET1) devoted more specific observation time from a close proximity in the large class (30\%) rather than the smaller (19.3\%) one in order to provide more performancerelated feedback. Interestingly, in small classes, both LETs devoted more time (30.9\%) to SO than did HETs (15.2\%). Thus, it appears that LETs took advantage of opportunities in smaller classes to increase SO behaviors more so than HETs.

Encouragement (Enc.). Enc. was defined as a teacher making a verbal statement in order to enhance the student's perception of their ability to accomplish a subsequent task and build students' confidence. Enc. ranged from 5.0\% to $0.2 \%$ and the mean of Enc during small and large classes was $1.7 \%$ and $1.5 \%$, respectively. The frequency of Enc. ranged from $0.2 / \mathrm{min}$. to 2.2/min. and the mean of Enc was 1.2/min for small classes and 0.7/min for large classes. Both less experienced teachers Nancy and Nathan along with Erin, a highly experienced teacher devoted a greater amount of encouragement to students in smaller classes. These teachers also provided encouragement more often, or at a greater frequency. However, Erick (HET1) devoted higher levels of duration and frequency of encouragement to students in the larger class (5.0\% /2.0 per min.) compared to other teachers. HET1 focused more on verbal statements to enhance the student's perceptions of their ability to accomplish tasks within the larger class. The remaining teachers spent similar amounts of time providing encouragement in the smaller classes. 
LET1 provided encouragement more frequently (1.3/min.) in the smaller class compared to LET2 (0.7/min) and HET2 (0.6/min.).

Positive Feedback (P.FB). P.FB was defined as an instance when a teacher makes a positive verbal statement or gesture which is designed to increase or maintain the appropriate responses in the future. P.FB ranged from $2.0 \%$ to $4.3 \%$ and the mean of P.FB for small classes was 3.3\% and $2.6 \%$ for large classes. The frequency of P.FB for small and large classes ranged from $0.7 / \mathrm{min}$. to $2.5 / \mathrm{min}$, respectively. The mean of P.FB for small classes was $1.9 / \mathrm{min}$. and 1.4/min. for large classes. Nancy, Nathan, and Erin (LET1, LET2, and HET2) had a longer duration and higher frequency of positive feedback in smaller classes (3.2-4.3\%/1.7-2.5 per min.). However, Erick (HET1) had a longer duration and higher frequency of positive feedback in the larger class (2.6\%/1.8 per min.) compared to the smaller class (2.0\%/1.1 per min.). Compared to all other teachers, Erick (HET1) provided the most positive feedback at the highest frequency in the larger class and the least PF in the smaller class. In fact, he used a station-based teaching approach for the large class and a cohort teaching strategy for the smaller class. Thus, Erick gave feedback more efficiently in the station-based lesson opposed to the cohort-based approach.

Nancy (LET1) had a high frequency of positive feedback (2.5 per min) in the smaller class size among all four teachers. Erin (HET2) spent the least amount of time and frequency providing positive feedback in the large class. Interestingly, when compared to all other teachers it was Erick (HET1) that provided positive verbal statements or gestures more often in the larger class, and Nancy (LET1) provided the most positive feedback at the greatest frequency in the smaller class. Overall, HETs provided positive feedback more consistently for both large and small classes (1.3 \& 1.4 per min.). However, LETs overcame this lack of consistency by 
providing more positive feedback in the smaller classes ( 2.3 per min.) compared to the larger classes (1.6 per min.).

Corrective Feedback (C.FB). C.FB was defined as an instance when a teacher makes a negative or critical verbal statement or gesture to decrease an inappropriate behavior in the future. C.FB ranged from $0.7 \%$ to $5.3 \%$ and the mean for C.FB was $2.8 \%$ within both small and large classes. The frequency of C.FB ranged from 1.8/min. to $0.4 / \mathrm{min}$. The mean of C.FB for small classes was 1.3/min. and 1.0/min. for the large. Corrective feedback was provided most frequently by Erick (HET1) in the large class size, while Nathan (LET2) provided corrective feedback least frequently in the larger classes. As mentioned earlier, station teaching was more conducive to providing feedback compared to cohort teaching. Erin (HET2) and Nancy (LET1) had similar frequencies of corrective feedback in larger classes. Across all teachers Nancy (LET1) delivered a higher percentage of corrective feedback in the large class (5.3\%/1 per min.) than in the small class (4.4\%/1.8 per min.). Among all four teachers Nathan (LET2) provided the least amount of corrective feedback in the large class. Overall (Table 4.3), in the large classes LETs provided corrective feedback less frequently ( 0.7 per min) compared to HETs (1.2 per min). In the smaller classes LETs provided corrective feedback more frequently (1.5 per min.) compared to the HET’s (1.1 per min.) provided by HETs. Thus, LETs seem to benefit from teaching to smaller numbers of students by taking advantage of fewer students to provide more corrective feedback. Meanwhile, HETs maintained consistent levels of corrective feedback frequency for both the small and large size classes (Table 4.1).

Management (Mgmt). Management was defined as the process in which the teacher is engaged in carrying out a non-subject matter task, such as setting up equipment, taking roll, or collecting papers. Management ranged from $11.0 \%$ to $31.8 \%$ with the mean of time management 
behaviors for small classes was $17.1 \%$ and $28.1 \%$ for large classes. Generally novice teachers devoted more time to managing the class. Among all four teachers, Nathan (LET2) spent more time managing the large class (31.8\%) compared to other teachers while Nancy (LET1) spent the most time managing her smaller class (29.3\%). Both Erick (HET1) and Erin (HET2) spent similar duration of management behavior in each class size, $26.8 \%$ in the large class and $14.2 \%$ and $13.7 \%$ in the small class (Table 4.1 ).

Verbal Instruction (V.I). VI was defined as an instance when the teacher verbally describes to the students how to perform a skill, which is to be a subject matter task. VI ranged from $14.2 \%$ to $44.4 \%$ and the mean of VI were $28.9 \%$ for small classes and $24.2 \%$ large classes. Nancy (LET1) used the station approach for both large and small classes but, she spent the most amount of time in verbal instruction in her large class (32.7\%) and the least amount in her small class (14.2\%). Erin (HET2) gave the most verbal instruction (44.4\%) of all teachers during her small class, and she used cohort teaching strategies for both classes. Nathan (LET2) gave the least verbal instruction (17.8\%) of all teachers during his large size class.

Modeling (Model). Modeling was defined as an instance when the teacher demonstrates to students how to do a subject matter task, or participates with students in a subject matter task or activity. Modeling ranged from $1.0 \%$ to $11.0 \%$ and the modeling behaviors mean for small classes was 3.9\% and 6.7\% large classes. Compared to the other teachers in small classes, Nathan (LET2) provided the most modeling behaviors by demonstrating to his students how to do each task (11.0\%). Compared to other teachers in large classes Erin (HET2) spent the most amounts of time demonstrating skills to her students (6.3\%). Nancy, Nathan, and Erick (LET1, LET2, and HET1) spent more time modeling in their smaller classes than did Erin (HET2) who spent more time modeling in her large class. 
Physical Guidance (Phy.Gui.). Physical guidance was defined as an instance when the teacher physically guides students through a subject matter task or activity. Physical guidance ranged from $0.0 \%$ to $2.7 \%$ and the mean of physical guidance for small and large classes was $0.4 \%$ and $0.8 \%$, respectively. Compared to other teachers, less experienced teacher 2 (Nathan) physically guided students the most, specifically in his large class (2.7\%), while Nancy and Erin (LET1, HET2) spent approximately $0.7 \%$ on physical guidance mostly in their smaller classes.

Non-Task Verbal (N. Tak.V). Non-task verbal was defined as an instance when the teacher talks to students about non-subject matter and non-managerial subjects. Non-task verbal ranged from $0.0 \%$ to $0.3 \%$ and the mean of non-task verbal for small and large classes was $0.1 \%$ and $0.2 \%$, respectively. Nancy (LET1) never accumulated any non-task verbal time. The rest of the teachers spent less than $0.3 \%$ engaged in non-task verbal behaviors.

Off Task (Off Tsk). Off task behavior was defined as an instance when the teacher is not paying attention to what are clearly his or her responsibilities regarding the class at hand. Overall, off task behaviors were very low ranging from $0.0 \%$ to $3.2 \%$ (Table 4.1). Only Erick, (HET1) spent any time off-task, 3.2\% for his small class. The remaining teachers avoided off-task behaviors all together for both large and small classes. In fact, during HET1s' large class instruction, one of his colleagues came in to the class and asked a question not related to the subject matter task so that he had to respond on the question, which was considered an off-task behavior.

\section{$\underline{\text { Student Behaviors }}$}

Motor Appropriate (Mo. Appr.). Motor appropriate behavior was defined as an instance when the student is engaged in a subject matter motor activity in order to produce a high degree of success. Motor appropriate behavior ranged from $14.0 \%$ to $42.6 \%$. The mean for motor 
appropriate behaviors were $29.6 \%$ for small classes and $18.3 \%$ for large classes. The duration time of motor appropriate student behaviors in the small class was much higher for all four teachers, compared to the larger classes. The highest duration of motor appropriate behavior was achieved in both of Erick's (HET1) lessons (large, 22.6\%, and small, 42.6\%). Station teaching was appropriate for the large class size and cohort teaching was effective for smaller class sizes in terms of increasing motor appropriate student behaviors. Students in Erick's (HET1) lessons were highly engaged in subject matter compared to other teachers' lessons. The least amount of time spent in motor appropriate student behaviors was found in Nathan's (LET2) large class lesson (14.0\%), where a cohort teaching strategy was utilized. The range of duration for motor appropriate behaviors among small classes taught by the three remaining teachers was $23.7 \%$ to 27.2\%, noticeably lower than Erick’s (HET1) small class (42.6\%).

Motor Inappropriate (Mo.Inapr.). Motor inappropriate behavior is defined as an instance when the student is engaged in a subject matter activity but the task is either to difficult or easy for the individual's capabilities that practicing it could not contribute to lesson goals. Motor inappropriate behavior ranged from $0.1 \%$ to $0.3 \%$. LETs had a mean of $0.15 \%$ motor inappropriate student behavior in the large classes and that of $0.2 \%$ motor inappropriate student behavior in the small classes. Meanwhile, HETs had a mean of $0.2 \%$ motor inappropriate student behavior in the large classes and that of $0.15 \%$ motor inappropriate student behavior in the small classes.

Motor Supporting (Mo. Sup.). Motor supporting was defined as an instance when the student is engaged in a subject matter motor activity in order to assist others to learn or perform the activity. Motor supporting ranged from $0 \%$ to $0.5 \%$. The mean of motor supporting was 
$0.25 \%$ for small classes and $0.1 \%$ for large classes. Motor supporting means and for LETs was $0 \%$, and $0.25 \%$ for HETs.

Cognitive (Cog.). Cognitive was defined as an instance when the student is appropriately involved in a cognitive task such as listening to a teacher describe a game, listening to verbal instructions about how to organize, watching a demonstration, participating in a discussion, or watching a film. Cognitive ranged from $17.4 \%$ to $64.4 \%$ and the mean of cognitive for small classes was 38.8\% and 37.2\% for large classes. Less experienced teachers devoted more cognitive time in larger classes than the smaller ones compared to highly experienced teachers. Erin (HET2) devoted the highest cognitive time in the large class (56.1\%) and the small class (64.4\%) because the HET2 often stopped the lessons and described tasks and skills. The least amount of cognitive time was found in Nathan's (LET2) small class size (17.4\%). LETs in this study reduced verbal instruction in smaller classes allowing more time for students to be active.

On Task Management (O.Tsk Mgmt.). On Task Management was defined as an instance when the student is appropriately engaged in carrying out an assigned non-subject matter task such as moving into squads, helping to place equipment, counting off, doing warm up exercise, or moving from the gym to a playing field. On task management ranged from $0.0 \%$ to $22.3 \%$ and the mean of on task management for small classes was 7.0\% compared to 3.8\% for large classes. Students in Nancy's (LET1) lessons were highly engaged in carrying out assigned non-subject matter tasks in both her large (22.3\%) and small (20\%) classes because the teacher asked them to stay at each station until everyone was lined up and ready to move to the next station.

Interestingly, the top three lessons that had a high amount of on task management were all station lessons. Nancy (LET1), used stations in both her large (22.3\%) and small (20.0\%) classes while Erick (HET1), taught using stations in his large class (18.8\%). Station teaching facilitated 
more on task management time in classes, behaviors like transitions and moving to different stations were more prevalent compared to using a cohort teaching style.

Off Task (Off.Tsk). Off task was defined as an instance when the student is either not engaged in the subject matter task or is engaged in an activity other than the subject matter task, such as behavior disruptions or misbehavior. Off task behavior ranged from $0.0 \%$ to $6.4 \%$ and the mean for off task behavior was $2.7 \%$ for both small and large classes. Off-task student behavior was never recorded in Erick’s (HET1) large class in lesson. The highest amount of offtask behavior occurred in Nancy’s (LET1) large class lesson (6.4\%). More off-task behavior occurred in experienced teachers’ small class lessons compared to the novice teachers’ small class lessons.

Interim (I). Interim was defined as an instance when the student is engaged in a noninstructional aspect of an ongoing activity such as retrieving balls, fixing equipment, retrieving arrows, or changing sides of a court in a tennis match. Interim ranged from $1.1 \%$ to $17.8 \%$ and the mean of interim was $5.8 \%$ for small classes and $7.7 \%$ for large classes. Students were engaged in interim behaviors (a non-instructional aspect of an ongoing activity) in Erick’s (HET1) large class lesson (17.8\%) and in his small class lesson (6.9\%). The least amount of interim behavior occurred in Erin's (HET2) large class lesson (1.1\%) and in her small class lesson (4.1\%). As a matter of fact, HET1 used both station teaching for the large class and cohort teaching in the small class with plenty of activity time. As students implemented tasks, they spent more time retrieving pucks than other students did HET2 classes. This could be a reason interim behaviors were prevalent in HET1's lessons compared to the HET2's classes.

Waiting (W). Waiting was defined as an instance when the student has completed a task and is awaiting the next instruction or opportunity to respond, such as in line for a turn. Waiting 
ranged from $5.1 \%$ to $41.9 \%$ and the mean for waiting behaviors in small classes was $18.6 \%$ compared to 20.2\% for large classes. Student waiting time was higher in Nathan’s (LET2) large lesson (41.0\%) and in his small class (41.9\%) compared to the other three teachers. Most of the waiting time occurred during the game Nathan used in both of his lessons. It was a speed game where the object was to have each member complete a pass to everyone else in the group, after which he or she would sit down and wait for other teams to finish. The least amount of waiting time occurred in the large class (8.8\%), a station-based lesson taught by Nancy (LET1) and in the small class (5.1\%), which was a cohort based lesson taught by Erin (HET2).

Comparison of Teaching Behaviors in Large/Small Classes

Teacher Behaviors. (Table 4.3) Highly experienced teachers (HETs) spent more time in general observation while teaching large (17.8\%) and small (20.7\%) classes than less experienced teachers' did teaching large (17.1\%) and small class sizes (11.7\%). However, the LETs devoted more time to general observation in larger classes than their smaller classes compared to HETs', who devoted more time to smaller classes than they did in larger classes. Meanwhile, HETs engaged in specific observation more in their larger classes (19.2\%), compared to LET's (16.9\%). HETs devoted less time for specific observation in smaller classes (15.2\%) than LETs did in their smaller classes (30.9\%). These findings help us understand that HETs attempt instructional supervision strategies (specific observation) more in the larger classes and managerial supervision strategies (general observation) more in smaller classes. Small classes appear to be a beneficial factor for LETs to observe students in close proximity nearly twice as much as they spend in larger classes.

In general, HETs provided encouragement more frequently than LETs and both groups provided encouragement more often in smaller classes rather than larger class sizes. LETs 
provided more positive feedback in large and small classes (1.6/min. and 2.3/min.) than HETs' provided (1.3/min. and 1.4/min.). HETs provided a similar frequency of corrective feedback in both class sizes (large: 1.2/min. and small: 1.1/min.) However, LETs provided corrective feedback more frequently in smaller classes $(1.5 /$ min.) twice as much as they spent in the large class (0.7/min.). Therefore, one can surmise that small class sizes were more helpful for LETs in order to interact with students by using more corrective feedback. HETs facilitated the lessons with more frequent encouragement in both class sizes than the LETs. They also seemed to put in more effort with larger classes than smaller classes to motivate students' and improve the quality of their performance.

LETs tend to focus more on class management issues for both class sizes than HETs' did in terms of the management time recorded. However, both the HETs and LETs devoted more time to management within the large class setting (HET: 26.8\% and LET: 29.4\%) than they did in small class sizes (HET: $14 \%$ and LET: 20.2\%).

LETs spent more time in verbal instruction behaviors during larger classes (25.3\%) compared to the HETs (23.1\%). One would expect the duration of verbal instruction to be higher than in larger classes; however, HETs spent more time in verbal instruction during smaller classes (38.1\%) than LETs (19.7\%) did. LETs took better advantage of working with a smaller number of students during verbal instruction as well.

LETs spent more time engaged in modeling behaviors for both large (4.2\%) and small (8.8\%) classes than did HETs': large (3.7\%) and small (4.5\%). Both HETs and LETs devoted more time in modeling behaviors in smaller classes than they did in larger classes. Physical guidance, non-task verbal, and off task behaviors were not utilized enough to make a significant comparison between class sizes. 


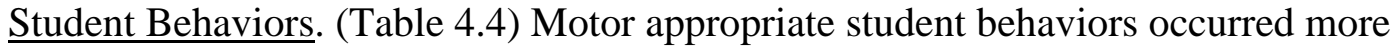
frequently in smaller classes for both HETs (33.2\%) and LETs (26.1\%) compared to the amount of motor appropriate behavior that occurred in larger classes: HETs (22.1\%) and LETs (14.5\%). These data illustrate that more motor appropriate behavior occurred during HETs' instruction than that of LETs'. Motor inappropriate and motor supporting behaviors were not present at sufficient levels that would allow for comparison between teaching behaviors and class sizes.

Student cognitive behavior, which is related to instructional tasks assigned by teachers, was much higher in HETs instruction (large: 38.2\%, and small: 51.2\%) than it was in LETs instruction (large: 36.2\%, and small: 26.5\%). Cognitive behavior also occurred more frequently in smaller classes (51.2\%) than it did in larger classes (38.2\%) during instruction by HETs. LETs engaged students in cognitive behaviors less in smaller classes (26.5\%) as opposed to larger classes (36.2\%).

Student on task management behaviors occurred more frequently in large class lessons that were taught by LETs' during both LETs and HETs' lessons. On task management behaviors in HETs larger classes (13.5\%) was substantially higher when compared to smaller classes $(1.4 \%)$.

In LETs' large class lessons the amount of time students engaged in off-task behaviors was highest (4.3\%), and the lowest in large class lessons taught by HETs (1.1\%). The highest occurrence of interim behavior also occurred in large classes (9.5\%) taught by HETs. The lowest occurrence of interim behavior occurred in HETs small class lessons (5.5\%). Waiting time was very high in lessons taught by both LET's to large classes $24.9 \%$ and small classes $26.2 \%$ compared to the HETs' large lessons (15.5\%) and small (5.6\%). As expected, these findings 
indicate that HETs were better able to manage larger classes than LETs in terms of the occurrence of the aforementioned student behaviors.

Based on the findings shown in Table 4.1, Table 4.2, Table 4.3, and Table 4.4, one large class lesson and one small class lesson from all four lessons taught by experienced teachers was chosen for analysis using field system analysis. One large and small class lesson was chosen from all four lessons taught by novice teachers. All teaching behaviors, such as content behaviors, and management behaviors including off task, and student behaviors such as: motor activity, waiting, and off task were contrasted in terms of the duration and frequency of behaviors to determine which lessons were selected. Considered above all were frequency of encouragement, positive feedback, and corrective feedback by teachers because teacher interaction with students through feedback are relevant to the improvement of students' performance and encouraging and motivating student's motor activity (Tjeerdsma, 1997). In addition, the duration of motor appropriate student activity was compared with waiting time, which influenced off-task behavior (Housner \& Griffey, 1985) and negatively influenced higher degrees of student success levels in motor activity and subject matter.

\section{Field System Analysis}

Though many behavioral differences were uncovered using the WVUTES analysis, correlations between the frequency of teacher and student behaviors across all teachers' lessons were significant (the range of correlation is from $r=.480$ to $r=.930$ ). Thus, the overall structure of the lessons by the four teachers was similar. Because the general lesson structure was similar across all lessons, a more in depth analysis was deemed necessary. Therefore, a field system analysis (FSA) was conducted on selected lessons. FSA is a technique for systematically observing instructional and managerial tasks that take place in complex interactions among 
teacher and student behaviors in instructional environmental context (Sharpe, Lounsbery, Hawkins, \& Eldar, 1995). FSA was used to analyze the teaching and learning behaviors for the selected lessons (4) from highly experienced teachers and less experienced teachers (Appendix C \& D). As mentioned before, the four lessons were selected based on the findings from Table 4.1, Table 4.2, Table 4.3, and Table 4.4 and student and teacher behaviors (such as the frequency of feedback, duration of general observation and specific observation, and student's appropriate activity time and waiting time). In particular, individual positive feedback and corrective feedback were added from the WVUTES to code for the purpose of comparing and contrasting the interrelationships of individual feedback, general feedback, general observation, and specific observation in two different class sizes as well as examining dual and triple sequential chains of individual corrective feedback, positive feedback, general observation, specific observation, and other behaviors. In addition, FSA was used to observe the lesson body itself without warm-up period, which is considered as a management behavior according to the definition of WVUTES.

FSA data were originated by separately viewing each lesson's teacher and student behavior. Thus, the investigator observed each lesson twice. The data and results of FSA are provided below.

\section{Lesson Descriptions}

\section{Erick Sam: Highly Experienced Teacher 1 (HET1)}

The large class lesson taught by Erick Sam (HET1) was 30 minutes, 23 seconds in duration. During the lesson, approximately 55.2\% (16’47”) of class time was instructional, which included verbal instruction (17.8\%), and specific observation (24.9\%), encouragement (2.422\%), general positive feedback (0.51\%/0.23 per min.) and general corrective feedback (0.078\%/0.066 per min.), individual positive feedback (2.13\%/1.843 per min.) and individual corrective 
feedback (1.545\%/0.921 per min.), modeling (0.694\%), and student demonstration with verbal instruction (5.038\%). Of the instructional time, 17.846\% was verbal instruction. In addition, transition time and grouping time between the tasks was $7.206 \%$ and $2.966 \%$, respectively. The highest duration of teacher behavior was the specific observation (24.957\%; Table 4.6)

As illustrated in Table 4.8, of the student behaviors in the large class taught by Erick (HET1), cognitive student behavior (29.4\%) was the highest block of time, and the activity time was second (27.957\%). Waiting time ranked third at $15.302 \%$ (Table 4.8 ).

The small lesson taught by Erick (HET1) lasted 33 minutes and 25 seconds in duration. During the lesson, $60.087 \%$ (20’05”) of instructional time was spent, including verbal instruction (25.206\%); specific observation (18.037\%); encouragement (2.903\%); general positive feedback (0.163\%/0.12 per min.); individual positive feedback (2.355\%/1.583 per min.) and individual corrective feedback (2.102\%/1.195 per min.); modeling (8.805\%); physical guidance (0.506\%); and student demonstration with verbal instruction (0.01\%). Throughout the total instructional time, the highest duration of teacher behavior was found in verbal instruction (25.206\%). Additionally, transition and grouping time between tasks was $5.797 \%$ and $1.794 \%$, respectively (Table 4.7).

During the small lessons taught by Erick (HET1), student activity time (45.754\%) made up the largest block of time spent, with student cognitive behavior (29.4\%) ranking second. Waiting time (4.427\%) ranked fifth, followed by management (6.763\%) and warm up time (6.506\%) (Table 4.9).

\section{Nancy Young: Less Experienced Teacher 1 (LET1)}

The large class lesson taught by Nancy Young (LET1) was 33 minutes, 48 seconds in duration. During the lesson, $46.639 \%$ (15’46”) of time was allocated to instruction, including 
verbal instruction (24.089\%), and specific observation (8.113\%), encouragement (0.58\%), general positive feedback (0.424\%/0.325 per min.), general corrective feedback (0.464\%/0.296 per min.), individual positive feedback (1.29\%/0.828 per min.) and individual corrective feedback (1.321\%/0.71 per min.), modeling (6.47\%), physical guidance (0.3\%), and student demonstration with verbal instruction (3.588\%). Of the instructional time, verbal instruction (24.089\%) was the highest duration. Transition time and grouping time between the tasks was $7.758 \%$ and $1.446 \%$, respectively (Table 4.10 ).

During the large class lesson taught by the Nancy (LET1), the student cognitive time (41.635\%) was predominant. Student activity time ranked second but was relatively low at $16.484 \%$. This was followed by warming up (15.038\%), interim (10.052\%), and off task (4.079\%). Waiting time (3.07\%) was sixth out of eight behaviors (supporting behavior did not take place; Table 4.12).

The small class lesson taught by Nancy (LET1) lasted 29 minutes, 47 seconds. During the lesson, $60.434 \%$ (18’00”) of time was allocated to instruction, including verbal instruction (14.282\%), and specific observation (28.456\%), encouragement (2.077\%), general positive feedback (0.193\%/0.134 per min.) and general corrective feedback (0.438\%/0.201 per min.), individual positive feedback (2.123\%/1.979 per min.) and individual corrective feedback (3.553\%/1.241 per min.), modeling (7.223\%), and physical guidance (2.099\%). In this lesson, the duration of the specific observation (28.456\%) was the highest. There was no student demonstration in this lesson. Verbal instruction time made up $14.282 \%$ of the instructional time while, transition and grouping time between tasks was $2.6 \%$ and $1.753 \%$, respectively (Table 4.11). 
During the small class lesson by Nancy, students’ activity time (27.958\%) was the highest and the cognitive student behavior was second (27.076\%), while warm up (16.787\%), interim (12.375\%), managing (10.31\%), and waiting time (4.082\%) followed in order (Table 4.13).

Teacher Comparisons HET/LET 1: Within Lessons (Large vs. Small)

Sequential behavioral chains (Tables 4.14, 4.15, 4.16 \& 4.17) chosen in this study were based on a statistical Z scores, which were utilized to determine statistical significance of a meaningful behavioral event sequence of interest within a larger time-based data set (Sharpe \& Koperwas, 2003). Therefore, the selected sequential behavioral chains in this study were meaningful due to the larger sequential structure of the entire sate set.

Erick Sam (HET1) within lessons (Large vs. Small)

Teaching Behaviors (HET 1). General observation in the large class13.173\% was less than in the small class (21.811\%). Specific observation was higher in larger classes (24.957\%) than in smaller classes (18.037\%). However, the sum of both observations was higher for smaller classes (39.84\%) compared to the large class (38.13\%), resulting more given feedback in the smaller class (5.07\%) than in the large class (3.87\%). However, the rate was still lower in the small class (2.898/min.) than it was in the large class (3.06/min.). Moreover, transition and grouping times were higher in the larger class (7.206\%/2.966\%) rather than in the small class (5.797\%/1.794\%).

As illustrated in Table 4.16 the instructions given by Erick (HET1), preceded individual feedback followed by specific observation occurred similarly in both small and large classes, 65 and 66, respectively. Table 4.16 also showed the conditional probability of individual corrective feedback and individual positive feedback, which was immediately followed by specific 
observation in the larger class, was 0.1261 , compared to 0.1313 of individual corrective feedback and individual positive feedback, which immediately followed specific observation in the small class. Therefore total duration of individual feedback followed by specific observation was higher in the smaller class.

Table 4.14 illustrates the instructional and managerial tasks which were used more during instruction and less during management tasks presented in large classes compared to the small classes (large: instructional 41\% and managerial 15\%; small: instructional 36\% and managerial 20\%). Instructional tasks taught by Erick (HET1) were dominant in both large and small classes; however, managerial tasks were higher in smaller classes rather than the larger classes. The differences between the two classes were size and teaching formation: station teaching or cohort teaching. Thus, station teaching in the larger class was more effective at focusing students on instructional tasks and reducing managerial tasks.

Student Behaviors (HET1). As indicated in Tables 4.8 and 4.9, Erick’s (HET1) lessons, showed a lot of activity time in the small class (45.754\%) was higher than that of the large class (27.957\%). Cognitive time was similar in both class sizes (large: 29.4\%; small: 31.35\%). However, waiting time was higher in the larger class (15.302\%) rather than in the smaller class (4.427\%). Management time was also higher in the large class (9.21\%) opposed to the smaller class (6.763\%). However, off-task student behavior was slightly higher in his small class (3.217\%) compared to his large class (2.32\%). The only difference between the two classes were size and teaching style: cohort or station. Thus, station teaching might help prevent students being off task during lessons. 
Nancy Young (LET1) within lessons (Large vs. Small)

Teaching Behaviors (LET 1). General observation in the large class (19.75\%) was higher than the small class (10.22\%). Specific observation was less in the large class (8.11\%) than in the small class (28.45\%). More individual feedback occurred in the small class (6.39\%) compared to the large class (3.49\%) as well as the rate of individual feedback per minute (3.22/min. for small and 1.538/min for large). Verbal instruction occurred more frequently in the large class (24.09\%) compared to the small class (14.28\%).

In addition, transition time was higher in the large class (7.75\%) than in the small class (2.60\%), however, grouping time was less in the large class (1.44\%) compared to the small class (1.75\%). Nancy (LET1) used student demonstrations in the large class but not in the small class size. However, more modeling time was spent in the small class (7.22\%) compared to the large class size (6.47\%).

As illustrated in Table 4.17 from the instructions by Nancy, frequency of individual feedback followed by specific observation was slightly more frequent in the large class (37) rather than the small class (31). No individual feedback was given followed by general observation in either class; however, there was general feedback followed by general observation in the small (5.0) and large class (17.0).

In addition, Table 4.17 compares the conditional probability of individual corrective feedback with individual positive feedback immediately following specific observation in the large class was 0.1164 compared to that of individual corrective feedback immediately following specific observation in the small class, which was 0.0697 . Thus, the total duration of individual feedback followed by specific observation was determined to be higher in the larger sized class. 
As Table 4.15 Indicated, more instructional tasks and fewer managerial tasks were evident in smaller classes compared to larger classes (large: instructional 26\% and managerial 18\%; small: instructional 48\% and managerial 5\%). Nancy (LET1) was able to focus more on instructional tasks and less on managerial tasks in the small class than in the large class. In fact, the teaching styles were the same (station teaching) in the both classes. According to the data in this study, class size influenced instruction and management behaviors teachers used during instruction. The evidence in this study shows LET1 benefited by working with a smaller number of students during her instruction to increase instructional tasks and decrease managerial tasks.

Student Behaviors (LET1). In lessons that Nancy Young taught, activity time in the small class (27.958\%) was higher than it was in the larger class (16.484\%). Additionally, cognitive time was higher in the large class (41.635\%) compared to the smaller class (27.076\%). Nancy devoted approximately 12 minutes 35 seconds to the introduction in her large class and addition to 5 minutes and 48 seconds in the small lesson. The introduction to lesson made a difference in the activity time in both classes' and cognition time. However, waiting (4.08\%) and managing time (10.31\%) was somewhat higher in the smaller class than in the large class (3.07\% and 9.52\%). Meanwhile, off-task student behavior time was higher in the large class (4.079\%) compared to the smaller class $(0.987 \%)$. Nancy (LET1) took advantage of the smaller number of students in her small class size to teach a lesson that was more effective at developing student skill and learning.

Teacher Behaviors Between Lessons (HET1 and LET1)

Large Class Size. HET1 spent less time in general observation than the LET1 (13.173\% vs. $19.755 \%$ ) but more time in specific observation (24.957\% vs. $8.813 \%)$. Erick (HET1) encouraged students in the lesson more frequently than the novice teacher (2.422\%/ 1.941 per 
min. vs. 0.580\%/0.384 per min.). The rate of individual feedback was also higher in the HET1's lesson (2.768/min) than in Nancy’s (LET1) lesson (1.538/min.). Erick (HET1) spent less time on verbal instruction (17.846\%) compared to the novice teacher (24.089\%). During the lesson introduction, Erick spent more time on student demonstration in the large class than the novice teacher, 5.038\% vs. 3.588\%, respectively. Transition times were similar in both lessons but grouping time took longer in the experienced teacher's lessons than it did in the student teacher's (2.966\% vs. $1.446 \%)$.

Small Class Size. In Erick Sam’s (HET1) small class lesson, he spent more time on general observation than the novice teacher, (21.811\% vs. $10.223 \%)$, but less time in specific observation than Nancy (LET1) (18.037\% vs. 28.456\%). In his large class, Erick encouraged the pupils more often than Nancy did (1.793/min. vs. 1.376/min.). However, Nancy (LET1) devoted more time to individual feedback (5.676\%/3.22 per min.) than the HET1 (4.457\%/2.778 per min.). Transition and grouping times were higher in the experienced teacher's lesson than in the Nancy’s (LET1) lesson, 5.797\%/1.794\% vs. 2.6\%/1.753, respectively. In addition, Erick devoted more time for verbal instruction rather than novice teachers, $25.206 \%$ vs. $14.282 \%$, respectively. Erick also spent more time for modeling (8.805\%) than the novice teacher (7.223\%), but both teachers used student demonstrations in the small class size.

\section{$\underline{\text { Student Behaviors Between Lessons (HET1 and LET1) }}$}

Large Class Size. Student activity time in the large class was higher in Erick’s (HET1) lesson (27.95\%) than it was in Nancy’s (LET1) lesson (16.48\%). However, cognitive behavior was high in Nancy’s (LET1) lesson (41.63\%) compared to the experienced teacher’s (29.4\%). In fact, those behaviors might be influenced by the introduction, according to the definition of student's cognitive behavior (Appendix D). The introduction in HET1 large class lasted 7 
minutes, 38 seconds compared to 12 minutes, 35 seconds for the LET1 large class introduction. Waiting time was higher in the HET1's lesson (15.30\%) compared to the LET1's (3.07\%). Managing time was a little higher in the novice teacher's lesson (9.52\%) compared to the experienced teacher’s (9.21\%). In addition, off-task time was higher in the student teacher's lesson (4.079\%) than in the experienced teacher's (2.32\%).

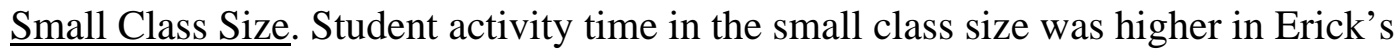
(HET1) lesson (45.754\%) than it was in Nancy's (LET1) lesson (27.958\%). This result occurred not only because of the instruction time in each lesson (HET1; 2'38” and LET1; 5'48”) but also because of the teaching formation, where LET1 used stations and HET1 used cohorts. Cognitive behavior was also higher in the HET1's lesson (31.35\%) than in the LET1's (27.076\%). Waiting time was spent similarly in both lessons (experienced teacher: 4.427\%; student teacher: 4.082\%). Meanwhile, managing time was higher in novice teacher lessons (10.31\%) than in the HET1's lesson (6.763\%). Off task student behavior was higher in the HET1's lesson (3.217\%) than it was in LET1's (0.987\%).

\section{Interrelationships between Class Size and Teacher Behavior}

The following interrelationships between class size and teacher experience have been found:

1. Comparison between individual feedback and general feedback

As illustrated in Table 4.18, both individual feedback (5.676\%/3.22 per min.) and general feedback $(0.631 \% / 0.335$ per min.) by Nancy (LET1) occurred more frequently in the small class compared to the lesson by Erick (HET1), 4.457\%/2.778 per min. and 0.163\%/0.12 per min. respectively. Erick and Nancy utilized cohort and station teachings in their smaller classes, respectively. Thus, it was found that station teaching made it a lot easier to provide both 
individual and general feedbacks compared to the cohort teaching. However individual feedback by Erick in the large class lesson occurred more frequently than in Nancy's lesson.

2. Relationship between individual feedback vs. off task student behavior

As illustrated in Table 4.19, in lessons taught by Nancy (LET1), once more individual feedback was provided, student off task behavior decreased. Conversely, once individual feedback decreased, student off task behavior increased. The results showed that there was an inversely proportional relationship between the teacher’s feedback and students' off task. In addition, when the teachers (HET1 vs. LET1) were compared in each class size, the inverse relationship between individual feedback and student off task was appropriate. However, when Erick’s (HET1) lessons were compared, the inverse relationship was not congruent. Thus, it can be concluded that more individual attention by teachers was effective to decrease students' off task no matter the class size.

3. Comparison among encouragement, positive feedback, and corrective feedback As illustrated in Table 4.20, Erick (HET1) provided more encouragement than Nancy (LET1) in both class sizes. Erick also provided more positive feedback in terms of both duration and frequency compared to Erin (HET2), and lower corrective feedback was given to the students by Erick. Erick praised and encouraged students more often than Nancy. In terms of available time for providing feedback, Erick had 17 minutes, 13 seconds in the small class and 15 minutes, 44 seconds in the large class. Nancy had 15 minutes and 41 seconds in the small class size and 11 minutes, 06 seconds in the large class. Accordingly, Erick (HET1) had more time for student activity and to provide feedback in general.

4. Specific and general observation 
As illustrated in Table 4.21, the duration of general observation Erick (HET1) provided was shorter than that of specific observation in the large class. The duration of general observation was longer than that of specific observation in the small class. Nancy had totally opposite results. The duration of general observation by Nancy was longer than that of specific observation in the large class. However, the duration of general observation was shorter than that of specific observation in the small class. It was found that Erick put more efforts into the large class size to interact with the students and provide feedback.

5. Academic Learning Time - physical education (ALT-PE)

Academic learning time was defined as a portion of class where students are involved with materials that are appropriate to their abilities (Parker, 1989). According to the WVUTES definition of motor appropriate, a student's motor appropriate time is considered ALT-PE for this study. As illustrated in (Table 4.22), the duration of the motor appropriate time by Erick (HET1) was $27.957 \%$ in the large class and $45.754 \%$ in the small class. The duration of the motor appropriate time by Nancy (LET1) was $16.484 \%$ in the large class and $27.958 \%$ in the smaller class. Erick managed and maintained a productive learning environment by providing for a higher degree of the student's time spent in motor appropriate behaviors.

FSA revealed Nancy (LET1) and Erick (HET1) gave individual feedback more often in smaller classes compared to lessons with the larger class size. Meanwhile, Erick provided more individual feedback in larger classes than Nancy did; however, she provided individual feedback more often in smaller classes as compared to Erick (Table 4.18). Nancy (LET1) took advantage of classes with fewer students by elevating individual feedback directed at decreasing off task student behaviors (Table 4.19). Furthermore, individual feedback was important for facilitating student engagement and enhancing student physical activity time (Table 4.22). 


\section{CHAPTER 5:}

\section{DISCUSSION AND CONCLUSIONS}

\section{Discussion}

The purpose of this chapter is to discuss the results and findings of this research investigation by describing the decision-making processes employed by two highly experienced teachers (HETs) and two less experienced novice teachers (LETs) as they planned, taught, and evaluated lessons presented to classes of different size, and by examining the teachers' concerns in terms of class size and the teacher-student behaviors in the two different class sizes.

Teaching characteristics provided different opportunities for students to interact with each other in class. In this study, it was found that teachers decided to utilize the same instructional format strategies based not only on their experience but also on the teaching conditions, including class size. Erick Sam (HET1) used a station teaching strategy utilizing three groups for the large class size, but Erin Hong (HET2) used a more general, direct instruction style (cohort teaching) for the entire group. For the small class size, both highly experienced teachers used the same style (cohort teaching), using the entire group and gymnasium. On the contrary, Nancy Young (LET1) used the station teaching strategy for both class sizes but Nathan Smith (LET2) used the general direct instruction with the entire group for both class sizes.

Erin mentioned in the first planning process that planning could be changed and modified based on the student behavior and gymnasium situations, which support the position of Housner and Griffey (1985) who posit teachers, monitor the student behavior during the instruction and then modify their plan during instruction. It is concluded that the highly experienced teacher has tried to incorporate a student-centered teaching style rather than strictly 
keeping the plan developed by the teacher prior to teaching. Teaching is a complex behavior in which the teacher should think of various situations and conditions during the planning process, as Peterson et al. (1978) described, such as a process of selecting educational objectives, diagnosing learner characteristics, and choosing instructional strategy for student achievement.

As Jones, Housner, and Kornspan (1995) found, one of the concerns of the highly experienced teachers, was "waiting time and off task" in order to minimize those activities to facilitate motor skill acquisition. Conversely, the less experienced student teachers never indicated those student behavior concerns during the planning process.

During the planning process, both HETs and LETs specifically determined the instructional process that was going to be utilized such as cohort teaching and station teaching. It is assumed that the instructional process is a priority for all teachers in the planning process as Jones, Housner, and Kornspan, (1995) found that experts concentrated on instructional process (28\%), evaluation (19\%), and objectives (13\%), and novices focused on instructional process (27\%), activity (17\%), and evaluation (16\%) in planning decision making.

Graham, Hopple, Manross, and Sitzman (1993) found that novice teachers stopped the lesson more frequently to present an extension, refinement, or application when compared to experienced teachers. This finding is somewhat contradictory in that both HETs and LETs stopped several times in the middle of the lesson to provide extensions and game applications during the lesson for the smaller class. However, in the current study, Erin (HET2) stopped the lesson more frequently in order to provide feedback in the middle of the students' activity session for the large class size. Thus, it is concluded that Erick (HET1) who used cohort teaching would have to stop more frequently in the middle of the lesson than the station teaching lesson by Erin. 
Hawkins and Sharpe (1992) found that experienced teachers encouraged students during the lesson and the proportion of positive feedback by the experienced teachers was higher than negative feedback compared to novice teachers. These findings were very similar to the results of the current study (Table 4.20).

Erick (HET1) used more encouragement in both size classes compared to Nancy (LET1). Erick also provided positive feedback more frequently and over a longer duration in both class sizes compared to corrective feedback that Nancy provided.

Additionally, individual feedback occurred more often followed by specific observation from Erick rather than Nancy in both class sizes (HET1: large 74 and small 87; LET1: large 37 and small 31). Higher rates of specific observation occurred in small classes related to a higher individual feedback rates (small; 3.220/min. and large; 1.538/min.).

Hawkins and Sharpe (1992) found that an expert's general observation time was shorter in duration than the novice's. These findings were similar to the current study but somewhat different depending on the size of the class. For larger classes, the percentage of general observation by Erick (13.17\%) was lower than that of general observation by Nancy (19.75\%). Erick had a higher level of specific observation (24.95\%) in the large class, compared to (8.11\%) for Nancy. On the contrary, Erick’s small class lesson had a higher percentage of general observation (21.81\%) than Nancy’s lesson (10.22\%). However, specific observation time in small class lessons taught by highly experienced teachers (18.03\%) was lower than less experienced novice teachers (28.45\%).

Hawkins and Sharpe (1992) indicated that the expert focused more on instruction tasks and the novice concentrated more on class management. This study supports that notion in that Erick focused more on instructional tasks (41\%) compared to managerial tasks (15\%) for the 
large class, while the opposite was true for Nancy (managerial: 26\% vs. instructional: 18\%)

(Table 5.1). However, in smaller classes the results were reversed experienced teachers has more management and novice teachers had more instruction.

In Carson’s 1994 descriptive study she expressed the merits of smaller class size, for both HETs and LETs and specified advantages of smaller class sizes from this study in that teachers were able to provide individual feedback, deal with better management and safety, and increase students' activity time. In contrast, the disadvantages of the large class size expressed by the HETs and LETs were longer waiting time and off task, less activity time, more stressful work, less successful teaching, and less space in the gymnasium.

These shortcomings with large size classes can influence teacher morale. Biddle and Berliner (2002) found that teacher's with higher morale in a small class settings were able to provide a better environment for student learning. A less stressful atmosphere with a smaller number of students was considered the most important aspect positively affecting teacher morale. All teachers that participated in this study mentioned that the large class size was more stressful because they had to raise their voice and spend more time on management. Therefore, teacher morale could be a significant factor influencing the amount of feedback given, enhancing student activity time, and decreasing management time, off task, and waiting time.

This current study also found negative effects of large class size through stimulated-recall interviews for both HETs and LETs. Nathan (LET2) mentioned during the interview that he could not see all of the students and had to increase the volume of his voice due to the large number of students in the class. Nathan also indicated that the large class size was more chaotic than the small class that he taught. Another difficulty for Nathan was the problem of students being off task during the lesson. 
Nancy (LET1) talked about the difficulty of “one-on-one interactions” with her students in the large class size, resulting in a lower percentage and rate of individual feedback in the large class size (2.611\% / 1.538 per min.) compared to the small class size (5.766\% / 3.22 per min.). She also had to focus more on managing the learning environment rather than students' skill performance due to the large number of students. Erin (HET2) mentioned that she could not provide feedback for everyone in the large class; however, providing feedback was much easier in the small class due to her ability to interact with everyone.

Erick (HET1) talked about how he was able to implement much smoother transitions in the small class compared to the large class. That supports FSA results noting that transition time in large classes (7.20\%) was higher than that in the small class (5.79\%).

Safety was a significant factor mentioned by all four teachers in this study for both class sizes, especially because of the subject matter, which was the sport of floor hockey. Hastie, Sanders, and Rowland (1999) found that in unsafe teaching settings, an instructor should teach the students to stay in their own space and move around in general space in order not to bump into each other at the beginning of the year. Kerst-Davis (1994) argued that large classes made it unsafe to teach active sports in physical education. These findings supported the results of the current investigation, which found that safety was a problematic issue because it prevented successful teaching and forced the teacher to focus more on instructional tasks rather than students' performance. It is assumed that managing safety issues interfered with student skill performance activities. Concerns about safety also could lead to potential discipline problems due to the increased off task and waiting time as the class size increases.

Theeboom, De Knop, and Bollaert (1995) mentioned that one of the most important motivations of sport participation is enjoyment. This study found that not only do the pupils 
enjoy physical activities and sport, but teachers also enjoy the lesson while they are teaching. Both HETs in the current study used music while they taught and mentioned that they enjoyed the lessons with the pupils. Erick (HET1) explained further that music was effective in encouraging the students to be active and enjoy physical activities in physical education. Actually, one of the students in Erick's large class asked a couple of times, "Why didn’t you turn on the music?” and he responded, "I forgot to turn it on. I will turn it on, just for you.” It seems that both the teacher and students enjoy music during instructions.

Educators believed that the number of students in a class influenced student learning (Wasley, 2002). Supporting this study results that more student activity occurred in smaller classes compared to larger class sizes from both Erick’s (45.75\%; 27.95\%) and Nancy's lessons (27.95\%; 16.48\%). In addition, Nathan mentioned during the stimulated-recall process that students in smaller classes were able to receive more practice than students in the larger class. Erick insisted that the students in the small class accomplished performance skills better than students in the larger class. Nancy also mentioned that it was hard to have a successful lesson with a larger class. Successful teaching could be correlated with student activity time during physical education lessons. The results support the findings of a Biddle and Berliner (2002) who found that achievements were greater when the classes had fewer than 20 students and Achilles et al. (2002) study that found students who were in smaller classes were able to achieve a higher of skill performance levels than those who participated in larger classes.

The findings of the current study support Posnick-Goodin (CTA, 2003) study which found a difference between the class sizes in terms of managing student misbehavior in a lesson. As the results showed, transition and grouping time was less in smaller classes than in the large class taught by Erick (transition time; 5.79\% vs. $7.20 \%$ and grouping time; $1.79 \%$ vs. 2.96\%) 
and Nancy (transition; $2.60 \%$ vs. $7.75 \%$ and $1.75 \%$ vs. $1.44 \%$ ). These findings are also congruent with Hastie and Saunders (1991) study about class size and equipment availability, which found significantly less transition time occurred as class size decreased. More transition time was spent in larger classes because teachers experienced greater difficulty organizing the large numbers of students. Students in smaller classes were also less disruptive during transition and grouping times in this study, resulting more student activity time and a better quality of feedback from teachers. McKenzie, Marshall, Sallis, and Conway (2000) found that large classes interfere with physical activity and limits the accomplishment of important physical education objectives such as health, fitness, and skill acquisition.

Hastie, Sanders, and Rowland (1999) investigated the effects of class size with three female elementary physical education teachers and found through their lessons that approximately $47.3 \%$ of time was devoted to activity, $25.7 \%$ to instruction, $18.6 \%$ to management, and $8.4 \%$ to waiting, levels that were thought to represent a high-quality instruction in terms of the duration of each category. The findings of the current research indicated that small class lessons were evaluated as a high quality instruction compared to the large class lessons in terms durations (Table 5.2).

As Graham (1987), Graham and Heimerer (1981), and Placek and Locke (1986) described, effective teachers motivate and encourage students to be physically active with the highest amount of praise and feedback possible in a class when compared to less effective teachers. Experienced teachers showed more warmth and cared more about students by encouraged and motivated students more during lessons. According to the interrelationship between activity time and feedback, students with exposure to more positive feedback devoted more time to activity. Most students were encouraged and motivated by teaching that includes 
ample amounts of positive feedback. Positive feedback was effective in enhancing the performance of the students' activity tasks in physical education.

Positive feedback also achieved similar favorable results in a study by Tjeerdsma (1997), which found that feedback improved student performance as well as motivated and encouraged the students, positively reinforced correct performance, and increased student effort in performing the task. Feedback was essential and beneficial to motivate and encourage students in fostering skill achievement.

Ryan and Yerg (2001) have also investigated the effects of feedback on off-task behavior and found that the occurrence of feedback was related to decreasing the off-task behavior of students. These findings are also congruent with the results of this study (Table 5.2). These results support the notion that teachers who give more attention to students can help reduce off-task student behavior and increase the on-task student behavior. Graham and Heimerer (1981) described the ability to keep students on-task as an essential behavior for effective teaching which is also supported by the results of this study.

Van der Mars, Vogler, Darst, and Cusimano (1998) found that teachers’ active supervision patterns, which include positioning, movement, feedback, and demonstration, correlated with the student physical activity level. Erick, one of the experienced teachers, was very active and enthusiastic in both of his lessons in observing the students. According to the results, he was fairy effective in terms of feedback through general observation and specific observation during his large class lesson. He also provided continually provided verbal prompts to encourage students during their lessons. 


\section{Conclusions}

Physical education is a subject matter that can provide enjoyment, health-related physical activity, and positive social interactions with teachers as well as pupils in the gymnasium. Many researches stress the importance of regular physical activity to decrease obesity and sedentary behaviors (Sallis \& McKenzie, 1991; NASPE, 2004; USHHS, 2000). Health-related physical activity may help delay the effects or prevent many conditions and causes of death that occur as a result of hypokinetic diseases (USDHHS, 2000). There are many variables that detract from health-related behaviors and regular physical activity in physical education such as large class size, lack of equipment, limited budgets, and misunderstanding of physical education. A lack of understanding of physical education causes barriers in terms of administrative support, resources, time, and physical education specialists. It is important to examine exactly why this happens in order to develop effective physical education program as well as support physical education teacher education (PETE) program for the future physical education program. In this study, the focus was on teacher experience and class size as it relates to ability to provide effective physical education instruction.

The findings of this research investigation reveal that the number of students in a class was associated with decisions teachers made during the planning process in terms of teaching content and organizational formation. Teachers chose different content and formations in order to get valuable and effective student behaviors enhancing the quality of student performance in classes of different size. Teaching experience was an important aspect for determining the contents and formation or teaching styles necessary to have a productive teaching environment based on a teacher's class size. In this study, all teachers believed that they had plenty of time to implement more content in their small class lesson resulting in additional game(s) for their 
lessons with the smaller class. However, Nancy Young (LET1) could not finish her planned game in the small class even if the student population was smaller whereas Erick Sam (HET1) did. Nathan Smith (LET2) ended up with more time to practice games in the smaller class compared to his larger class. Erin Hong (HET2) could not implement her lesson as she planned due to the school curriculum. Erick Sam used two different teaching formations in the two different class sizes, station teaching for large class and cohort teaching for small class. The rest of teachers utilized the same teaching formations for both classes either station or cohort teaching formation. As a result of determination of teaching styles, it was found that feedback was provided more efficiently in the station teaching than in the cohort teaching by Erick. Another conclusion was that station teaching appears to be effective for concentrating on instructional tasks and reducing managerial tasks with the large class size. It was also found that station teaching was useful to prevent off task student behavior during the lesson.

Both highly experienced teachers used music that was effective at increasing the degree of student physical activity and enjoyment. Both experienced teachers were trained to use a Sports, Play, and Active Recreation for Kids (SPARK) teaching style and the less experienced teachers were trained in the SPARK method at their PETE program. However, only the HETs used the music, which was a part of SPARK program. The LETs should have the ability to apply the concepts that have been taught and trained into practice like the HETs were able to do.

Another concern that was mentioned during the think-aloud process was safety for students. Only female teachers, Nancy (LET1) and Erin (HET2), conveyed this concern of safety during the think aloud planning procedure. Regarding teaching and learning behaviors by WVUTES, the less experienced teachers (LETs) have been benefited the small number of population in their small class size. A high degree of frequency and duration for effective 
teaching behaviors such as specific observation, encouragement, positive feedback, corrective feedback, verbal instruction, modeling, and physical guidance as well as a few students' learning behaviors such as motor appropriate activity and cognitive was demonstrated by LETs in the small class compared to the large class. Small class size was apparently one beneficial factor for LETs. On the other hand, the results showed that highly experienced teachers (HETs) demonstrate a similar amount of duration and frequency in the effective teaching behaviors within both size classes. However, highly experienced teachers spent more in specific observation during large classes, and provided more verbal instruction in smaller classes.

FSA results showed that both Nancy (LET1) and Erick (HET1) provided individual feedback more often in small classes compared to the large class size. Erick also provided individual feedback more often in the large size class rather than Nancy, whereas Nancy provided individual feedback more frequently in the smaller class compared to Erick (Table 4.18). Nancy took advantage of the small number of students to increase her frequency of individual feedback. This study also found that individual feedback related to decreasing the student's off task in Nancy's lessons (Table 4.19). Providing individual feedback was a critical cue in facilitating student engagement and enhancing student physical activity time (Table 4.22).

This study found several implications for the less experienced physical educators and PETE programs. First, PETE students should be able to obtain a variety of instructional skills in physical education and the skills should enhance their ability to better execute instruction in real settings. They can plan and develop valuable and effective teaching based on conditions that they are exposed to. Second, less experienced teachers benefit from their small class lessons. On the contrary, the large class was a harmful aspect for novice teachers executing effective instructional behaviors. Effort and experience are necessary components for becoming an 
effective teacher. Class size does make a difference in teaching and learning behaviors; however, a teacher's enthusiasm makes a much greater impact on students. If teachers put forth a great effort to deal with difficult situations expending creativity by creating more stations or incorporating more students, class size becomes less of a challenge in teaching physical education. Third, once you compare teaching behaviors and student learning behaviors, you recognize situations that can be improved and are better able to solve problems students may have with skill development. If teachers demonstrate effective teaching behaviors and witness student learning occur, they can become more efficient and effective at teaching physical education. This is a good rationale for a better understanding of teaching and learning behaviors and their importance for becoming an effective teacher.

\section{Recommendations for Future Research}

Based on the results of this study, the researcher suggests the following recommendations for future research. This study examined lessons that were taught only within the context of one sport (field hockey), future research is necessary to investigate the impact of class size within different sport contexts, including both team sports (e.g., basketball, soccer) and individual sports (e.g., gymnastics, wrestling). Determining the impact class size has on the instruction of a particular team or individual sports may also be helpful for directing student skill development and ensuring students are placed in an environment conducive for learning that type of skill or team strategy. Future research should:

- Seek to replicate these findings within other student populations (e.g., middle school, high school, and college level). The research with different populations will allow for greater generalization across populations. 
- Examine student achievement in different class sizes including interactions between teaching and learning behaviors, and student achievement.

- Physical activity levels should be examined to understand the relationship between class size and moderate to vigorous physical activity level of students. 


\section{Tables and Figures}

Figure 3.1 The first lesson diagram

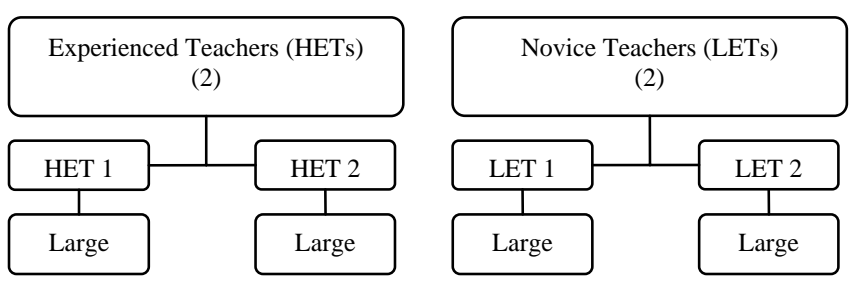

Figure 3.2 The second lesson diagram

\begin{tabular}{|c|c|c|c|}
\hline \multicolumn{2}{|c|}{$\begin{array}{l}\text { Experienced Teachers (HETs) } \\
\text { (2) }\end{array}$} & \multicolumn{2}{|c|}{$\begin{array}{l}\text { Novice Teachers (LETs) } \\
\text { (2) }\end{array}$} \\
\hline HET 1 & HET 2 & LET 1 & LET 2 \\
\hline 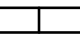 & \begin{tabular}{l|l} 
& \\
\end{tabular} & \begin{tabular}{l|l} 
& \\
\end{tabular} & \begin{tabular}{l|l} 
& \\
\end{tabular} \\
\hline Small & Small & Small & Small \\
\hline
\end{tabular}


Table 4.1: WVUTES (Teacher Behaviors \% \& \#/min.)

G.O. Enc. P.FB $\quad$ C.FB $\quad$ Mgmt $\quad$ V.I. $\quad$ Model. Phy.Gui N.Tsk.V Off.Ts. S.O.

\begin{tabular}{|c|c|c|c|c|c|c|c|c|c|c|c|c|}
\hline \multirow[t]{2}{*}{ LET1 } & LG & 10.9 & $0.3 / 0.2$ & $2.8 / 1.4$ & $5.3 / 1$ & 27 & 32.7 & 6.1 & 0 & 0 & 0 & 15 \\
\hline & SM & 7.6 & $1.5 / 1.3$ & $3.2 / 2.5$ & $4.4 / 1.8$ & 29.3 & 14.2 & 6.6 & 0.7 & 0 & 0 & 32.5 \\
\hline \multirow[t]{2}{*}{ LET2 } & LG & 23.3 & $0.2 / 0.2$ & $2.8 / 1.7$ & $0.7 / 0.4$ & 31.8 & 17.8 & 2.3 & 2.7 & 0.2 & 0 & 18.8 \\
\hline & SM & 15.7 & $0.9 / 0.7$ & 4.3/2.3 & $2.7 / 1.2$ & 11.0 & 25.1 & 11.0 & 0 & 0 & 0 & 29.2 \\
\hline \multirow[t]{2}{*}{ HET1 } & LG & 8.1 & $5.0 / 2.0$ & $2.6 / 1.8$ & $3.2 / 1.3$ & 26.8 & 20 & 1 & 0 & 0.3 & 3.2 & 30 \\
\hline & SM & 21.8 & $2.9 / 2.2$ & 2.0/1.1 & $2.2 / 1.1$ & 14.2 & 31.7 & 5.3 & 0.3 & 0.3 & 0 & 19.3 \\
\hline \multirow[t]{2}{*}{ HET2 } & LG & 27.4 & $0.4 / 0.3$ & $2.0 / 0.7$ & $2.1 / 1.1$ & 26.8 & 26.1 & 6.3 & 0.3 & 0.3 & 0 & 8.4 \\
\hline & SM & 19.5 & $1.4 / 0.6$ & $3.6 / 1.7$ & $1.9 / 1.0$ & 13.7 & 44.4 & 3.7 & 0.7 & 0 & 0 & 11.1 \\
\hline
\end{tabular}

Table 4.2: WVUTES (Student Behaviors \%)

Mo. Appr. Mo. Inapr Mo.Sup. Cog. $\quad$ O. Tskma. Off.Tsk. Interim Waiting

\begin{tabular}{llllllllll} 
LET1 & LG & 14.9 & 0.2 & 0 & 40.2 & 22.3 & 6.4 & 7.3 & 8.8 \\
& SM & 25.0 & 0.1 & 0 & 35.6 & 20.0 & 2.9 & 6.0 & 10.4 \\
\cline { 2 - 10 } LET2 & LG & 14.0 & 0.1 & 0.2 & 32.1 & 6.0 & 2.1 & 4.6 & 41.0 \\
& SM & 27.2 & 0.3 & 0.5 & 17.4 & 5.1 & 1.5 & 6.1 & 41.9 \\
HET1 & LG & 22.6 & 0.2 & 0.5 & 20.2 & 18.8 & 0 & 17.8 & 20.0 \\
& SM & 42.6 & 0.1 & 0 & 37.9 & 2.8 & 3.8 & 6.9 & 6.0 \\
\hline HET2 & LG & 21.5 & 0.2 & 0 & 56.1 & 8.1 & 2.1 & 1.1 & 11.0 \\
& SM & 23.7 & 0.2 & 0 & 64.4 & 0 & 2.6 & 4.1 & 5.1
\end{tabular}


Table 4.3: Comparison of teacher behaviors between LETs vs. HETs and Class sizes (WVUTES)

\begin{tabular}{|c|c|c|c|c|c|c|c|c|c|c|c|c|}
\hline & & G.O. & Enc. & P.FB & C.FB & Mgmt & V.I. & Model. & Phy.Gui. & N.Tsk.V. & Off.Ts. & S.O. \\
\hline \multirow[t]{2}{*}{ LETs } & LG & $17.1 \%$ & $0.2 / \mathrm{m}$. & $1.6 / \mathrm{m}$. & $0.7 / \mathrm{m}$. & $29.4 \%$ & $25.3 \%$ & $4.2 \%$ & $1.4 \%$ & $0.1 \%$ & $0 \%$ & $16.9 \%$ \\
\hline & SM & $11.7 \%$ & $1 / \mathrm{m}$ & $2.3 / \mathrm{m}$. & $1.5 / \mathrm{m}$. & $20.2 \%$ & $19.7 \%$ & $8.8 \%$ & $0.3 \%$ & $0 \%$ & $0 \%$ & $30.9 \%$ \\
\hline \multirow[t]{2}{*}{ HETs } & LG & $17.8 \%$ & $1.2 / \mathrm{m}$. & $1.3 / \mathrm{m}$. & $1.2 / \mathrm{m}$. & $26.8 \%$ & $23.1 \%$ & $3.7 \%$ & $0.1 \%$ & $0.3 \%$ & $1.6 \%$ & $19.2 \%$ \\
\hline & SM & $20.7 \%$ & $1.4 / \mathrm{m}$. & $1.4 / \mathrm{m}$. & $1.1 / \mathrm{m}$. & $14 \%$ & $38.1 \%$ & $4.5 \%$ & $0.5 \%$ & $0.1 \%$ & $0 \%$ & $15.2 \%$ \\
\hline
\end{tabular}

Table 4.4: Comparison of student behaviors between LETs and HETs and Class sizes (WVUTES)

Mo. Appr. Mo. Inapr Mo. Sup. Cog. $\quad$ O. Tskma. Off.Tsk. Interim Waiting

\begin{tabular}{llllllllll}
\multirow{2}{*}{ LETs } & LG & $14.5 \%$ & $0.2 \%$ & $0.1 \%$ & $36.2 \%$ & $14.2 \%$ & $4.3 \%$ & $6 \%$ & $24.9 \%$ \\
& SM & $26.1 \%$ & $0.2 \%$ & $0.3 \%$ & $26.5 \%$ & $12.6 \%$ & $2.2 \%$ & $6.1 \%$ & $26.2 \%$ \\
\cline { 2 - 13 } HETs & LG & $22.1 \%$ & $0.2 \%$ & $0.3 \%$ & $38.2 \%$ & $13.5 \%$ & $1.1 \%$ & $9.5 \%$ & $15.5 \%$ \\
& SM & $33.2 \%$ & $0.2 \%$ & $0 \%$ & $51.2 \%$ & $1.4 \%$ & $3.2 \%$ & $5.5 \%$ & $5.6 \%$ \\
\hline
\end{tabular}


Table 4.5. Correlations between all lessons for percentages of Teacher and Student Behaviors

\begin{tabular}{|c|c|c|c|c|c|c|c|c|}
\hline & $\begin{array}{l}\text { HET1 } \\
\text { (LG) }\end{array}$ & $\begin{array}{l}\text { HET1 ( } \\
\text { SM) }\end{array}$ & $\begin{array}{l}\text { HET2 } \\
\text { (LG) }\end{array}$ & $\begin{array}{l}\text { HET2 } \\
\text { (SM) }\end{array}$ & $\begin{array}{l}\text { LET1 } \\
\text { (LG) }\end{array}$ & $\begin{array}{l}\text { LET1 } \\
\text { (SM) }\end{array}$ & $\begin{array}{l}\text { LET2 } \\
\text { (LG) }\end{array}$ & $\begin{array}{l}\text { LET2 } \\
\text { (SM) }\end{array}$ \\
\hline HET1 ( & 1 & $.656 * *$ & $.576 * *$ & $.506^{*}$ & $.745 * *$ & $.874^{* *}$ & $.739 * *$ & $.732 * *$ \\
\hline \multirow[t]{2}{*}{$\mathrm{LG)}$} & & .002 & .010 & .027 & .000 & .000 & .000 & .000 \\
\hline & & 19 & 19 & 19 & 19 & 19 & 19 & 19 \\
\hline HET1 & $.656^{* *}$ & 1 & $.835 * *$ & $.873 * *$ & $.757 * *$ & $.739 * *$ & $.591^{* *}$ & $.639 * *$ \\
\hline \multirow[t]{2}{*}{$(\mathrm{SM})$} & .002 & & .000 & .000 & .000 & .000 & .008 & .003 \\
\hline & 19 & & 19 & 19 & 19 & 19 & 19 & 19 \\
\hline HET2 & $.576^{* *}$ & $.835 * *$ & 1 & $.930 * *$ & $.880 * *$ & $.751 * *$ & $.750 * *$ & $.503 *$ \\
\hline \multirow[t]{2}{*}{ (LG) } & .010 & .000 & & .000 & .000 & .000 & .000 & .028 \\
\hline & 19 & 19 & & 19 & 19 & 19 & 19 & 19 \\
\hline HET2 & $.506^{*}$ & $.873 * *$ & $.930 * *$ & 1 & $.851^{* *}$ & $.662 * *$ & $.598 * *$ & $.480 *$ \\
\hline \multirow[t]{2}{*}{$(\mathrm{SM})$} & .027 & .000 & .000 & & .000 & .002 & .007 & .037 \\
\hline & 19 & 19 & 19 & & 19 & 19 & 19 & 19 \\
\hline LET1 & $.745^{* *}$ & $.757 * *$ & $.880 * *$ & $.851^{* *}$ & 1 & $.841^{* *}$ & $.686^{* *}$ & $.508 * *$ \\
\hline \multirow[t]{2}{*}{ (LG) } & .000 & .000 & .000 & .000 & & .000 & .001 & .026 \\
\hline & 19 & 19 & 19 & 19 & & 19 & 19 & 19 \\
\hline LET1 & $.874^{* *}$ & $.739 * *$ & $.751^{* *}$ & $.662 * *$ & $.841 * *$ & 1 & $.689 * *$ & $.597 * *$ \\
\hline \multirow[t]{2}{*}{$(\mathrm{SM})$} & .000 & .000 & .000 & .002 & .000 & & .001 & .007 \\
\hline & 19 & 19 & 19 & 19 & 19 & & 19 & 19 \\
\hline LET2 & $.739 * *$ & $.591 * *$ & $.750 * *$ & $.598 * *$ & $.686^{* *}$ & $.689 * *$ & 1 & $.809 * *$ \\
\hline \multirow[t]{2}{*}{ (LG) } & .000 & .008 & .000 & .007 & .001 & .001 & & .000 \\
\hline & 19 & 19 & 19 & 19 & 19 & 19 & & 19 \\
\hline LET2 & $.732 * *$ & $.639 * *$ & $.503 *$ & $.480 *$ & $.508 * *$ & $.597 * *$ & $.809 * *$ & 1 \\
\hline \multirow[t]{2}{*}{$(\mathrm{SM})$} & .000 & .003 & .028 & .037 & .026 & .007 & .000 & \\
\hline & 19 & 19 & 19 & 19 & 19 & 19 & 19 & \\
\hline
\end{tabular}


Table 4.6. HET1's teaching behavior description by FSA

Large class size

\begin{tabular}{lllllll}
\hline Key & Count & Mean & StdDev & Percentage & Rate & Duration \\
1 & 59 & 4.102 & 3.262 & 13.173 & 1.941 & 241.816 \\
2 & 59 & 0.762 & 0.527 & 2.422 & 1.941 & 44.453 \\
3 & 7 & 1.348 & 1.094 & 0.514 & 0.230 & 9.434 \\
4 & 2 & 0.703 & 0.156 & 0.078 & 0.066 & 1.426 \\
5 & 5 & 26.465 & 24.180 & 7.206 & 0.165 & 132.285 \\
6 & 26 & 12.598 & 20.332 & 17.846 & 0.855 & 327.598 \\
7 & 8 & 1.602 & 1.953 & 0.694 & 0.263 & 12.734 \\
8 & 3 & 2.090 & 2.227 & 0.342 & 0.099 & 6.270 \\
9 & 3 & 12.480 & 21.270 & 2.040 & 0.099 & 37.441 \\
0 & 1 & 113.203 & 0.645 & 6.167 & 0.033 & 113.203 \\
A & 162 & 2.832 & 2.363 & 24.957 & 5.330 & 458.125 \\
E & 28 & 1.016 & 0.762 & 1.545 & 0.921 & 28.359 \\
H & 3 & 2.598 & 2.148 & 0.425 & 0.099 & 7.793 \\
M & 11 & 4.902 & 5.313 & 2.932 & 0.362 & 53.828 \\
P & 2 & 85.645 & 6.094 & 9.331 & 0.066 & 171.289 \\
R & 2 & 27.227 & 37.891 & 2.966 & 0.066 & 54.453 \\
W & 56 & 0.703 & 0.391 & 2.130 & 1.843 & 39.102 \\
Y & 24 & 3.848 & 3.828 & 5.038 & 0.790 & 92.480 \\
Z & 1 & 3.594 & 0.273 & 0.196 & 0.033 & 3.594 \\
\hline
\end{tabular}

1 General observation

2 Encouragment

3 Positive feedback (general)

4 Corrective feedback (general)

5 Transition

6 Verbal instruction (general)

7 Modeling

8 Non-task verbal

9 Off-task

0 Review
A Specific observation

E Corrective feedback (indivudal)

$\mathrm{H}$ Help

M Management

$\mathrm{P} \quad$ Warming up

R Grouping

W Positive feedback

Y Student demonstration with V.I.

$\mathrm{Z}$ Attention 
Table 4.7. HET1's teaching behavior description by FSA

Small Class size

\begin{tabular}{lllllll}
\hline Key & Count & Mean & StdDev & Percentage & Rate & Duration \\
1 & 106 & 4.121 & 3.438 & 21.811 & 3.167 & 437.129 \\
2 & 60 & 0.977 & 1.035 & 2.903 & 1.793 & 58.184 \\
3 & 4 & 0.820 & 0.430 & 0.163 & 0.120 & 3.262 \\
5 & 10 & 11.621 & 10.078 & 5.797 & 0.299 & 116.172 \\
6 & 49 & 10.313 & 13.516 & 25.206 & 1.464 & 505.156 \\
7 & 20 & 8.828 & 6.387 & 8.805 & 0.598 & 176.465 \\
8 & 2 & 1.484 & 0.996 & 0.148 & 0.060 & 2.969 \\
0 & 1 & 64.395 & 0.137 & 3.213 & 0.030 & 64.395 \\
$\mathrm{~A}$ & 137 & 2.637 & 2.715 & 18.037 & 4.093 & 361.484 \\
$\mathrm{E}$ & 40 & 1.055 & 0.840 & 2.102 & 1.195 & 42.129 \\
$\mathrm{H}$ & 6 & 1.914 & 1.387 & 0.575 & 0.179 & 11.523 \\
$\mathrm{M}$ & 1 & 0.938 & 0.156 & 0.047 & 0.030 & 0.938 \\
$\mathrm{P}$ & 1 & 130.020 & 0.059 & 6.488 & 0.030 & 130.020 \\
$\mathrm{R}$ & 3 & 11.992 & 10.098 & 1.794 & 0.090 & 35.957 \\
$\mathrm{~V}$ & 2 & 5.078 & 2.305 & 0.506 & 0.060 & 10.137 \\
$\mathrm{~W}$ & 53 & 0.898 & 0.801 & 2.355 & 1.583 & 47.188 \\
$\mathrm{Y}$ & 1 & 0.195 & 0.117 & 0.010 & 0.030 & 0.195 \\
$\mathrm{Z}$ & 1 & 0.840 & 0.059 & 0.042 & 0.030 & 0.840 \\
\hline & & & & & &
\end{tabular}

1 General observation

2 Encouragment

3 Positive feedback (general)

4 Corrective feedback (general)

5 Transition

$6 \quad$ Verbal instruction (general)

7 Modeling

8 Non-task verbal

9 Off-task

0 Review
A Specific observation

E Corrective feedback (indivudal)

$\mathrm{H}$ Help

M Management

$\mathrm{P} \quad$ Warming up

$\mathrm{R} \quad$ Grouping

W Positive feedback

Y Student demonstration with V.I.

$\mathrm{Z}$ Attention 
Table 4.8. Student behavior description in HET1's lesson by FSA

Large class size

\begin{tabular}{lllllll}
\hline Key & Count & Mean & StdDev & Percentage & Rate & Duration \\
1 & 25 & 20.234 & 18.984 & 27.957 & 0.825 & 505.664 \\
2 & 18 & 29.551 & 54.902 & 29.400 & 0.594 & 531.758 \\
3 & 3 & 2.109 & 2.559 & 0.351 & 0.099 & 6.348 \\
4 & 13 & 21.289 & 21.133 & 15.302 & 0.429 & 276.758 \\
5 & 13 & 12.813 & 10.957 & 9.210 & 0.429 & 166.582 \\
6 & 15 & 7.461 & 5.547 & 6.190 & 0.495 & 111.953 \\
7 & 1 & 4.180 & 0.332 & 0.231 & 0.033 & 4.180 \\
8 & 13 & 3.223 & 4.180 & 2.320 & 0.429 & 41.953 \\
9 & 2 & 81.758 & 114.414 & 9.039 & 0.066 & 163.496 \\
\hline
\end{tabular}

$\begin{array}{ll}1 & \text { Activity } \\ 2 & \text { Cognitive } \\ 3 & \text { Supporting } \\ 4 & \text { Waiting } \\ 5 & \text { Management } \\ 6 & \text { Interim } \\ 7 & \text { Non-task verbal } \\ 8 & \text { Off task } \\ 9 & \text { Warming up }\end{array}$


Table 4.9. Student behavior description in HET1's lesson

Small class size

\begin{tabular}{lllllll}
\hline Key & Count & Mean & StdDev & Percentage & Rate & Duration \\
1 & 22 & 41.719 & 45.938 & 45.754 & 0.658 & 917.949 \\
2 & 20 & 31.445 & 48.340 & 31.350 & 0.598 & 628.965 \\
3 & 2 & 0.879 & 0.996 & 0.088 & 0.060 & 1.758 \\
4 & 13 & 6.836 & 6.094 & 4.427 & 0.389 & 88.828 \\
5 & 12 & 11.309 & 11.641 & 6.763 & 0.359 & 135.684 \\
6 & 6 & 6.328 & 5.020 & 1.895 & 0.180 & 38.027 \\
8 & 11 & 5.859 & 5.898 & 3.217 & 0.329 & 64.551 \\
9 & 4 & 32.637 & 59.414 & 6.506 & 0.120 & 130.527 \\
\hline
\end{tabular}

1 Activity

2 Cognitive

3 Supporting

4 Waiting

5 Management

6 Interim

7 Non-task verbal

8 Off task

$9 \quad$ Warming up 
Table 4.10. LET1's teaching behavior description

Large class size

\begin{tabular}{lllllll}
\hline Key & Count & Mean & StdDev & Percentage & Rate & Duration \\
& & & & & & \\
1 & 66 & 6.074 & 5.547 & 19.755 & 1.951 & 401.152 \\
2 & 13 & 0.898 & 0.664 & 0.580 & 0.384 & 11.777 \\
3 & 11 & 0.781 & 0.508 & 0.424 & 0.325 & 8.613 \\
4 & 10 & 0.938 & 0.371 & 0.464 & 0.296 & 9.414 \\
5 & 7 & 22.500 & 14.648 & 7.758 & 0.207 & 157.539 \\
6 & 42 & 11.641 & 11.895 & 24.089 & 1.242 & 489.160 \\
7 & 19 & 6.914 & 5.781 & 6.470 & 0.562 & 131.387 \\
0 & 1 & 154.551 & 0.332 & 7.611 & 0.030 & 154.551 \\
$\mathrm{~A}$ & 66 & 2.500 & 1.992 & 8.113 & 1.951 & 164.746 \\
$\mathrm{E}$ & 24 & 1.113 & 0.703 & 1.321 & 0.710 & 26.816 \\
$\mathrm{H}$ & 7 & 2.695 & 4.180 & 0.929 & 0.207 & 18.867 \\
$\mathrm{M}$ & 3 & 0.938 & 0.508 & 0.139 & 0.089 & 2.813 \\
$\mathrm{P}$ & 1 & 303.613 & 0.098 & 14.952 & 0.030 & 303.613 \\
$\mathrm{R}$ & 3 & 9.785 & 16.094 & 1.446 & 0.089 & 29.355 \\
$\mathrm{~V}$ & 3 & 2.031 & 1.328 & 0.300 & 0.089 & 6.094 \\
$\mathrm{~W}$ & 28 & 0.938 & 0.605 & 1.290 & 0.828 & 26.191 \\
$\mathrm{Y}$ & 15 & 4.863 & 7.559 & 3.588 & 0.444 & 72.852 \\
$\mathrm{Z}$ & 10 & 1.563 & 1.445 & 0.771 & 0.296 & 15.664 \\
\hline
\end{tabular}

1 General observation

2 Encouragment

3 Positive feedback (general)

4 Corrective feedback (general)

5 Transition

6 Verbal instruction (general)

7 Modeling

8 Non-task verbal

9 Off-task

0 Review
A Specific observation

E Corrective feedback (indivudal)

$\mathrm{H}$ Help

M Management

$\mathrm{P} \quad$ Warming up

R Grouping

W Positive feedback

Y Student demonstration with V.I.

$\mathrm{Z}$ Attention 
Table 4.11. LET1's teaching behavior description

Small class size

\begin{tabular}{lllllll}
\hline Key & Count & Mean & StdDev & Percentage & Rate & Duration \\
& & & & & & \\
1 & 53 & 3.457 & 3.047 & 10.223 & 1.778 & 183.145 \\
2 & 41 & 0.898 & 0.879 & 2.077 & 1.376 & 37.207 \\
3 & 4 & 0.859 & 0.313 & 0.193 & 0.134 & 3.457 \\
4 & 6 & 1.309 & 0.723 & 0.438 & 0.201 & 7.852 \\
5 & 6 & 7.773 & 5.449 & 2.600 & 0.201 & 46.582 \\
6 & 22 & 11.621 & 15.469 & 14.282 & 0.738 & 255.859 \\
7 & 18 & 7.188 & 10.332 & 7.223 & 0.604 & 129.395 \\
8 & 1 & 4.238 & 0.449 & 0.237 & 0.034 & 4.238 \\
0 & 1 & 59.570 & 0.098 & 3.325 & 0.034 & 59.570 \\
$\mathrm{~A}$ & 170 & 3.008 & 2.910 & 28.456 & 5.704 & 509.766 \\
$\mathrm{E}$ & 37 & 1.719 & 1.250 & 3.553 & 1.241 & 63.652 \\
$\mathrm{H}$ & 8 & 1.758 & 2.324 & 0.789 & 0.268 & 14.141 \\
$\mathrm{M}$ & 10 & 5.039 & 5.176 & 2.812 & 0.336 & 50.371 \\
$\mathrm{P}$ & 1 & 316.406 & 0.313 & 17.662 & 0.034 & 316.406 \\
$\mathrm{R}$ & 1 & 31.406 & 0.078 & 1.753 & 0.034 & 31.406 \\
$\mathrm{~V}$ & 8 & 4.707 & 5.195 & 2.099 & 0.268 & 37.598 \\
$\mathrm{~W}$ & 59 & 0.645 & 0.410 & 2.123 & 1.979 & 38.027 \\
$\mathrm{Z}$ & 2 & 1.367 & 1.211 & 0.154 & 0.067 & 2.754 \\
\hline
\end{tabular}

1 General observation

2 Encouragment

3 Positive feedback (general)

4 Corrective feedback (general)

5 Transition

6 Verbal instruction (general)

7 Modeling

8 Non-task verbal

9 Off-task

0 Review
A Specific observation

E Corrective feedback (indivudal)

$\mathrm{H}$ Help

M Management

$\mathrm{P} \quad$ Warming up

R Grouping

W Positive feedback

Y Student demonstration with V.I.

$\mathrm{Z}$ Attention 
Table 4.12. Student behavior description in LET1's lesson

Large class size

\begin{tabular}{lllllll}
\hline Key & Count & Mean & StdDev & Percentage & Rate & Duration \\
1 & 37 & 9.023 & 9.199 & 16.484 & 1.094 & 333.965 \\
2 & 35 & 24.102 & 26.230 & 41.635 & 1.035 & 843.555 \\
4 & 4 & 15.547 & 6.602 & 3.070 & 0.118 & 62.207 \\
5 & 8 & 24.102 & 21.777 & 9.520 & 0.237 & 192.871 \\
6 & 30 & 6.797 & 5.254 & 10.052 & 0.887 & 203.652 \\
7 & 2 & 1.230 & 0.469 & 0.121 & 0.059 & 2.461 \\
8 & 39 & 2.109 & 3.301 & 4.079 & 1.154 & 82.637 \\
9 & 1 & 304.707 & 0.254 & 15.039 & 0.030 & 304.707 \\
\hline
\end{tabular}

$\begin{array}{ll}1 & \text { Activity } \\ 2 & \text { Cognitive } \\ 3 & \text { Supporting } \\ 4 & \text { Waiting } \\ 5 & \text { Management } \\ 6 & \text { Interim } \\ 7 & \text { Non-task verbal } \\ 8 & \text { Off task } \\ 9 & \text { Warming up }\end{array}$


Table 4.13. Student behavior description in LET1's lesson

Small class size

\begin{tabular}{lllllll}
\hline Key & Count & Mean & StdDev & Percentage & Rate & Duration \\
1 & 39 & 12.813 & 12.051 & 27.958 & 1.309 & 499.395 \\
2 & 11 & 43.965 & 104.375 & 27.076 & 0.369 & 483.652 \\
3 & 3 & 1.406 & 1.055 & 0.235 & 0.101 & 4.199 \\
4 & 8 & 9.121 & 5.527 & 4.082 & 0.269 & 72.910 \\
5 & 6 & 30.703 & 15.430 & 10.310 & 0.201 & 184.160 \\
6 & 26 & 8.496 & 8.105 & 12.375 & 0.873 & 221.055 \\
7 & 2 & 1.680 & 0.586 & 0.189 & 0.067 & 3.379 \\
8 & 4 & 4.414 & 4.609 & 0.987 & 0.134 & 17.637 \\
9 & 1 & 299.863 & 0.293 & 16.787 & 0.034 & 299.863 \\
\hline
\end{tabular}

$\begin{array}{ll}1 & \text { Activity } \\ 2 & \text { Cognitive } \\ 3 & \text { Supporting } \\ 4 & \text { Waiting } \\ 5 & \text { Management } \\ 6 & \text { Interim } \\ 7 & \text { Non-task verbal } \\ 8 & \text { Off task } \\ 9 & \text { Warming up }\end{array}$


Table 4.14. HET1's managerial and instructional sequential chains

\section{Instructional}

\begin{tabular}{|c|c|c|c|c|c|c|c|c|c|}
\hline \multicolumn{5}{|c|}{ Large Class Size } & \multicolumn{5}{|c|}{ Small Class Size } \\
\hline $\begin{array}{l}\text { Sequential } \\
\text { Chains }\end{array}$ & Freq & Prob & Zscore & & $\begin{array}{l}\text { Sequential } \\
\text { Chains }\end{array}$ & Freq & Prob & Zscore & \\
\hline A- 2- A & 49 & 0.1068 & 9.478 & +++ & A-W-A & 39 & $\begin{array}{l}0.078 \\
9\end{array}$ & 8.643 & +++ \\
\hline A- W- A & 33 & 0.0719 & 6.860 & +++ & A- 2- A & 35 & $\begin{array}{l}0.070 \\
9\end{array}$ & 8.864 & +++ \\
\hline 2- A- 2 & 20 & 0.0436 & 5.735 & +++ & A- E- A & 16 & $\begin{array}{l}0.032 \\
4\end{array}$ & 5.499 & +++ \\
\hline A- E- A & 19 & 0.0414 & 5.292 & +++ & 6- 7- 6 & 14 & $\begin{array}{l}0.028 \\
3\end{array}$ & $\begin{array}{l}10.93 \\
4\end{array}$ & +++ \\
\hline 2- A- W & 14 & 0.0305 & 3.413 & +++ & W- A- W & 14 & $\begin{array}{l}0.028 \\
3\end{array}$ & 5.079 & +++ \\
\hline$Y-W-Y$ & 11 & 0.0240 & 14.120 & +++ & 2- A- 2 & 13 & $\begin{array}{l}0.026 \\
3\end{array}$ & 3.731 & +++ \\
\hline W- A- 2 & 9 & 0.0196 & 2.475 & ++ & W- A- 2 & 13 & $\begin{array}{l}0.026 \\
3\end{array}$ & 4.051 & ++ \\
\hline W- A- W & 8 & 0.0174 & 2.114 & ++ & 7-6- 7 & 12 & $\begin{array}{l}0.024 \\
3\end{array}$ & $\begin{array}{l}14.39 \\
9\end{array}$ & ++ \\
\hline A- 6- $A$ & 7 & 0.0153 & 2.667 & +++ & 2- A- W & 9 & $\begin{array}{l}0.018 \\
2\end{array}$ & 2.241 & +++ \\
\hline Y- E- Y & 5 & 0.0109 & 9.520 & +++ & E- A- 2 & 5 & $\begin{array}{l}0.010 \\
1\end{array}$ & 2.179 & +++ \\
\hline 7- 6- $\mathrm{Y}$ & 4 & 0.0087 & 7.511 & +++ & E- A- E & 5 & $\begin{array}{l}0.010 \\
1\end{array}$ & 3.222 & +++ \\
\hline W- Y- W & 4 & 0.0087 & 2.449 & ++ & E- A- W & 4 & $\begin{array}{l}0.008 \\
1\end{array}$ & 1.705 & + \\
\hline E- Y-W & 4 & 0.0087 & 4.632 & +++ & & & & & \\
\hline
\end{tabular}

(Note: A. Specific Observation, 2. Encouragement, W. Positive Feedback (individual), E. Corrective Feedback (individual), Y. Student demonstration with verbal instruction, 6. Verbal Instruction (general), 7. Modeling) 


\section{$\underline{\text { Managerial }}$}

\begin{tabular}{|c|c|c|c|c|c|c|c|c|c|}
\hline \multicolumn{5}{|c|}{ Large Class Size } & \multicolumn{5}{|c|}{ Small Class Size } \\
\hline $\begin{array}{l}\text { Sequential } \\
\text { Chains }\end{array}$ & Freq & Prob & Zscore & & $\begin{array}{l}\text { Sequential } \\
\text { Chains }\end{array}$ & Freq & Prob & Zscore & \\
\hline A- 1- A & 15 & 0.0327 & 2.203 & +++ & $1-6-1$ & 22 & 0.0445 & 8.668 & +++ \\
\hline W- A- 1 & 8 & 0.0174 & 1.955 & + & 1- E- 1 & 17 & 0.0344 & 6.922 & +++ \\
\hline 1- A- E & 8 & 0.0174 & 4.834 & +++ & $1-A-W$ & 15 & 0.0304 & 7.526 & +++ \\
\hline $1-\mathrm{W}-1$ & 7 & 0.0153 & 6.308 & +++ & 6- $1-6$ & 13 & 0.0263 & 6.559 & +++ \\
\hline $1-A-W$ & 7 & 0.0153 & 1.964 & ++ & $1-2-1$ & 11 & 0.0223 & 5.547 & +++ \\
\hline 1- $2-1$ & 7 & 0.0153 & 6.889 & +++ & $1-W-1$ & 7 & 0.0142 & 5.062 & +++ \\
\hline A- M- A & 6 & 0.0131 & 3.317 & +++ & E- 1- 2 & 6 & 0.0121 & 2.752 & +++ \\
\hline M- A- 2 & 5 & 0.0109 & 4.630 & +++ & E-1- E & 5 & 0.0101 & 3.061 & +++ \\
\hline W- $1-\mathrm{W}$ & 4 & 0.0087 & 2.956 & +++ & 1- 5- 6 & 4 & 0.0081 & 4.710 & +++ \\
\hline
\end{tabular}

(Note: A. Specific Observation, 1. General Observation, W. Positive Feedback (individual), 2. Encouragement, M. Management, W. Positive Feedback (individual), 6. Verbal Instruction (general), E. Corrective Feedback (individual), 5. Transition) 
Table 4.15 LET1's managerial and instructional sequential chains

\section{Instructional}

\begin{tabular}{|c|c|c|c|c|c|c|c|c|c|}
\hline \multicolumn{5}{|c|}{ Large Class Size } & \multicolumn{5}{|c|}{ Small Class Size } \\
\hline $\begin{array}{l}\text { Sequential } \\
\text { Chains }\end{array}$ & \multirow{2}{*}{$\begin{array}{l}\text { Freq } \\
17\end{array}$} & Prob & \multicolumn{2}{|l|}{ Zscore } & \multirow{2}{*}{$\begin{array}{l}\text { Sequential } \\
\text { Chains } \\
\text { A- W- A }\end{array}$} & \multirow{2}{*}{$\begin{array}{l}\text { Freq } \\
52\end{array}$} & \multirow{2}{*}{$\begin{array}{l}\text { Prob } \\
0.1171\end{array}$} & \multicolumn{2}{|l|}{ Zscore } \\
\hline 6- $7-6$ & & 0.0536 & 10.161 & +++ & & & & 8.960 & +++ \\
\hline$A-E-A$ & 16 & 0.0505 & 6.518 & +++ & A- $2-A$ & 31 & 0.0698 & 6.818 & +++ \\
\hline A- W- A & 14 & 0.0442 & 6.249 & +++ & A- E- A & 25 & 0.0563 & 4.852 & +++ \\
\hline 7- 6- 7 & 11 & 0.0347 & 10.198 & +++ & W- A- W & 18 & 0.0405 & 4.247 & +++ \\
\hline Y- W- Y & 5 & 0.0158 & 8.311 & +++ & 2- A- W & 16 & 0.0360 & 5.956 & +++ \\
\hline 6- $6-7$ & 4 & 0.0126 & 5.701 & +++ & W- A- 2 & 13 & 0.0293 & 3.689 & +++ \\
\hline W- Y- 6 & 4 & 0.0126 & 3.859 & +++ & W- A- E & 11 & 0.0248 & 3.130 & ++ \\
\hline W- A- W & 4 & 0.0126 & 2.434 & +++ & 6- $7-6$ & 9 & 0.0203 & $\begin{array}{l}12.39 \\
3\end{array}$ & +++ \\
\hline W- A- E & 4 & 0.0126 & 2.796 & +++ & E- A- W & 8 & 0.0180 & 2.268 & +++ \\
\hline \multirow[t]{5}{*}{ 7- 6- $\mathrm{Y}$} & 4 & 0.0126 & 3.650 & +++ & A- $6-A$ & 7 & 0.0158 & 2.863 & +++ \\
\hline & & & & & 7- 6- 7 & 7 & 0.0158 & $\begin{array}{l}11.21 \\
4\end{array}$ & +++ \\
\hline & & & & & E- A- E & 7 & 0.0158 & 3.079 & +++ \\
\hline & & & & & $2-\mathrm{A}-2$ & 7 & 0.0158 & 2.377 & ++ \\
\hline & & & & & A- $7-A$ & 4 & 0.0090 & 1.919 & + \\
\hline
\end{tabular}

(Note: 6. Verbal Instruction (general), 7. Modeling, A. Specific Observation, E. Corrective Feedback (individual), W. Positive Feedback (individual), Y. Student demonstration with verbal instruction, 2. Encouragement) 


\section{Managerial}

\begin{tabular}{|c|c|c|c|c|c|c|c|c|c|}
\hline \multicolumn{5}{|c|}{ Large Class Size } & \multicolumn{5}{|c|}{ Small Class Size } \\
\hline $\begin{array}{l}\text { Sequential } \\
\text { Chains }\end{array}$ & Freq & Prob & Zscore & & $\begin{array}{l}\text { Sequential } \\
\text { Chains }\end{array}$ & Freq & Prob & Zscore & \\
\hline E- A- 1 & 10 & 0.0315 & 3.630 & +++ & E- A- 1 & 8 & 0.0180 & 2.599 & +++ \\
\hline 1- A-W & 10 & 0.0315 & 6.488 & +++ & 1- A- E & 6 & 0.0135 & 3.081 & +++ \\
\hline 1- $4-1$ & 7 & 0.0221 & 4.208 & +++ & 1- 4- 1 & 5 & 0.0113 & 6.073 & +++ \\
\hline 1- A- E & 7 & 0.0221 & 4.637 & +++ & $1-3-1$ & 4 & 0.0090 & 5.432 & +++ \\
\hline A- 1- 4 & 6 & 0.0189 & 7.089 & +++ & & & & & \\
\hline $1-6-1$ & 5 & 0.0158 & 4.361 & +++ & & & & & \\
\hline $1-2-1$ & 5 & 0.0158 & 4.361 & +++ & & & & & \\
\hline 1- H- 1 & 4 & 0.0126 & 3.900 & +++ & & & & & \\
\hline $1-3-6$ & 4 & 0.0126 & 3.066 & +++ & & & & & \\
\hline
\end{tabular}

\{Note: E. Corrective Feedback (individual), A. Specific Observation, 1. General Observation, W. Positive Feedback (individual), 4. Corrective Feedback (general), 6.

Verbal Instruction (general), 2. Encouragement, H. Help, 3. Positive Feedback (general)\}

Table 4.16. Behavioral and stimulus elements dual examples of the HET1

\begin{tabular}{|c|c|c|c|c|c|c|c|}
\hline \multicolumn{4}{|c|}{ Large Class Size } & \multicolumn{4}{|c|}{ Small Class Size } \\
\hline \multirow{5}{*}{$\begin{array}{l}\mathrm{D} \\
\mathrm{A}\end{array}$} & Chair & & Freq./Pro. & & hai & & Freq./Pro. \\
\hline & $\rightarrow$ & 2 & (49/0.1065) & A & $\rightarrow$ & W & (46/0.0929) \\
\hline & $\rightarrow$ & W & (37/0.0804) (21/0.0 & & $\rightarrow$ & 2 & (38/0.0768) \\
\hline & $\rightarrow$ & $\mathrm{E}$ & 457) & & $\rightarrow$ & $\mathrm{E}$ & $(19 / 0.0384)$ \\
\hline & & & & 1 & $\rightarrow$ & $\mathrm{E}$ & $(20 / 0.0404)$ \\
\hline
\end{tabular}

(Note: these dual chains were selected with significant z scores. A; specific observation, 1; general observation, 2; encouragement, W; individual positive feedback, E; individual corrective feedback) 
Table 4.17. Behavioral and stimulus elements dual examples of the LET1

\begin{tabular}{|c|c|c|c|c|c|c|c|}
\hline \multicolumn{4}{|c|}{ Large Class Size } & \multicolumn{4}{|c|}{ Small Class Size } \\
\hline & Chair & & Freq./Pro. & & hai & & Freq./Pro. \\
\hline A & $\begin{array}{l}\rightarrow \\
\rightarrow\end{array}$ & $\begin{array}{l}E \\
W\end{array}$ & $\begin{array}{l}(20 / 0.0629) \\
(17 / 0.0535)\end{array}$ & A & $\begin{array}{l}\rightarrow \\
\rightarrow\end{array}$ & $\begin{array}{l}2 \\
\mathrm{E}\end{array}$ & $\begin{array}{l}(32 / 0.0719) \\
(31 / 0.0697)\end{array}$ \\
\hline 1 & $\rightarrow$ & $\begin{array}{l}4 \\
3\end{array}$ & $\begin{array}{l}(9 / 0.0283) \\
(8 / 0.0252)\end{array}$ & 1 & $\rightarrow$ & 4 & $(5 / 0.0112)$ \\
\hline
\end{tabular}

(Note: these dual chains were selected with significant $\mathrm{z}$ scores. A; specific observation, 1; general observation, 2; encouragement, W; individual positive feedback, E; individual corrective feedback)

Table 4.18. Comparison between individual feedback and general feedback (\%/rate per min.)

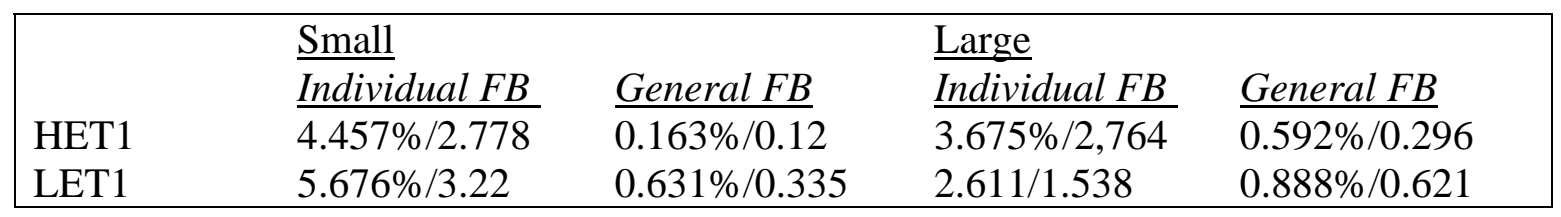

Table 4.19. Relationship between between individual feedback and off task

\begin{tabular}{|lllll|}
\hline & $\underline{\text { Small }}$ & & Large & \\
& $\underline{\text { Individual FB }}$ & $\underline{\text { Off Task }}$ & $\underline{\text { Individual FB }}$ & $\underline{\text { Off Task }}$ \\
HET1 & $4.457 \% / 2.778$ & $3.217 \%$ & $3.675 \% / 2,764$ & $2.32 \%$ \\
LET1 & $5.676 \% / 3.22$ & $0.987 \%$ & $2.611 / 1.538$ & $4.079 \%$ \\
\hline
\end{tabular}

Table 4.20. Comparison among encouragement, positive feedback, and corrective feedback

\begin{tabular}{|c|c|c|c|c|}
\hline & \multicolumn{2}{|l|}{ HET1 } & \multicolumn{2}{|l|}{ LET1 } \\
\hline & $\begin{array}{l}\text { Small } \\
\text { \%/Rate per min }\end{array}$ & $\begin{array}{l}\text { Large } \\
\text { \%/Rate per min }\end{array}$ & $\begin{array}{l}\text { Small } \\
\text { \%/Rate per min }\end{array}$ & $\begin{array}{l}\text { Large } \\
\text { \%/Rate per min }\end{array}$ \\
\hline Encouragement & $2.903 / 1.793$ & $2.422 / 1.941$ & 2.077 / 1.376 & $0.58 / 0.384$ \\
\hline $\begin{array}{l}\text { Positive Feedba } \\
\text { ck (G\&I) }\end{array}$ & $2.518 / 1.703$ & 2.644 / 2.073 & 2.316 / 2.113 & 1.714 / 1.153 \\
\hline $\begin{array}{l}\text { Corrective Feed } \\
\text { back (G\&I) }\end{array}$ & 2.102 / 1.195 & $1.623 / 0.987$ & 3.991 / 1.442 & $1.785 / 1.906$ \\
\hline
\end{tabular}


Table 4.21. Observations by HET1 and LET1

\begin{tabular}{|l|ll|ll|}
\hline & HET1 & & LET1 & \\
\cline { 2 - 5 } & Large & Small & Large & Small \\
\hline $\begin{array}{l}\text { General observ } \\
\text { ation }\end{array}$ & $13.173 \%$ & $21.811 \%$ & $19.755 \%$ & $10.223 \%$ \\
$\begin{array}{l}\text { Specific observ } \\
\text { ation }\end{array}$ & $24.957 \%$ & $18.037 \%$ & $8.113 \%$ & $28.456 \%$ \\
\hline
\end{tabular}

Table 4.22. Interrelationship between individual feedback and student's activity time

\begin{tabular}{|l|ll|ll|}
\hline & HET1 & & LET1 & \\
\cline { 2 - 5 } & Small & Large & Small & Large \\
\hline Indivi. FB & $4.457 \% / 2.778$ & $3.675 \% / 2.764$ & $5.676 \% / 3.22$ & $2.611 / 1.538$ \\
Student's A.T. & $45.754 \%$ & $27.957 \%$ & $27.958 \%$ & $16.484 \%$ \\
\hline
\end{tabular}

Table 5.1 Feedback and off-task by HET1 and LET1

\begin{tabular}{|c|c|c|c|c|}
\hline $\begin{array}{l}\text { - HET1: } \\
\text { - LET1: }\end{array}$ & $\begin{array}{l}\text { Small } \\
\text { Feedback } \\
4.62 \% / 2.898 \\
6.297 \% / 3.555\end{array}$ & $\begin{array}{l}\text { Off Task } \\
3.217 \% \\
0.987 \%\end{array}$ & $\begin{array}{l}\text { Large } \\
\text { Feedback } \\
4.717 \% / 2.610 \\
3.499 \% / 2.049\end{array}$ & $\begin{array}{l}\text { Off Task } \\
2.32 \% \\
4.079 \%\end{array}$ \\
\hline
\end{tabular}

Table 5.2 Duration of student behaviors

\begin{tabular}{|c|c|c|c|c|}
\hline \multirow{4}{*}{$\begin{array}{ll}\text { - } & \text { Activity } \\
\text { - } & \text { Cognitive }\end{array}$} & \multicolumn{2}{|c|}{ Student behaviors in HET1's lesson } & \multicolumn{2}{|c|}{ Student behaviors in LET1's lesson } \\
\hline & Small & Large & Small & Large \\
\hline & $45.745 \%$ & $29.957 \%$ & $27.958 \%$ & $16.484 \%$ \\
\hline & $31.35 \%$ & $29.4 \%$ & $27.076 \%$ & $41.635 \%$ \\
\hline - Managing & $6.763 \%$ & $9.21 \%$ & $10.31 \%$ & $9.52 \%$ \\
\hline - Waiting & $4.427 \%$ & $15.302 \%$ & $4.082 \%$ & $3.07 \%$ \\
\hline - Off - task & $3.217 \%$ & $2.32 \%$ & $0.987 \%$ & $4.079 \%$ \\
\hline
\end{tabular}




\section{Appendix A \\ West Virginia Teaching Evaluation System (WVUTES) Teacher Behavior Definitions}

1. General Observation: Teacher is watching student groups or individuals engaged in any category of student behavior. The teacher must not be engaged in any other category of teacher behavior in order to record general observation. This category includes passive supervision, and there is no relationship of the observation to an instructional focus.

2. Encouragement: Teacher makes a verbal statement, the purpose of which is to enhance the student's perception of their ability to accomplish a subsequent task. The teacher is not telling the student what to do (an instructional prompt) but is clearly trying to build confidence. ("You can do it," or "If you did the last task you can surely do this," etc.)

3. Positive Feedback: Teacher makes a positive verbal statement or gesture following an appropriate student behavior (skill or organization) clearly designed to increase or maintain such responses in the future. The statement or gesture must follow soon enough after the behavior that the student clearly associates it with the behavior.

4. Corrective Feedback: Teacher makes a negative or critical verbal statement or gesture following an inappropriate behavior (skill or organizational) clearly designed to decrease such responses in the future. The statement or gesture must follow soon enough after the behavior that the student clearly associates it with the behavior.

5. Management: Teacher is engaged in carrying out a non-subject matter task (setting up equipment, taking roll, collecting papers, etc.). Teacher may be directing students verbally in a management task.

6. Verbal Instruction: Teacher is verbally describing to the students how to do a skill, or is using a verbal prompt to direct students in attempting a skill or activity. The activity must be a subject matter task in order to record instruction.

7. Modeling: Teacher demonstrates to students how to do a subject matter task, or participates with students in a subject matter task or activity. 
8. Physical Guidance: Teacher physically guides students through a subject matter task or activity. A physical guidance prompt or spotting, as long as there is physical contact, are examples of physical guidance.

9. Non-Task Verbal: Teacher talks to students about non-subject matter and nonmanagerial subjects. Commenting on student's clothing or talking about what one student did over the weekend are examples of non-task behavior.

10. Off Task: Teacher is not paying attention to what are clearly his or her responsibilities regarding the class at hand. A teacher who is making notes on what to do during football practice is an example of off task behavior.

11. Specific Observation: Teacher is watching one student engaged in a subject matter task for the purpose of providing feedback related to performance. Teacher position must be proximal to student position so that observation is clearly focused on a specific student who is performing. Specific observation could be scored when teacher is watching pairs or small groups, e.g., observation of five players executing a fast break during an instructional session on the fast break. 


\section{Appendix B}

\section{West Virginia Teaching Evaluation System (WVUTES) Student Behavior Definitions}

M. MOTOR APPROPRIATE -- The student is engaged in a subject matter motor activity in such a way as to produce a high degree of success.

M-1. MOTOR INAPPROPRIATE -- The student is engaged in a subject matter motor activity but the task is either too difficult for the individual's capabilities or is so easy that practicing it could not contribute to lesson goals.

S. MOTOR SUPPORTING -- The student is engaged in a subject matter motor activity, the purpose of which is to assist others to learn or perform the activity. Examples include spotting in gymnastics, feeding balls to a hitter in a tennis lesson, throwing a volleyball to a partner who is practicing set up passing, clapping a rhythm for a group of students practicing a dance movement pattern, etc.

C. COGNITIVE -- The student is appropriately involved in a cognitive, subject matter task. Examples include listening to the teacher explain a subject matter task, watching a modeling episode, engaging in overt cognitive responses to teacher subject matter inquiries or to instructional materials, participating in a discussion, writing answers to study questions, etc.

N. ON TASK MANAGEMENT -- The student is appropriately engaged in carrying out an assigned non-subject-matter task (a management task, a transition task, a warm up task). Examples include moving into squads, helping to place equipment, counting off, doing warm up exercises, or moving from the gymnasium to the playing field.

F. OFF TASK -- The student is either not engaged in an activity in which he or she should be engaged, or is engaged in an activity other than the one in which he or she should be engaged. Examples include behavior disruptions, misbehavior and general offtask behavior, such as talking when a teacher is explaining a skill, misusing equipment, fooling around, fighting, etc.

I. INTERIM -- The student is engaged in a non-instructional aspect of an ongoing activity. Examples include retrieving balls, fixing equipment, retrieving arrows, changing sides of a court in a tennis match, etc.

W. WAITING -- The student has completed a task and is awaiting the next instructions or opportunity to respond. Examples include waiting in line for a turn, waiting for the next teacher direction, waiting to get into a game from the sideline, waiting for the next activity to begin, etc. 


\section{Appendix C}

\section{Field System Analysis (FSA) \\ Teacher Behavior Definitions}

1. General observation: Teacher is watching student groups or individuals engaged in any category of student behavior. The teacher must not be engaged in any other category of teacher behavior in order to record general observation. This category includes passive supervision, and there is no relationship of the observation to an instructional focus.

2. Encouragement: Verbal statement to enhance a student's perception of ability to accomplish a subsequent task.

3. Positive feedback (general): Verbal statement, immediately following a student behavior, designed to increase/maintain that behavior, but not containing information specific to the activity.

4. Corrective feedback (general): Teacher makes a negative or critical verbal statement or gesture following an inappropriate behavior (skill or organizational) clearly designed to decrease such responses in the future. The statement or gesture must follow soon enough after the behavior that the student clearly associates it with the behavior. This general corrective feedback is generally provided to a class related to skill or organization.

5. Transition: Class as a whole changes from one task/activity to the next.

6. Verbal Instruction (general): Verbal explanation of rules, strategies, tactics, and procedures required for successful participation in an activity.

7. Modeling: Teacher demonstrates a subject matter task.

8. Non-Task Verbal: Teacher talks to students about non-subject matter and nonmanagerial subjects. Commenting on student's clothing or talking about what one student did over the weekend are examples of non-task behavior.

9. Off Task: Teacher is not paying attention to what are clearly his or her responsibilities regarding the class at hand. A teacher who is making notes on what to do during football practice 0 off task behavior.

0. Review: The final phase of the lesson, an overview of the prior instruction and closing comments by the teacher.

A. Specific observation: Watching one student or a small group engaged in the same activity. 
E. Corrective Feedback (individual): Teacher makes a negative or critical verbal statement or gesture following an inappropriate behavior (skill or organizational) clearly designed to decrease such responses in the future. The statement or gesture must follow soon enough after the behavior that the student clearly associates it with the behavior. This individual corrective feedback must be provided to an individual related to skill or organization.

H. Help: Teacher helps students to retrieve balls and other objects while subject matter task is proceeding.

M. Management: Teacher is engaged in carrying out a non-subject matter task (setting up equipment, taking roll, collecting papers, etc.)

P. Warming Up: The beginning phase of the lesson, a few activities that are not related to the subject matter tasks leading by the teacher, usually prior to the introduction.

R. Grouping: Teacher divides the class into a few groups.

V. Physical Guidance: Teacher physically guides students through a subject matter task or activity. A physical guidance prompt or spotting, as long as there is physical contact, are examples of physical guidance.

W. Positive Feedback (individual): Verbal statement, immediately following a student behavior, designed to increase/maintain that behavior, and containing information or not containing information of the activity to a specific individual.

Y. Student demonstration with verbal instruction: Teacher describes the activity of one or more students who model the task for the class.

Z. Attention: Teacher's attention is directed to the class to gain students' attention as a whole or an individual (e.g., blowing a whistle, calling a name, issuing a verbal command like "stop" or "quiet"). 


\section{Appendix D}

\section{Field System Analysis (FSA) Student Behavior Definitions}

1. Activity: The student is engaged in a subject matter motor activity.

2. Cognitive: The student is appropriately involved in a cognitive task such as listening to a teacher describe a game, listening to verbal instructions about how to organize, watching a demonstration, participating a discussion, or watching a film.

3. Supporting: The student is engaged in a subject matter motor activity the purpose of which is to assist others to learn or perform the activity.

4. Waiting: The student has completed a task and is awaiting the next instructions or opportunity to respond such as waiting in line for a turn, having arrived at an assigned space waiting for the next teacher direction, standing on a sideline waiting to get in a game, or having organized into the appropriate formation waiting for an activity to begin.

5. Management: The student is appropriately engaged in carrying out an assigned non-subject matter task (a management task, a transition task, a warm up task) such as moving into squads, helping to place equipment, counting off, doing warm up exercises, or moving from the gym to a playing field.

6. Interim: The student is engaged in a non-instructional aspect of an ongoing activity such as retrieving balls, fixing equipment, retrieving arrows, or changing sides of a court in a tennis match.

7. Non-task verbal: Student talks to teacher about non-subject matter and nonmanagerial subjects.

8. Off Task: The student is either not engaged in an activity he or she should be engaged in, or is engaged in an activity other than the one he or she should be engaged in - behavior disruptions, misbehavior and general off-task behavior, such as talking when a teacher is explaining a skill, misusing equipment, fooling around, fighting, disrupting a drill through inappropriate behavior.

9. Warming up: In the beginning of the lesson, students implement a few activities/stretches that are not related to the subject matter tasks lead by the teacher, usually prior to the introduction. 


\section{References}

Achilles, C.M., Finn, J.D., \& Pate-Bain, H. (2002). Measuring class size: Let me count the ways. Educational Leadership, 59, 24-26.

Ahlgren, R.L., Housner, L.D., \& Jones, D.F. (1998). Qualitative analysis of experienced and inexperienced basketball coaches during practice. Applied Research in Coaching and Athletics Annual. 142-163

Allison, P.C. (1987). What and how preservice physical education teachers observe during an early field experience. Research Quarterly for Exercise and Sport,58(3), 242-249.

Allison, P.C. (1990). Classroom teachers' observations of physical education lessons. Journal of Teaching in Physical Education, 9, 272-283.

Biddle, B., \& Berliner, D.C. (2002). Small class size and its effects. Educational Leadership, 59, 12-23.

Burgeson, C.R., Wechsler, H., Brener, N.D., Young, J.C., \& Spain, C.G. (2003). Physical education and activity: results from the school health policies and programs study 2000. Journal of Physical Education, Recreation and Dance, 74(1), 20-36.

Byra, M., \& Sherman, M.A. (1993). Preactive and interactive decision-making tendencies of less and more experienced preservice teachers. Research Quarterly for Exercise and Sport, 64(1), 46-55.

California Teacher Association <Posnick-Goodwin, S.> (2003). Smaller classes workDon’t turn back the clock. California Educator, 7(8), 6-9.

Carlson, J.B. (1994). Smaller is better-faith or fact? Teaching Elementary Physical Education, 5, 5.

Chen, A., \& Darst, P.W. (2001). Situational interest in physical education: A function of learning task design. Research Quarterly for Exercise and Sport, 72(2), 150-164.

Delprato, D.J. (1992). Behavioral field system analysis: History and scientific relatives. Journal of Teaching in Physical Education, 12, 3-8.

Ennis, C. (1994). Urban secondary teachers' value orientations: Delineating curricular goals for social responsibility. Journal of Teaching in Physical Education, 13, 163-179

Feingold, R.S. (1995). Public health: role of physical education. AIESEP World Congress (Wingate Institute, Israel). 115-120. 
Fredenburg, K.B., Lee, A.M., \& Solmon, M. (2001). The effects of augmented feedback on students' perceptions and performance. Research Quarterly for Exercise and Sport, 72(3), 232-242.

Finn, J.D., Pannozzo, G.M., \& Achilles, C.M. (2003). The “why’s” of class size: Student behaviors in small classes. Review of Educational Research, 73, 321-368.

Graber, K. (2001). Research on teaching in physical education. In V. Richardson (Ed.), Handbook of research on teaching ( $4^{\text {th }}$ ed.) (pp. 491-519). Washington, DC: American Educational Research Association.

Graham, G. (1987). Motor skill acquisition-an essential goal of physical education programs. Journal of Physical Education, Recreation and Dance, 58, 44-48.

Graham, G., \& Heimerer, E. (1981). Research on teacher effectiveness: A summary with implications for teaching. Quest, 33, 14-21.

Graham, K.C. (1987). A description of academic work and student performance during a middle school volleyball unit. Journal of Teaching in Physical Education, 7, 22-37.

Graham, G., Hopple, C., Manross, M., \& Sitzman, T. (1993). Novice and experienced children's physical education teachers, insight into their situational decision making. Journal of Teaching in Physical Education, 12, 197-214.

Griffey, D.C. (1987). Trouble for sure a crisis-perhaps. Journal of Physical Education, Recreation and Dance, 58, 20-21.

Hawkins, A. \& Sharpe, T. (1992). Expert and novice elementary specialists: a comparative analysis. Journal of Teaching in Physical Education, 12, 55-75.

Hawkins, A. \& Wiegand, R. (1989). Analyzing physical education and sport instruction, ch26 West Virginia University Teaching Evaluation System and Feedback Taxonomy.

Hastie, P.A., \& Saunders, J.E. (1991). Effects of class size and equipment availability on student involvement in physical education. The Journal of Experimental Education, 59, 212-224.

Hastie, P.A, Sanders, S.W., \& Rowland, R.S. (1999). Where good intentions meet harsh realities: teaching large classes in physical education. Journal of Teaching in Physical Education, 18, 277-289.

Henry, J. (2000). Fitness fiasco as pupils dodge PE. Times Educational Supplement, 7. 
Housner, L.D. (1991). Teacher cognition. In Martenik, T. (Ed.) Psycho-Social Dynamics of Teaching Physical Education. William C Brown. (p.35-55).

Housner, L.D., \& Griffey, D.C. (1985). Teacher cognition: Differences in planning and interactive decision making between experienced and inexperienced teachers. Research Quarterly for Exercise and Sport, 56(1), 45-53.

Jones, D.F., Housner, L.D., \& Kornspan, A.S. (1995). A comparative analysis of expert and novice basketball coaches' practice planning. Applied research in Coaching and Athletics Annual, 201-227.

Kerby, S. (1994). A start in the right direction. Teaching Elementary Physical Education, 5, 10-11.

Kerst-Davis, C. (1994). No double classes: a Tennessee victory. Teaching Elementary Physical Education, 5, 1.

Lambdin, D., \& McKenzie, T.L. (2003). Analysis in wonderland wickets and winners in elementary school physical education. Journal of Physical Education, Recreation and Dance,74(4), 20-23, 40.

Lee, A.M., Landin, D.K., \& carter, J.A. (1992). Student thoughts during tennis instruction. Journal of Teaching in Physical Education, 11, 256-267.

Livingston, C. \& Borko, H. (1989). Expert-novice differences in teaching: A cognitive analysis and implications for teacher education. Journal of Teacher Education, 40, 36-42.

Lyle, J. (2003). Stimulated-recall: A report on its use in naturalistic research. British Educational Research Journal, 29(6), 861-878.

Martinek, T.J. \& Griffith, J.B. (1994). Learned helplessness in physical education: A developmental study of causal attributions and task persistence. Journal of Teaching in Physical Education, 13, 108-122.

McKenzie, T.L., Marshall, S.J., Sallis, J.F, \& Conway, T.L. (2000). Student activity levels, lesson context, and teacher behavior during middle school physical education. Research Quarterly for Exercise and Sport, 71, 249-259.

McKenzie, T.L., Sallis, J.F., \& Nader, P.R. (1991). SFOIT: System for observing fitness instruction time. Journal of Teaching in Physical Education, 11, 195-205.

Metzler, M.W. (2005). Instructional models for physical education ( $2^{\text {nd }}$ Ed.). Scottsdale, AZ: Holcomb Hathaway. 
Mowling, C.M., Brock, S.J., Eiler, K.K., \& Rudisill, M.E. (2004). Student motivation in physical education. Journal of Physical Education, Recreation and Dance, 75(6), 40-45,51.

National Association for Sport and Physical Education [NASPE]. (1995). Moving into the future: National standards for physical education. St. Louis: Mosby.

Parker, J., \& Pitney, W. (2003). Are content and competencies enough? Strategies to encourage reflective practice among athletic-training students. Journal of Physical Education, Recreation and Dance,74(2), 46-51.

Parker (1989). Analyzing physical education and sport instruction, Ch17 Academic Learning Time-Physical Education (ALT-PE), 1982 Revision.

Pate-Bain, H., Achilles, C.M., Boyd-Zaharias, J., \& McKenna, B. (1992). Class size does make a difference. Phi Delta Kappan, 74, 253-256.

Peterson, P.L., Marx, R.W., \& Clark, C.M. (1978). Teacher planning, teacher behavior, and student achievement. American Educational Research Journal, 15, 417-432.

Placek, J.H., \& Locke, L.F. (1986). Research on teaching physical education: new knowledge and cautions optimism. Journal of Teacher Education, 24-28.

Research Points (2003). Class size: Counting students can count. American Educational Research Association, 1(2), 1-4.

Rink, J.E. (2002). Teaching physical education for learning (4 ${ }^{\text {th }}$ ed.). New York, NY: McGraw Hill.

Rink, J.E., French, K.E., Werner, P.H., Lynn, S., \& Mays, A. (1992). The influence of content development on the effectiveness of instruction. Journal of Teaching in Physical Education, 11, 139-149.

Ryan, S., \& Yerg, B. (2001). The effects of crossgroup feedback of off-task behavior in a physical education setting. Journal of Teaching in Physical Education, 20, 172188.

Sallis, J.F., \& McKenzie, T.L. (1991). Physical education's role in public health. Research Quarterly for Exercise and Sport, 62, 124-137.

Sander, A.N. (1996). Organizational strategies for teaching large classes. Teaching Secondary Physical Education, 2, 10-13.

Schempp, P.G. (1995). Learning of the job: An analysis of the acquisition of a teacher's knowledge. Journal of Research and Development in Education, 28(4), 237-244. 
Schuldheisz, J.M., \& Van Der Mars, H. (2001). Active supervision and students' physical activity in middle school physical education. Journal of Teaching in Physical Education, 21, 75-90.

Sharpe, T., \& Hawkins, A. (1992). Strategies and tactics for field system analysis. Journal of Teaching in Physical Education, 12, 9-23.

Sharpe, T., \& Koperwas, J. (2003). Behavior and sequential analyses, Ch3. An interbehavioral Multi-Event perspective.

Sharpe, T., \& Lounsbery, M., Hawkins, A., \& Eldar, E. (1995). Practice and implication of a field system analysis. AIESEP World Congress (Wingate Institute, Israel). 91-100.

Silverman, S. (1988). Relationship of selected presage and context variables to achievement. Research Quarterly for Exercise and Sport, 59, 35-41.

Stratton, G. (1997). Children's heart rates during British physical education lessons. Journal of Teaching in Physical Education, 16, 357-367.

Supaporn, S., Dodds, P, \& Griffin, L. (2003). An ecological analysis of middle school misbehavior through student and teacher perspectives. Journal of Teaching in Physical Education, 22, 328-349.

Theeboom, M., De Knop, P., \& Bollaert, L. (1995). Motivational strategies for the youth sport pedagogical practice. AIESEP World Congress (Wingate Institute, Israel). 532-537.

Tan, S.K.S. (1996). Differences between experienced and inexperienced physical education teachers' augmented feedback and interactive teaching decisions. Journal of Teaching in Physical Education, 15, 151-170.

Tjeerdsma, B.L. (1997). A comparison of teacher and student perspectives of tasks and feedback. Journal of Teaching in Physical Education, 16, 388-400.

U.S. department of Health and Human Services. (2000). Healthy People 2010: Understanding and Improving Health. (Conference edition-Volume I). Washington, DC: U.S. Government Printing Office.

U.S. department of Health and Human Services. (1996). Physical activity and health: A report of The Surgeon general. Atlanta: Centers for Disease Control and Prevention.

Van der Mars, H., Vogler, B., Darst, P., \& Cusimano, B. (1998). Students’ physical activity level and teachers' active supervision during fitness instruction. Journal of Teaching in Physical Education, 18, 57-75. 
Verducci, F. (1969). Effects of class size upon the learning of a motor skill. The Research Quarterly, 40, 391-395.

Walkwitz, E., \& Lee, A. (1992). The role of teacher knowledge in elementary physical education instruction: An exploratory study. Research Quarterly for Exercise and Sport,63(2), 179-185.

Wasley, P.A. (2002). Small classes, small schools: The time is now. Educational Leadership, 59, 6-11. 